\title{
CAMPUS TRANSPORTATION PLANNING : A CASE STUDY OF THE LAFAYETTE CAMPUS OF PURDUE UNIVERSITY
}

\section{FEBRUARY 1969 - NUMBER 5}

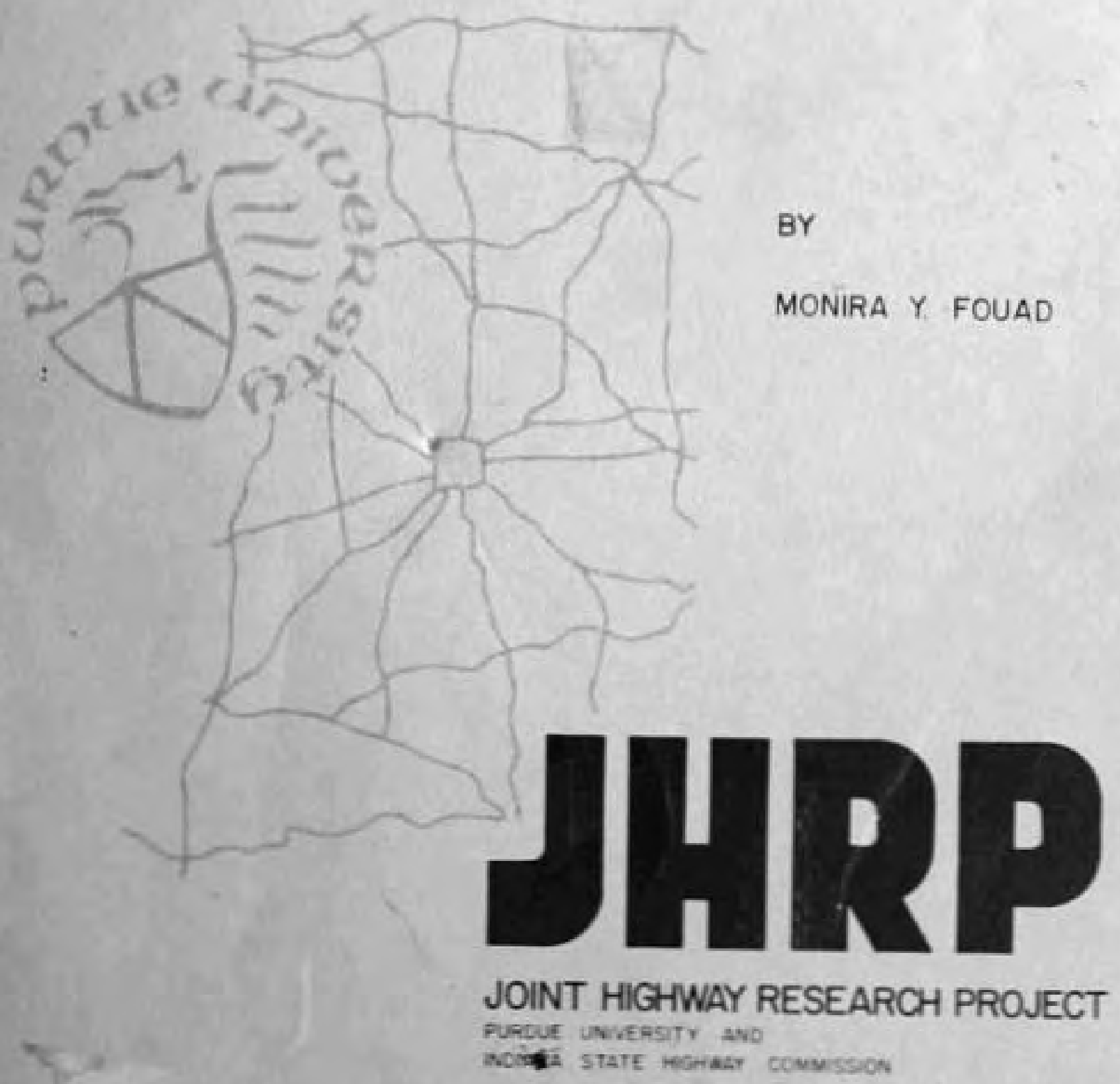




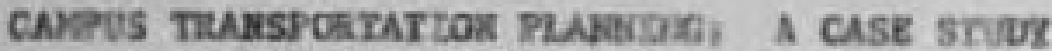

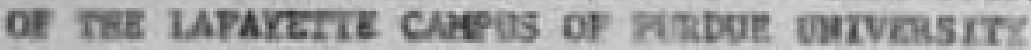

To: $I_{\text {, }} \boldsymbol{F}$, McLaughifn, Director

Joint Bighusy Regearch Project

Froa: H. L. Xtchael, AssocLate Director

7ebruaty 14, 1965

File: $9-12-2$ Joint Miglway kieseerch Project

The attached Final Beport "Caspus Transportation Planningi a Care Study of the Lefoyette Caepus of Purlee Dolvarsity" has beet prepared by Mrs. Konira Y. Fouad uncler the direction of Professor n. L. Wichael, The research vas finabed by Rurdae latversity. ifrs. Foued alao used the report of her thanis for the as degree.

The study exanted the fature requiranents of transportetion on the Purdue Lafayette Camus. A nubler of feasibla plans are exacafned to aeet these treasportation requireats for an ultinete carpus population of 35,000 studeatan.

The report io presented to the Board as information.

$$
\text { Rnspectfelly subalted, }
$$

Barold L. Michaet Ascociate Director

ALM:rg

Attechaent

\section{Copy $:$}
Y. L. Ashboucher
R. H. Horrel1
C. P. Scholer
H. L. Dolch
J. A. Hevers
M. B, Scott
H. H. Goetz
ק. $\boldsymbol{Z}$, Bervey
W. $\mathbf{X}$. Spoacer
H. L. Greceo
G. A, Leonards "
B. R. 3. Helsh
G. K. Intlock
F. B. Kendenha11
R. B. Moods
M. E. Rart
R. D. Miles
z. J. Toder 
Tinal Report.

CAKPUS TRAMSPORTATIOI PLAKYYRG:

A CASE STUDR OF THE LAFAYETR CAIPUS

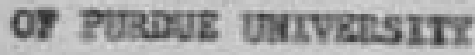

\author{
by \\ Honira $Y$, Found \\ Graduete Assistant in Research
}

Jolnt Aigheay Research Projeet

File Ho: $9-12-2$

Purdue Universicy

Lefayette, Indinna

Tebruary 14, 1969 


\section{ACKNOWL EDGMENTS}

The author wishes to express her sincere thanks to Professor Harold L. Michael, Head of Urban Planning and Engineering at Purdue University and Associate Director, Joint Highway Research Project for his guidance and advice throughout the preparation of this study and for his critical review of the manuscript. Special thanks are extended to Professor William L. Grecco, Professor of Urban Planning and Engineering for his advice and review of the manuscript and to Professor 3. 0. Wadde11, Department of Sociology, for his review of the manuscript.

Mr. 6. M. Jouris, Statistics Department is thanked for his advice on the statistical aspects of the analyses. Acknowledgments are also given to $\mathrm{Mr}$. W. E. Jobusch, Director of Development Planning; Mr. J. F. Blakesley, Coordinator of Schedule and Space Office; Mr. J. C. Smalley, Director of University Residences; Mr. R. L. Page, Director of Men's Residence Halls; Mr. C. M. Matthews, Deputy Coordinator of Schedule and Space Office; Mr. T. N. Gunderson, Assistant Registrar: Mr. W. E. Dah1, Assistant Registrar; Mr. R. C. Cadwe11, Manager of Graduate House I; Mr. I. F. Milson, Director of Fanily Housing Office; Mr. J. J. Faulkner, Comptroller's Office; Miss E. K. Skadberg, Krannert Lfbrary; 
Miss J. Bodenhafer, Main Library; Miss A. E. Limbach, Cafeteria Manager, Memorial Union; Mr. R. J. Carol1, Sweet Shop Manager: and Miss N. L. Clerget, Home Economics Food Service, for the generous time and efforts they gave to make available the data used in this study. 


\section{Digitized by the Internet Archive}

in 2011 with funding from

LYRASIS members and Sloan Foundation; Indiana Department of Transportation
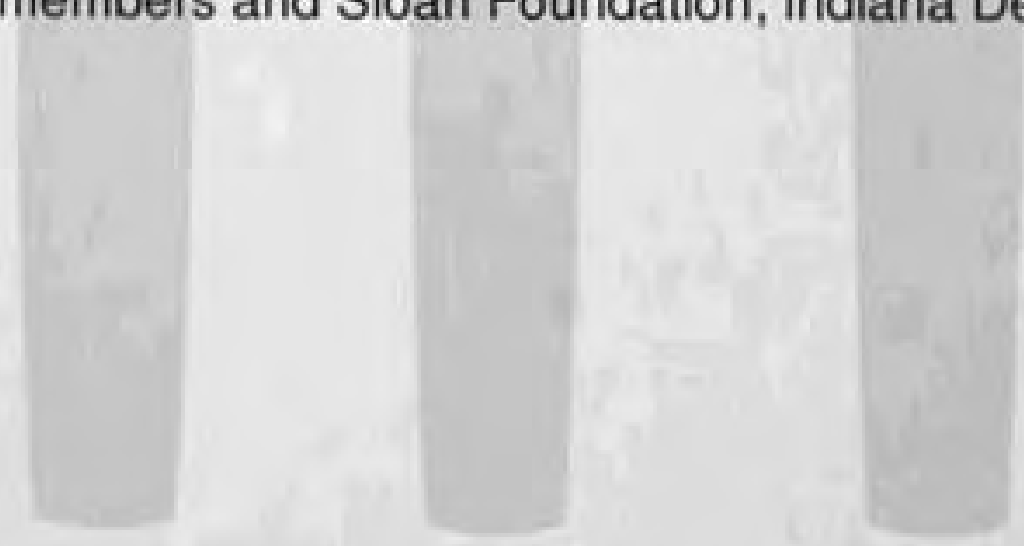

http://www.archive.org/details/campustransporta00foua 
TABLE OF CONTENTS

Page

LIST OF TABLES........................... vi

LIST OF FIGURES............................. vit

ABSTRACT ..........................

CHAPTER I. INTRODUCTION................... 1

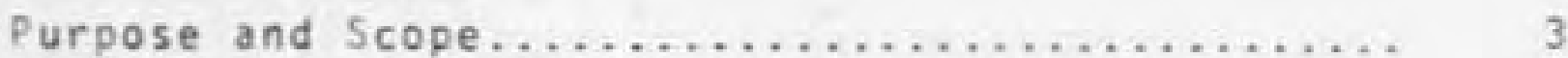

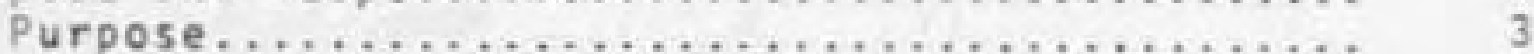

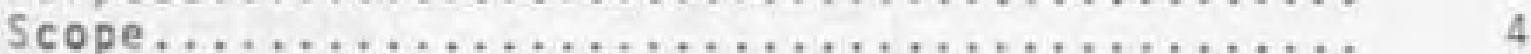

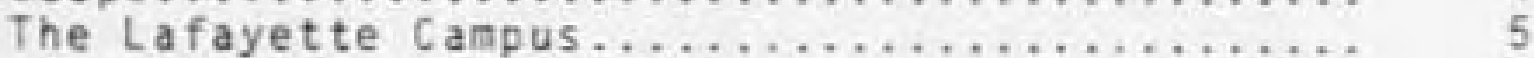

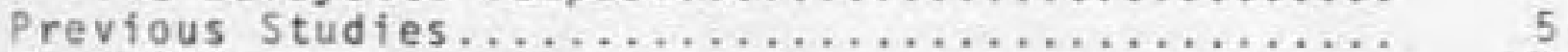

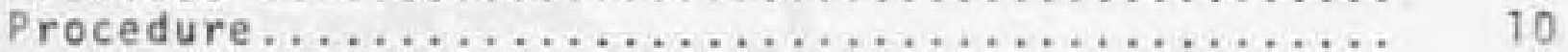

CHAPTER II. DATA COLLECTION, DATA ANALYSIS,

AND FORECASTING....................... 13

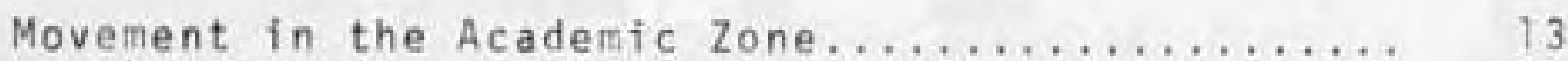

The Efficiency of Pedestrian Circulation....... 14

Pedestrian-Vehicle Conflicts................. 20

Commuting to and from the Academic Zone............ 21

Campus Population Characteristics

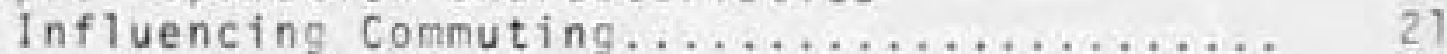

Campus Population: Size and Composition....

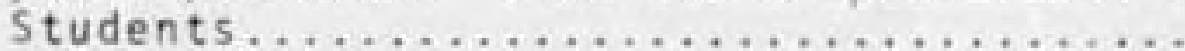

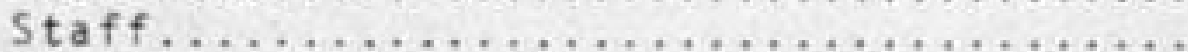

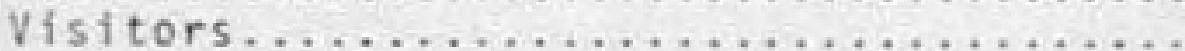

Daytine Population in the Academic Zone.....

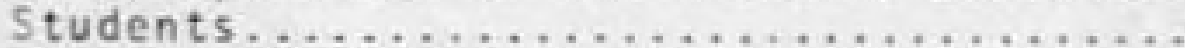

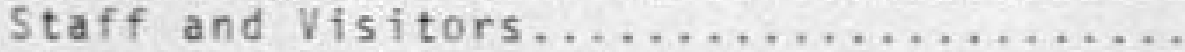

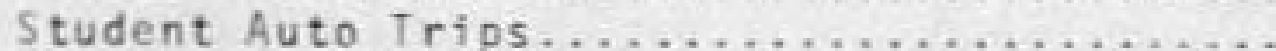

Residential Distribution of Students........

Students" Choice of Residence

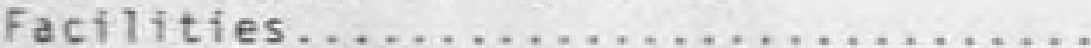

The Spatial Distribution of Student

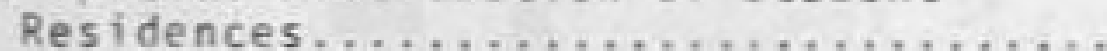

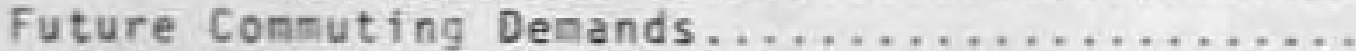

Future Parking Denands .....................

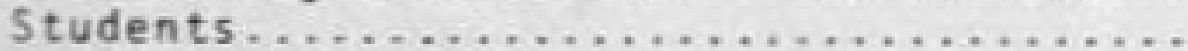

Staff and Visitors. 
TABLE OF CONTENTS (continued)

Page

Future Provision of Bus Systems............ 60

Pedestrian Commuting................... 62

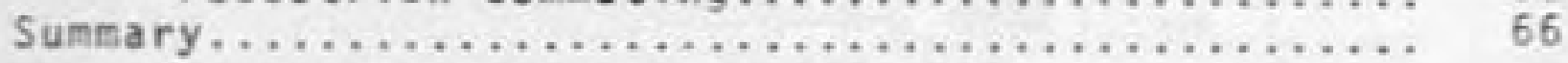

CHAPTER 1II. ALTERNATIVE PLANS FOR CIRCULATION

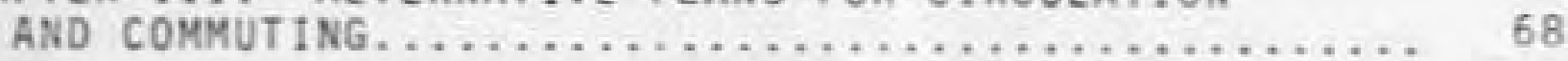

Objectives and Criteria...................... 68

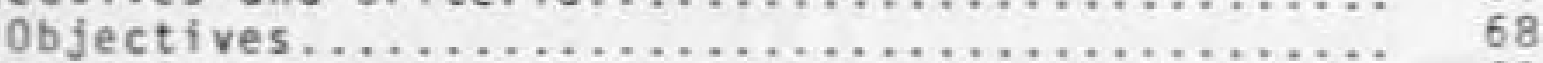

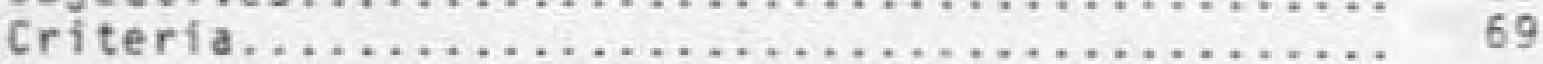

Alternative Circulation Plans (In the

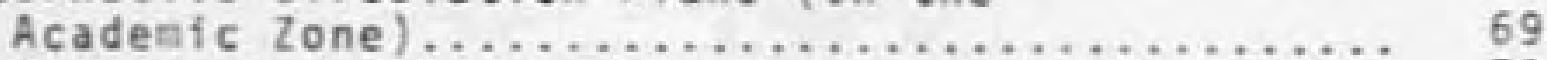

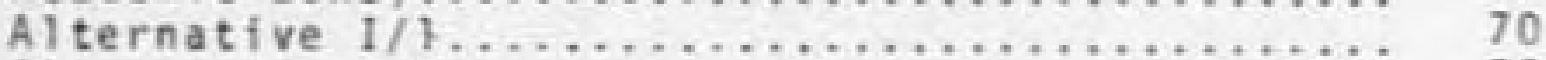

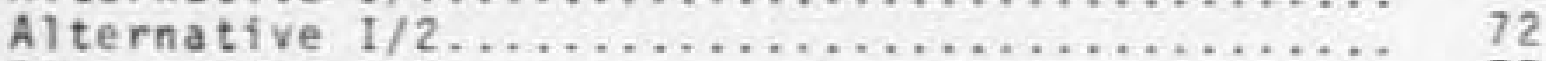

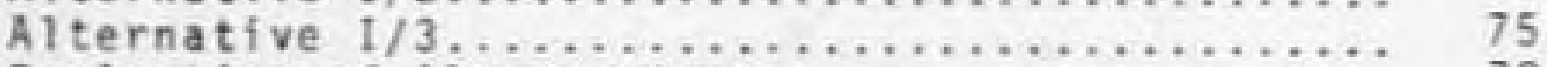

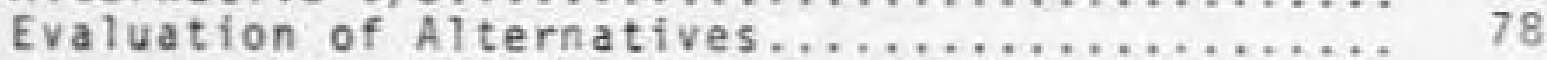

Alternative Comating Plans (To and From the

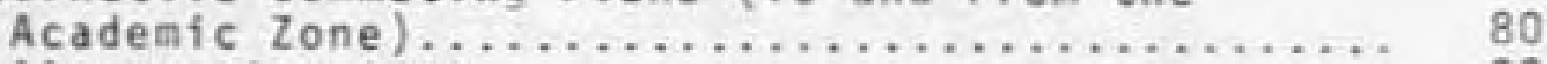

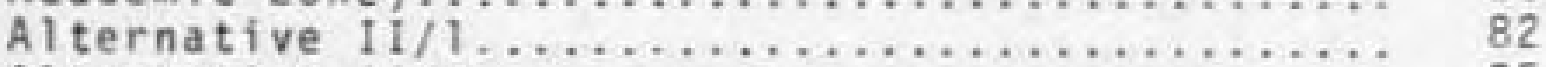

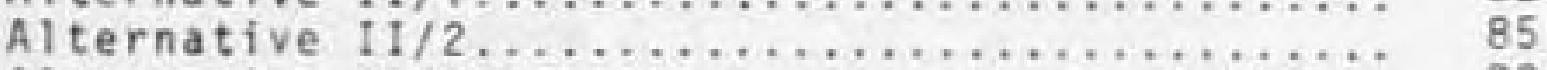

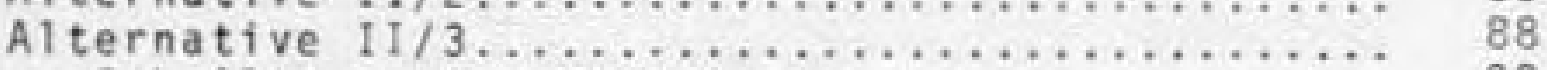

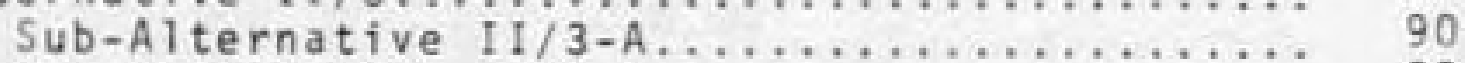

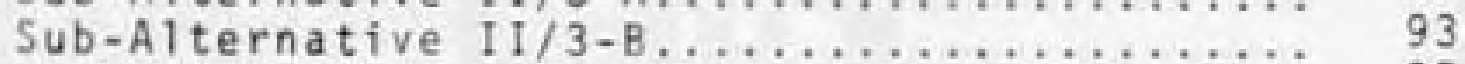

Evaluation of Alternatives....................... 95

CHAPTER IV. CONCLUSIONS AND RECOMMENDATIONS ........ 100

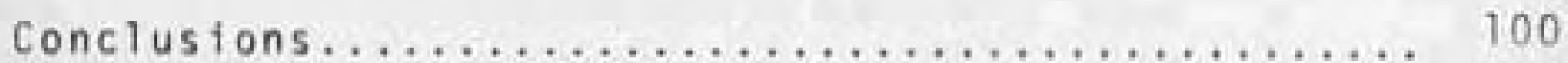

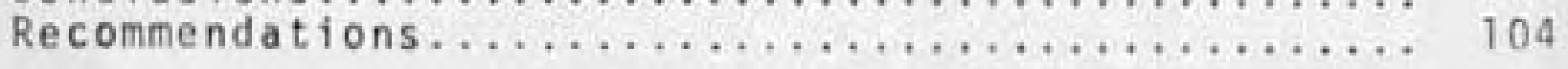

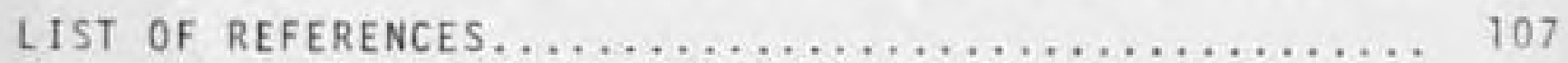

APPENDIX A: SUMMARY OF RESULTS - FACULTY

QUESTIONNAIRE ON UNIVERSITY POLICIES AFFECTING

DEVELOPMENT OF MASTER PLAN OF THE LAFAYETTE

CAMPUS OF PURDUE UNIVERSITY.

110

APPENDIX B: ALTERNATIVE COMMUTING PLANS -

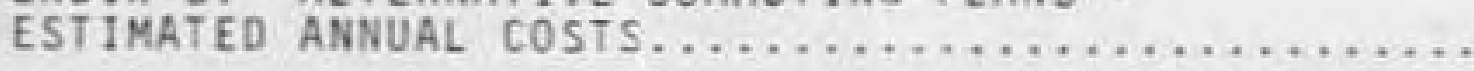


1. Students' Daytime Population in the Acadenic

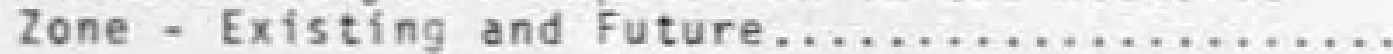

2. Existing Distribution of Students in the Different Kinds of Available Housing

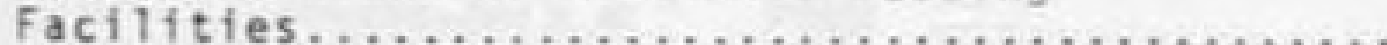

3. Existing Percentages of Students Living in Different Kinds of Housing Facilities at Different Distances from the Acadenic Zone......

4. Estimated Future Percentages of Students Living in Different Kinds of Housing Facilities at Different Distances from the

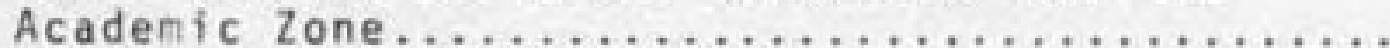

5. Evaluation of Alternative Commuting Plans...... 


\section{LIST OF FIGURES}

Figure

1. Purdue University Lafayette Canpus - General

Location..................................

2. Purdue University Lafayette Campus - General

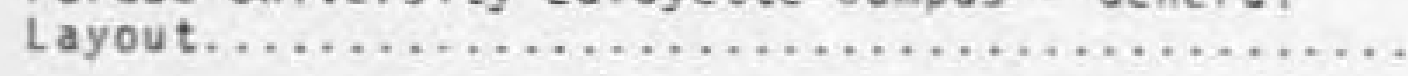

3. Average Dafly Pedestrian Trip Ends to

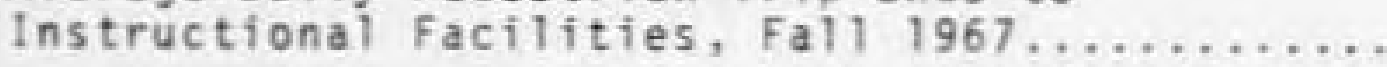

4. Average Dally Pedestrian Trip Ends by Instructional Facilfty by Distance from

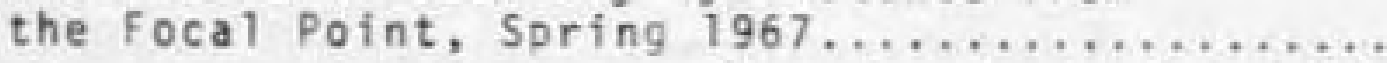

5. Average Dafly Pedestrian Trip Ends by Instructional Facility by Distance from the Focal Point, Fall $1967 \ldots \ldots \ldots \ldots \ldots \ldots \ldots$.

6. Enrollment on the Lafayette Campus, 1956 - 1967.

7. Percentages of Students Present in Scheduled Facilities in the Acadenic Zone at Different

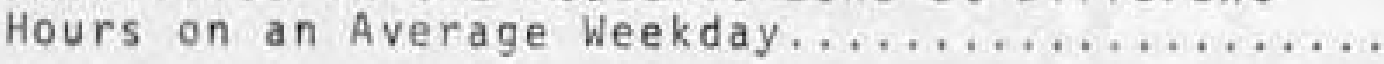

8. Student Auto Trips Per Student by Trip Length...

9. Existing Student Housing Facilities (Other

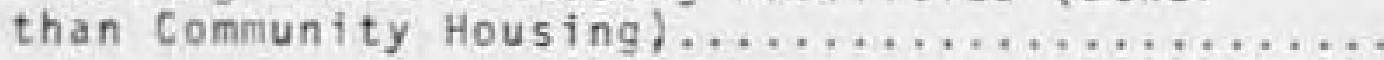

10. Percentages of Students Living in Different Kinds of Housing Facilities by Student Subgroup. Fal1 1967

11. Residential Distribution of Students Distance Zones.

12. Percentages of Students Living at Different

Distances from the Academic Zone, Spring 1967...

13. Probable Locations of Future University Housing Facilities. 


\section{LIST OF FIGURES (continued)}

Figure

Page

14. Number of Staff Parking Spaces Provided by the University Per Staff Member Working in the

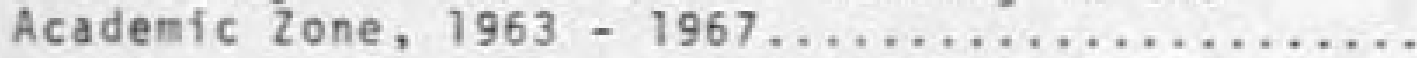

15. Schematic Configuration of Pedestrian Desire Lines to and from the Academic Zone, Fall 1967...

16. Average Daily Traffic Volume Map, 1967.........

17. Alternative P1an $1 / 1$ - (Circulation in the

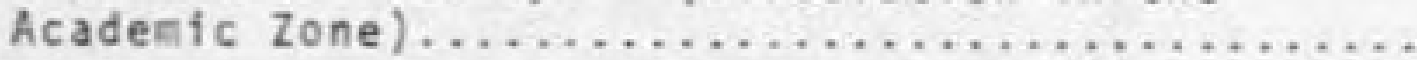

18. Proposed Integration of the North and South

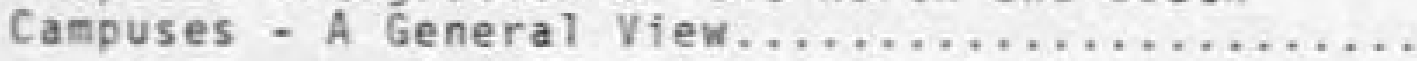

19. Alternative Plan $1 / 2$ - (Circulation in the Academic Zone) ........................... 74

20. Proposed Pedestrian Underpass - A General View... 76

21. Alternative Plan $1 / 3$ - (Circulation in the

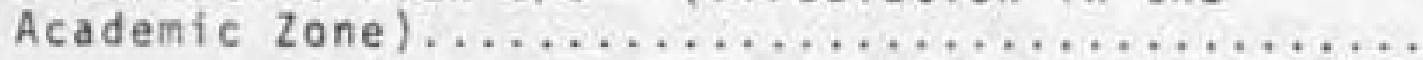

22. Alternative Plan $11 / 1$ - (Commuting to and

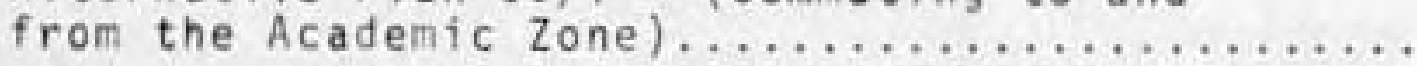

23. Alternative $P 1$ an $11 / 2$ - (Commuting to and

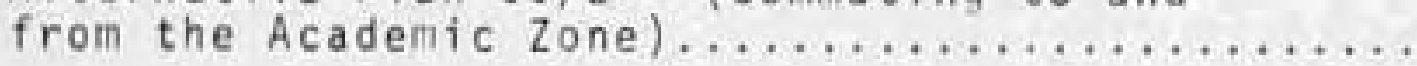

24. Sub-A1ternative Plan $11 / 3-A-$ (Commuting to and from the Academic Zone) $\ldots \ldots \ldots \ldots \ldots$.

25. Sub-Alternative Plan $11 / 3-B$ - (Commuting to and from the Academic Zone $) \ldots \ldots \ldots \ldots \ldots \ldots$ 
ABSTRACT

Fouad, Monira Yehya. M.S., Purdue University, June 1969. CAMPUS TRANSPORTATION PLANNING: A CASE STUDY OF THE LAFAYETTE CAMPUS OF PURDUE UNIVERSITY. Major Professor: Harold L. Michael.

This study exanined the problems and future requirements related to transportation on the Purdue Lafayette campus. A number of feasible alternative solutions were proposed to meet future transportation requirements for an established ultimate campus population.

On the campus, a central academic zone was identified as the locus of 1 nstructional, research, administrative, and assembly facilities. Pedestrian and automobile circulation in this zone and commuting to and from it were analyzed. Future requirements related to the pedestrian circulation system in the acadenic zone, to the major pedestrian-vehicle conflicts in and around the academtc zone, and to parking facilities for students, staff, and visitors and/or mass transportation systems serving them were estimated.

A number of alternative plans were developed to meet the future needs for circulation in the academic zone and for commuting to and from it. These alternatives were evaluated in terms of cost as well as a number of other qualitative criteria. It was found by eliminating through 
vehicular traffic on the north campus and by connecting it to the south campus through an open pedestrian underpass under State Street, that future pedestrian-vehicle conflicts in the academic zone could be minimized. Implementation of such a plan would only require reasonable changes in the existing conditions.

Insofar as commuting to and from the acadenic zone is concerned, two plans appeared to offer appropriate solutions. One of these by providing for future parking demands of students, staff, and visitors on close-by locations around the academic zone (mostiy in multi-story garages) would offer a high level of convenience in terms of the trip times involved. The second by providing for the future parking demands in remote parking facilities connected to the academic zone by street bus systems would offer a lower annual cost than that of the first plan but not as high a level of convenience. It was recommended that the first plan be implemented. 
CHAPTER I. INTRODUCTION

In many respects, a university campus reserbles a city. Frequently, the size of the campus population (students, staff, and visitors) cones close to that of a soall city. The activities performed on the campus are almost as complex and diversified as those performed in the city. The campus is not only a place for learning, for research, and for the development of the society's cultural life, but also a place where people live, work, shop, and move. To such extents, a university campus can be conceived as a micro-city to which many urban planning and transportation concepts are applicable.

In recent years, university campuses started to face the problems of population expansion. Their facilities, once simply laid out in close proximity to each other, had to expand upwards as we11 as outwards. Movement to and from these facilities and between them became more complex, intense, and time consuming. "Like most municipalities in the United States," writes Jakad, "American colleges and universities have come face to face with the explosive traffic problem." (1, p. 47)*

* Numbers in parentheses refer to numbered ftens in the List of References. 
Both the campus population and the surrounding community suffered. Students are often obliged to walk longer distances than what is generally considered tolerable. They have to rush between classes to move from one building to another and in many cases, they have to cross heavy vehicular traffic. In the same time, automobile trips to the canpus have become more difficult and time consuming due to lack of parking facilities on or around the campus. Traffic problems are equally felt by students, staff, and visitors. The surrounding communities also suffer from the intense traffic generated by the expanding campuses. The rapidly increasing enrollments and the mounting rates of automobile ownership and usage appear to be the two major factors behind campus transportation problems.

At already existing campuses, transportation problems are rendered even more severe by the inherited physical layout of buildings and circulation systems. At relatively old campuses, efforts were seldom made to provide an automobilefree environment. As a result, typical layouts inevitably create pedestrian-vehicle conflicts, especially in the central area of the campus where both pedestrian and vehicular traffic take place most intensely.

While many concepts and solutions have been presented to overcome (or at least to minimize) transportation problems for newly developed campuses, relatively little has been done to explore the possibilities of relieving existing 
campuses of such problems. The need exists to develop appropriate techniques to examine and analyze the transportation problems at already existing campuses as well as to develop sound and practical solutions to meet then.

\section{Purpose and Scope}

Purpose

The purpose of this study was to examine the nature and extent of the transportation problens on an already existing campus and to develop a number of alternative solutions to meet its future transportation requirements. The campus investigated in this study was the Lafayette campus of Purdue University. The study had the following specific objectives:

1. To develop an appropriate technique (or techniques) for examining the nature and magnitude of the transportation problems on an existing campus where the majority of the students were not commuters.

2. To estimate, for an ultimate campus population, the future campus transportation requirements.

3. To develop feasible alternative solutions to meet these estimated requirements.

4. To provide the decision-makers in the university with the necessary facts and evaluations about these developed alternatives. 


\section{Scope}

In this study, the future campus transportation requirements are estimated for an ultimate campus population regardless of the future date at which this ultimate population might be reached. The study is limited to the investigation of campus transportation problems created by the traffic movements to and from as well as within the academic zone. As used in this study, traffic movements include both automobile and pedestrian traffic. The academic zone is defined as the 10 cus of the contiguous instructional, research and administration functions of the campus. Traffic movements generated (or attacted) by peripheral areas of the campus represent a negligible fraction of the total traffic generated by the campus and are not considered in this study. Traffic routes to and from the surrounding community are also outside the scope of this study.

Emphasis is given to the movements of students to and from as well as within the academic zone. Movements of staff and visitors are also considered. Due account is given to the access of service and energency vehicles.

Two main aspects related to campus transportation are analyzed: (1) pedestrian movements to and fron as well as within the academic zone, and (2) parking demands of students, staff, and visitors on and around the academic zone. 
The Lafayette Campus

The location of the Purdue Lafayette campus as related to the urban area (Lafayette and West Lafayette) is shown in Figure 1. The campus is located just west of the central business area of the city of Hest Lafayette and southwest of Northwestern Avenue, a major urban arterial. State Street, another major arterial, passes through the campus and a railroad line bounds it from the south. Commuity residential areas abut the east and northeast sides of the campus and open recreational areas surround both its west and northwest sides. Purdue's enrollment on this campus $(23,370$ in 1967/68) is, and has been, larger than what could be entirely accommodated by privately owned community housing facilities. The university, therefore, provides a substantial portion of the students' housing requirements. A general layout of the Purdue Lafayette campus appears in Figure 2 .

Within the campus, the academic zone was delineated as the area where instructiona 1, research, administrative, and principal assembly facilities are located. Figure 2 shows the delineation of the academic zone. State Street divides the academic zone into two parts referred to in this study as the north and the south campuses.

\section{Previous Studies}

Canpus transportation problens are often studied in connection with campus physical planning. Few are the studies, however, that were primarily concerned with aspects of canpus 
Lafayette and West Lafayette

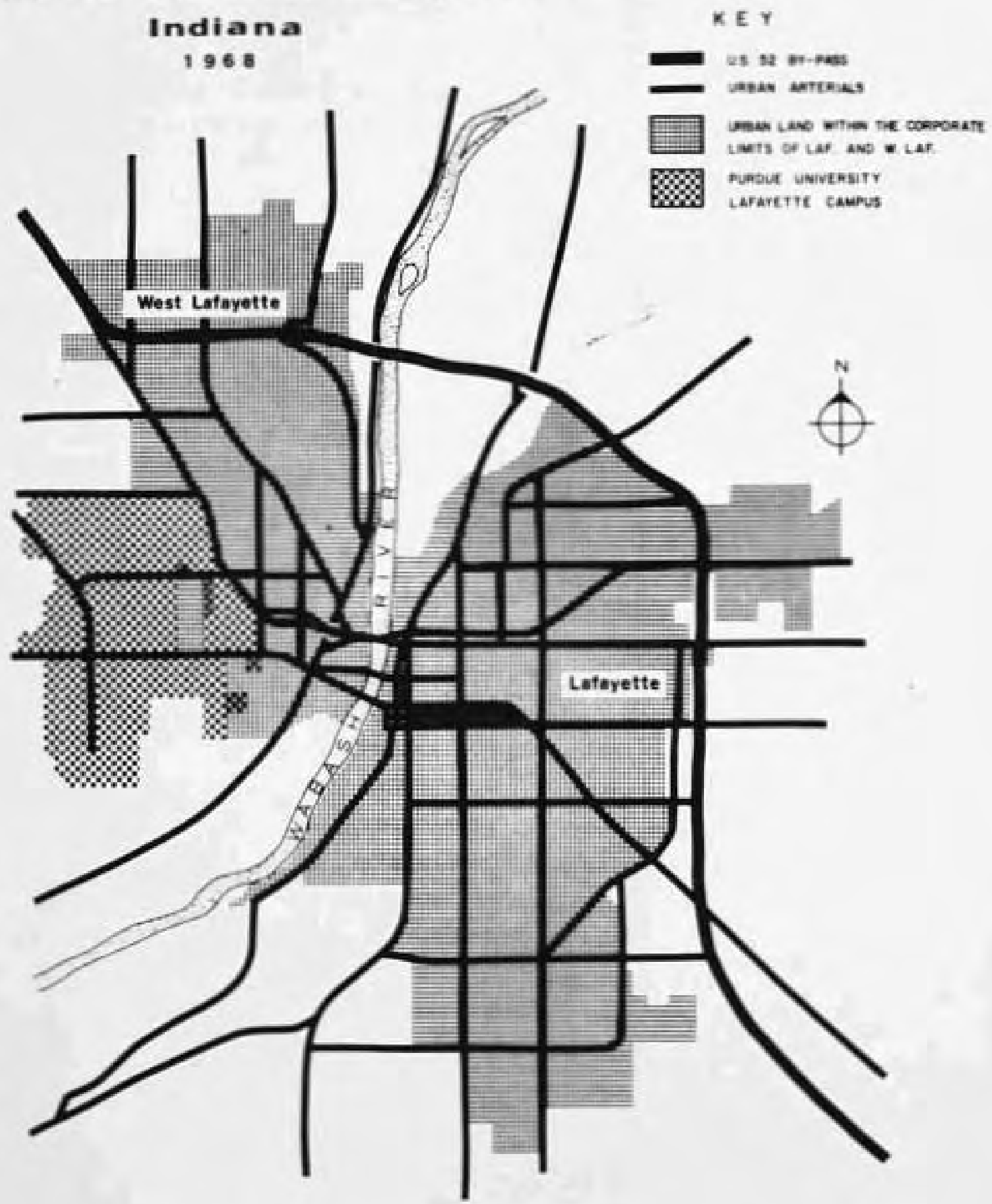

FIGURE I - PURDUE UNIVERSITY LAFAYETTE CAMPUS GENERAL LOCATION 
PURDUE UNIVERSITY LAFAYETTE CAMPUS งเลa

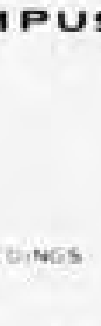

$\square$ ACADEMIC ZONE

UNIVERSITY HOUSING athleEtic facilities

$\square$ OPEN SPACES

D ShOPPIng center ER PURDUE airport Dervices a storage
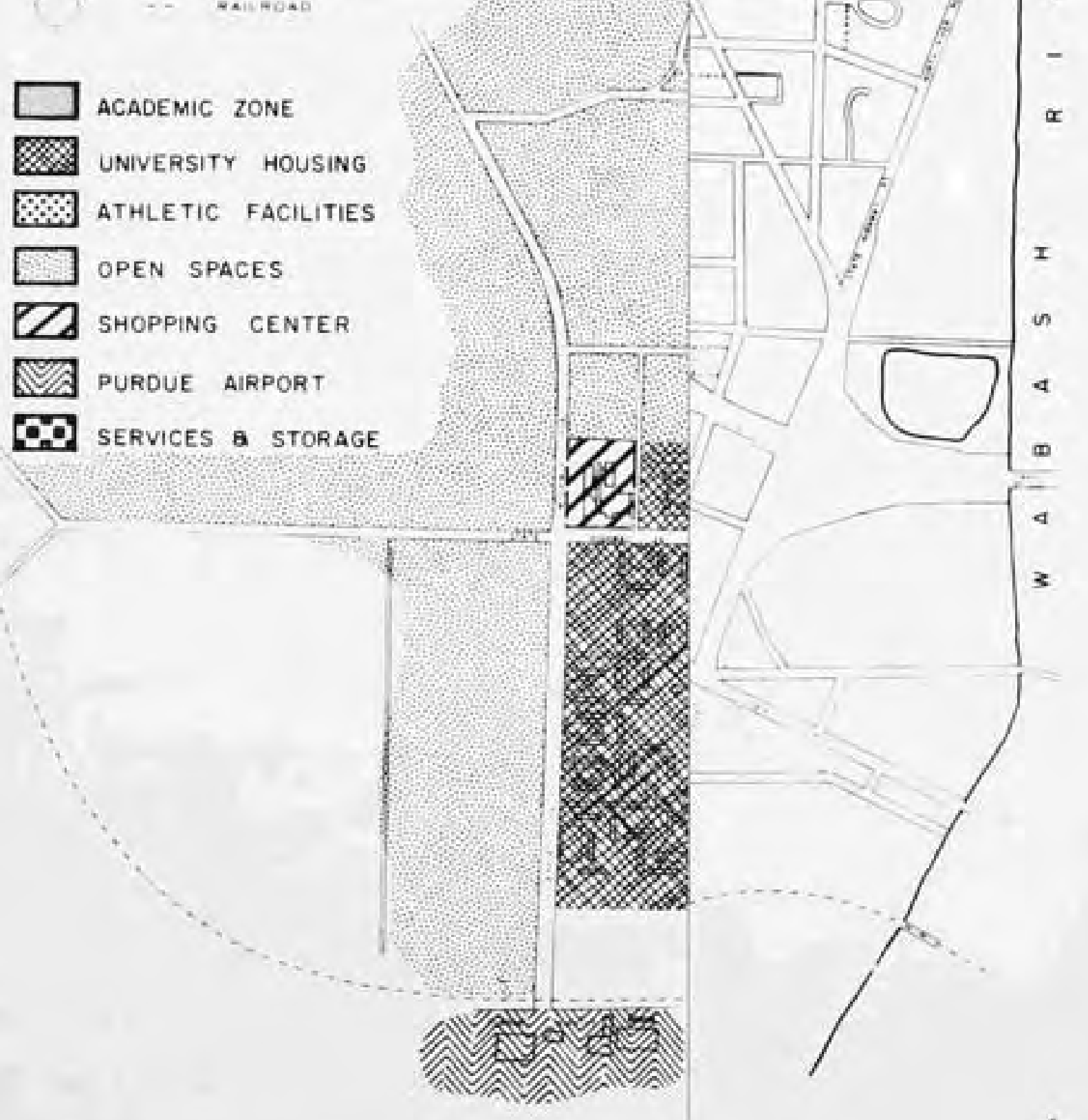

FIGURE 2 - PURDUE UNIVERSITY 


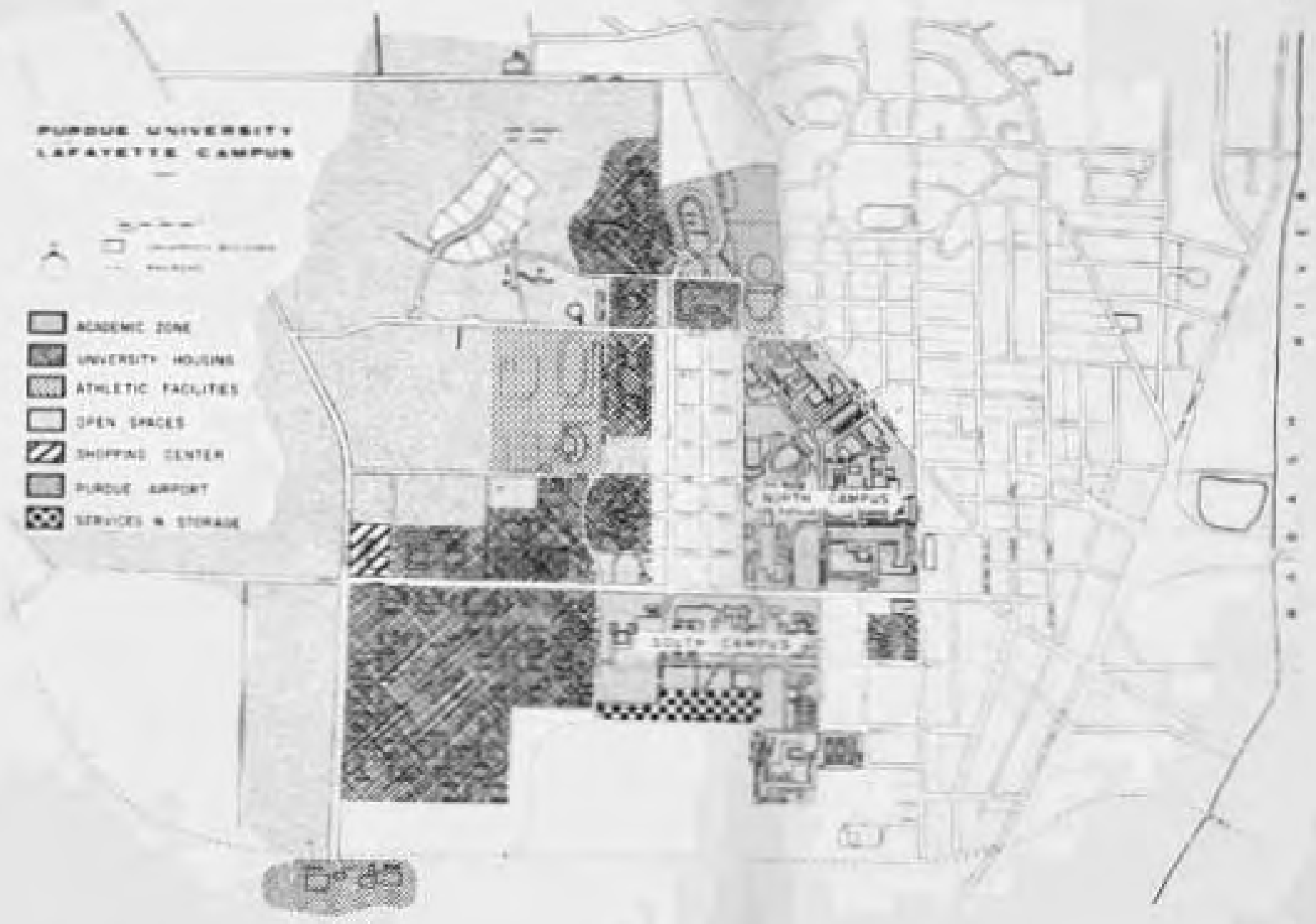

FIOURE 2 - PURDUE UNIVERSITY LAFAYETTE CAMPUS - GENERAL LAYOUT 
transportation. Fewer still are those directed to comprehensive campus transportation planning.

To examine the pedestrian traffic generated by students on university campuses, the Educational Facilities Laboratories and Duke University developed a computer aided technique to simulate pedestrian traffic patterns by using information reported by a sample of students in the form of diaries. By means of the proposed technique, existing pedestrian traffic maps can be plotted. Future pedestrian traffic volumes and patterns can also be estimated (2). While the technique is conceptually sound, it has a number of operational 1 imitations. The difficulties of obtaining diary information and the conceivable inaccuracies involved in using them (especial1y in forecasting) tend to limit the usefulness of the technique.

The University of Michigan and the University of Mississippi used an observed vehicle trip generation rate per capita (to the campus) to estimate future vehicular traffic $(3,4)$. Although Dober recognized the simplicity of using such observed rates, he pointed out that consideration should be given to other factors such as changes in university housing supply, changes in the populations of graduate and married students, improvements in mass transportation systems, and increasing campus parking supply (5).

In preparing parking plans for the University of I11inois and the University of Mississippi, Bartholomew \& Associates 
stressed the importance of considering vehicle ownership trends in estimating parking demands. He also pointed out that the policies adopted by the university relative to parking supply, fees, and controls have a great influence on parking demand. Accordingly, Bartholonew developed a number of alternative parking plans assuming different levels of future demand. The level of denand that could be economically met was, then, selected. The university's future parking policies were planned accordingly $(4,6)$. Provided that the assumed alternate levels of parking demand are realistically established on the basis of observed parking habits and patterns, this approach can provide sound estimates of future campus parking requfrements.

Marconi investigated the factors affecting parking deInand on two different campuses in San Francisco. He found that parking demand was substantially higher on the campus that had the higher percent of non-resident students (7). In essence, these results indicated that the distances from the students' residences to the campus have a decisive effect on the rates of autonobile usage and consequently on the parking demand.

The variables most often pointed out in the several studies found in the 1 iterature as influencing campus traffic and parking denands are: (1) size and composition of the campus population, (2) proportion of resident students living in university housing facilities, (3) class schedules 
and office hours, (4) availability and conditions of mass transportation, (5) university parking policies, and (6) parking availability and fees in the surrounding community $(3-8)$.

While variables affecting campus transportation have been separately recognized and used, it appears that no comprehensive technique has yet been developed to include a combination of these variables in estinating future campus traffic and parking demands.

\section{Procedure}

In this study, two major phases of campus transportation are considered. First, movement in the academic zone is examined. The efficiency of pedestrian circulation is analyzed in terms of trip lengths and frequencies. Inefficiencies in the existing layout and uses of instructional facilities are pointed out. Locations and intensities of pedestrian-vehicle conflicts are also discussed. Second, commuting to and from the academic zone is subjected to a detailed analysis. Four campus population characteristics are considered to have a combined effect on the numbers of trips made to and from the academic zone in different hours and on the modes of travel used in these trips. First, the size and composition of the campus population (students, staff, and visitors) is used in determining the nagnitude of traffic movements to and from the acadenic zone. Second, the numbers of users of instructional facilities, offices, 
and other assembly facilities in the academic zone (referred to in this study as the daytime population) provides the basis for examining the temporal patterns of traffic movements to and from the academic zone. Third, the students' behavioral patterns in using their automobiles to and from the academic zone are examined. Based on these patterns, probabilities of automobile usage by students living at different distances from the academic zone are established. Fourth, the residential distribution of students (both in university housing facilities and in the surrounding community housing) is used to estabiish the proportions (and numbers) of students living at different distances from the academic zone. On the basis of the observed patterns of automobile usage, the students ' residential distribution is used to estimate the expected numbers of student auto trips (and non-auto trips) made to the academic zone. Since almost al1 staff members and visitors, regardless of where they live, tend to use their automobiles to commute to the academic zone, their residential distributions were not considered.

The present university regulations on traffic and parking, the existing conditions of relative parking availability on and around the acaderic zone, and the existing patterns of automobile usage in commuting to the acadenic zone are assumed to remain almost unchanged for the future.

For an established ultinate campus population, the future patterns and magnitudes of vehicular and pedestrian traffic movements in as well as to and from the acadenic zone are 
estimated on the basis of the above assumptions and the analyses of the existing traffic movements. Future transportation requirements (in terms of pedestrian walkways, parking facilities, and/or mass transportation systems) are determined. Several alternative plans are developed to meet the future needs for circulation in the academic zone and for commuting to and from it. These alternatives are evaluated in terms of cost as well as a number of other qualitative criteria. Conclusions are drawn and recommendations made. 
CHAPTER II. DATA COLLECTION, DATA ANALYSIS, AND FORECASTING

The following is a discussion of the data collected for this study, the analyses performed on each data iten, and the forecasting of future conditions relevant to canpus transportation planning. In the following discussions, the term student is used to indicate full-time and part-tine registered students. By staff is meant all ful1-time members of the faculty and of the clerical and service staffs. Instructional facilities refer to buildings where classes or laboratory sessions are held.

\section{Movement in the Academic Zone}

Movement in the academic zone is mainly done by foot. Vehicular movement is relatively 1 imited. However, pedestrian-vehicle conflicts exist at certain locations in the zone. The analysis of the movement in the academic zone, therefore, focused on two aspects: (1) the efficiency of pedestrian circulation (and the general layout of the different facilities), and (2) the pedestrian-vehicle conflicts. Since students represent the majority of pedestrians in the acadenic zone, only their movenent was considered. The analys is provided the basis for developing proposals to minimize pedestrian-vehicle conflicts and for making 
recommendations on the future layout of facilities in the academic zone. Student pedestrian trips are unique in that their origins and destinations (in the academic zone) are mainly dictated by class schedules, the time-break allowed between classes, the locations of the existing facilities, and the use of these facilities. The analysis, therefore, took into consideration these fundamental temporal and spatial determinants of pedestrian circulation in the acadenic zone.

The Efficiency of Pedestrian Circulation

Ideally, facilities most used in common should be centrally located to be most accessible from all other locations in the acadenic zone. Instructional facilities should also be located within "walkable" distances from each other; "walkable" within the time-break allowed between classes. Under these ideal conditions, a relationship between pedestrian trip lengths and trip frequencies would show a high frequency of short trips with a decreasing frequency as trip length increases. Such an fdeal pattern may not be found on all existing campuses. However, an analysis of the existing relationship between trip lengths and freauencies provides a measure of the degree to which the ideal is fulfilled. The analysis was thus performed as follows.

For each instructional facility in the academic zone, the weekly total number of student contact hours was used to estimate the average dafly pedestrian trips attracted by 
the facility (9).* Non-instructional facilities were not considered. Estimates on average daily pedestrian trip ends by facility were obtained for both the Spring and Fall semesters of 1967. Results obtained for both semesters did not show appreciable differences. Figure 3 shows groupings of instructional facilities according to their estimated average daily pedestrian trip ends for the Fall of 1967 . Presently, the tine-break allowed between classes is ten minutes, about two minutes of which are usually spent in going in and out of classrooms and going up and down staircases at both origin and destination. The actual walking should thus be done in eight minutes. Because instructional facilities are presently classified and used by major fields (Electrical Engineering, Physics, Chenistry...etc.) and not by functions (1ecture halls, laboratories, offices... etc.), 1 inkages exist (fron a circulation standpoint) between each instructional facility and virtually all others.

To examine the efficiency of the existing layout of facilities and the pedestrian circulation systen, a hypothetical non-problenatic circular zone was delineated whose diameter can be walked within eight minutes at an average speed of about 275 feet per minute.** By superimposing the

* A student contact hour refers to one student attending one instructional session. Every class contact hour and every three laboratory contact hours were considered equivalent to one pedestrian trip.

** A recent standard observed in a survey conducted at Cornell University $(10)$. 


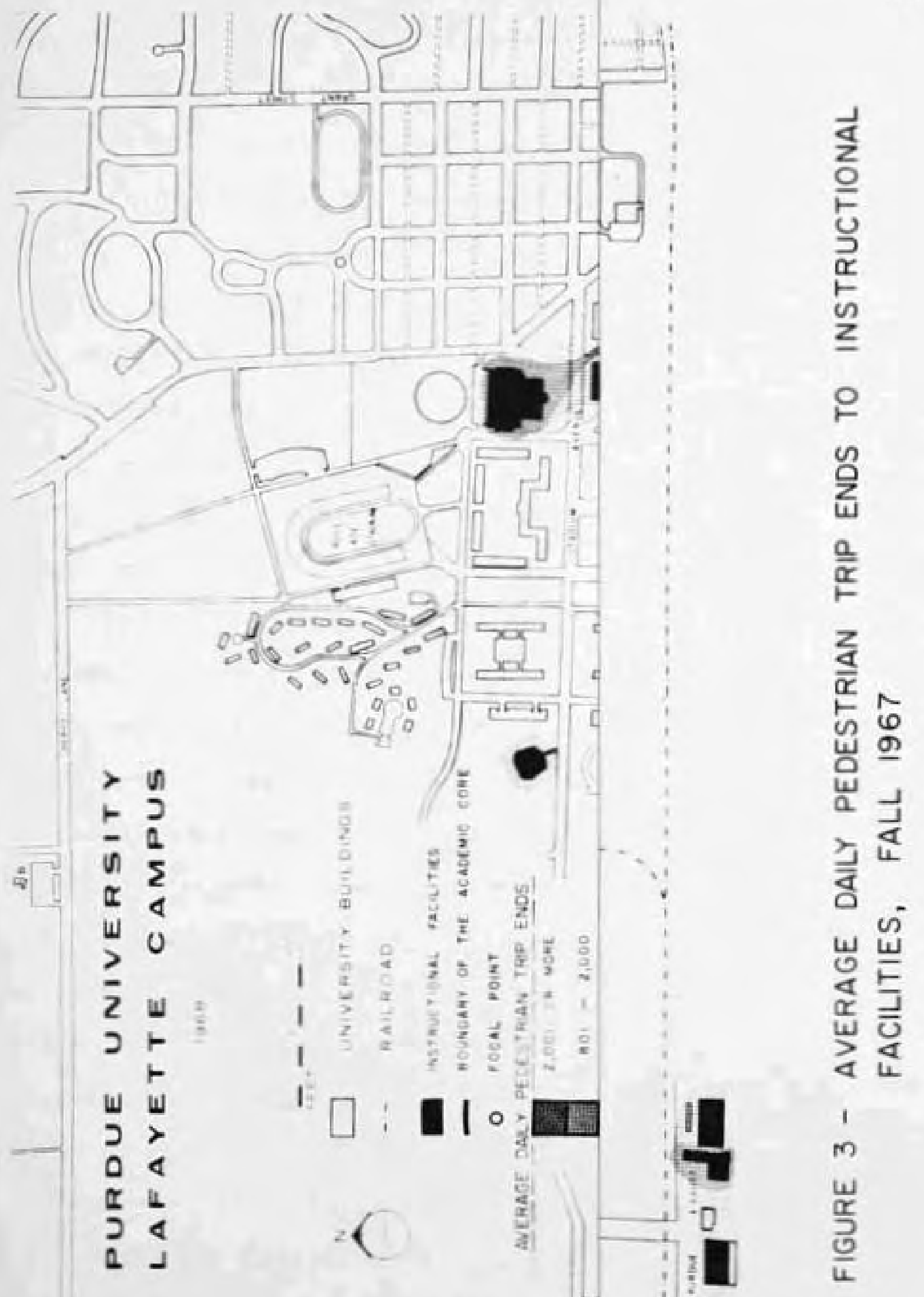



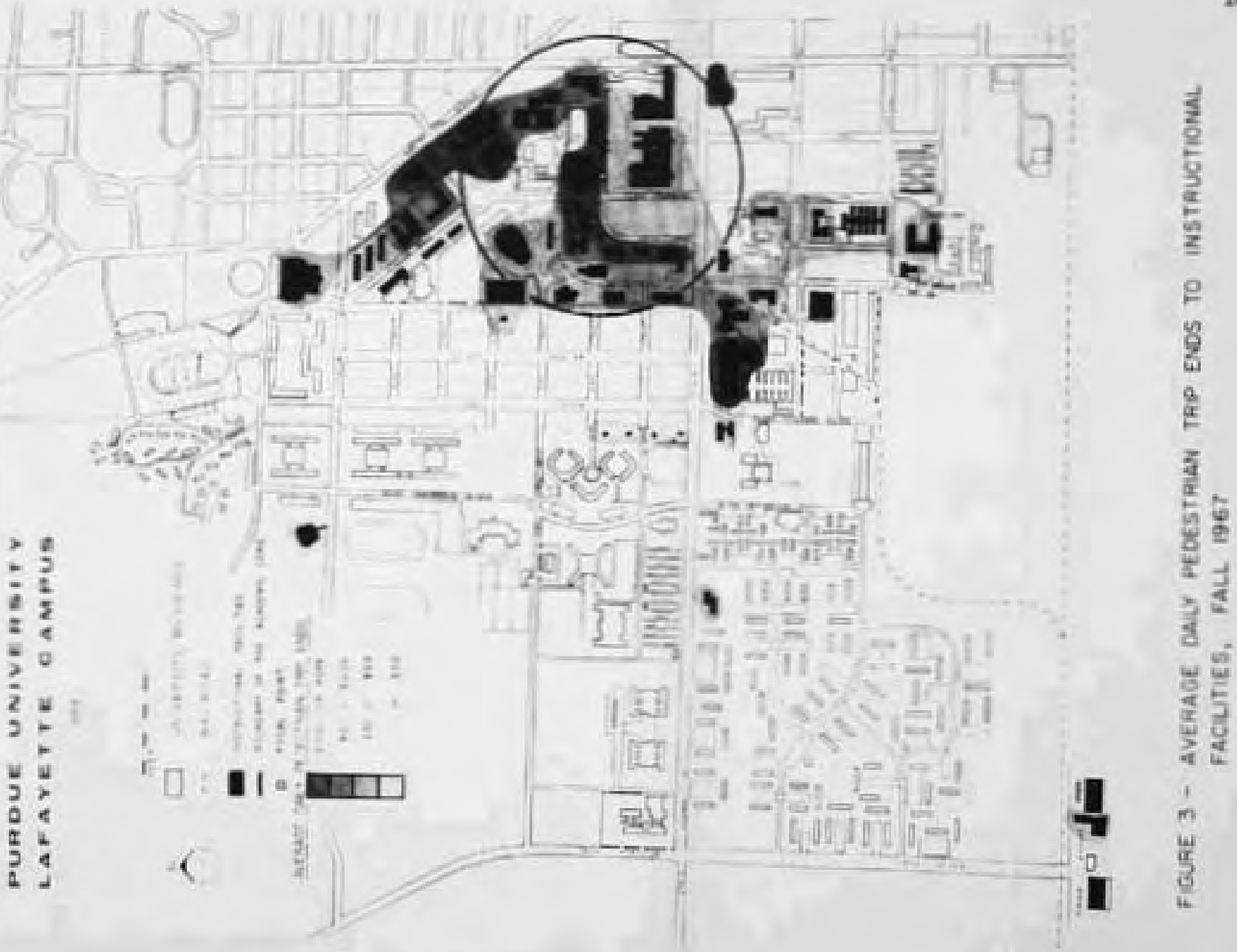
hypothetical zone on a map of the existing academic zone, a position was found that allows inclusion, within the nonproblenatic "core," of the maximum number of instructional facilities with the highest frequencies of use (Figure 3 ). The center of this "core" (referred to later as the focal point) was considered as the theoretical center of the academic zone. The actual trip lengths from the focal point to each instructional facility were measured and a relationship between trip lengths and frequencies was established. Figures 4 and 5 give the estimated average daily pedestrian trip ends by instructional facility by distance from the focal point for the Spring and Fall semesters of 1967.

The analysis shows that pedestrian trips exist that cannot be walked in eight minutes. However, no conclusive data were available to show how many such trips had to be made between two consecutive classes. Thus, the magnitude of these problematic trips could not be determined. The analysis, however, indicates that the present layout and use of the instructional facilities within the academic zone does not provide the most efficient 1 inkages between facilities and hence does not minimize pedestrian travel. Some heavily used fnstructional factlities are located outside the non-problenatic "core" (e.g., Life Science and Physics Buildings) while inside it are located some totally noninstructional facilities (e.g., the Engineering Administration building, the heating and power plant, and the Heavilon 


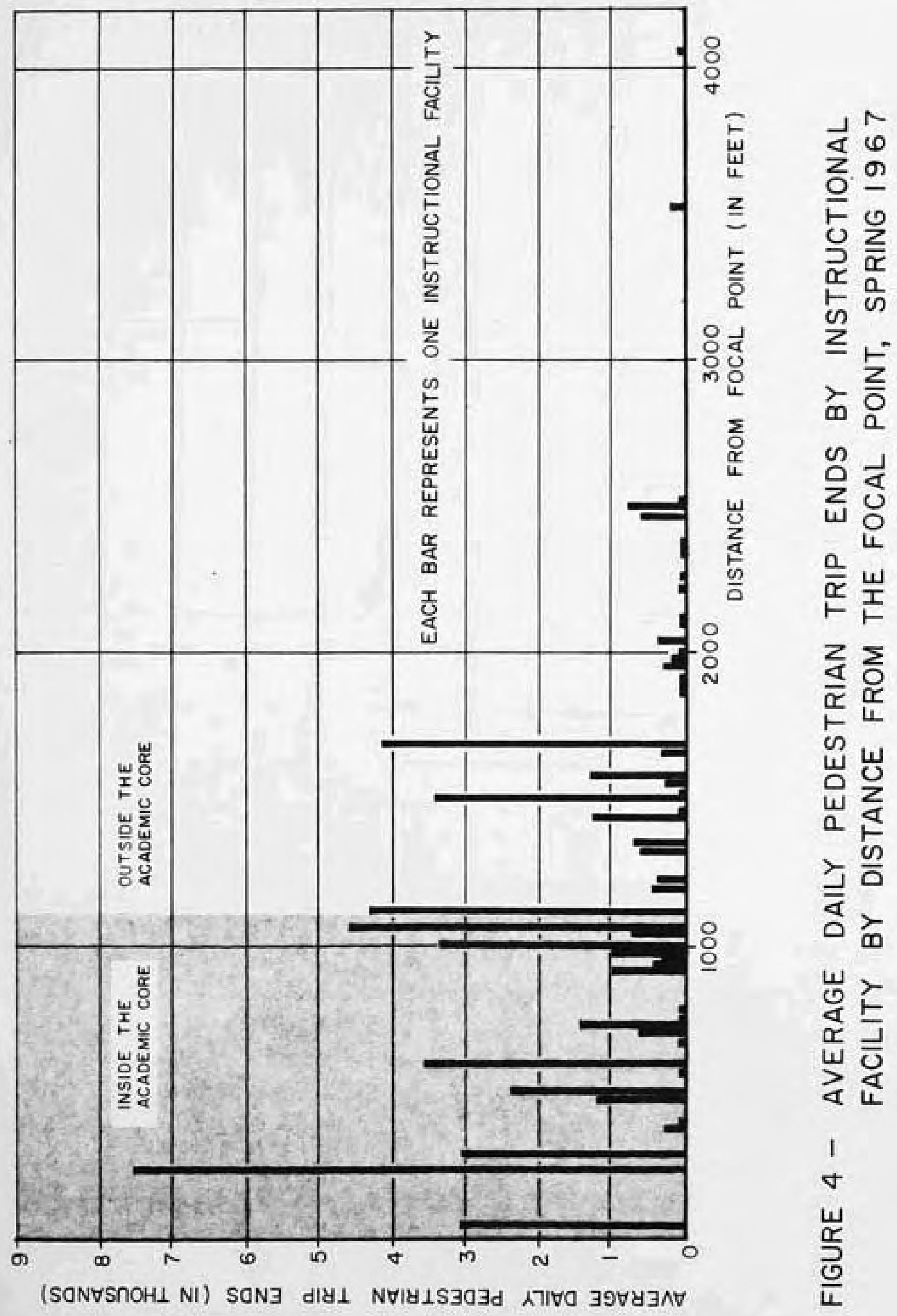




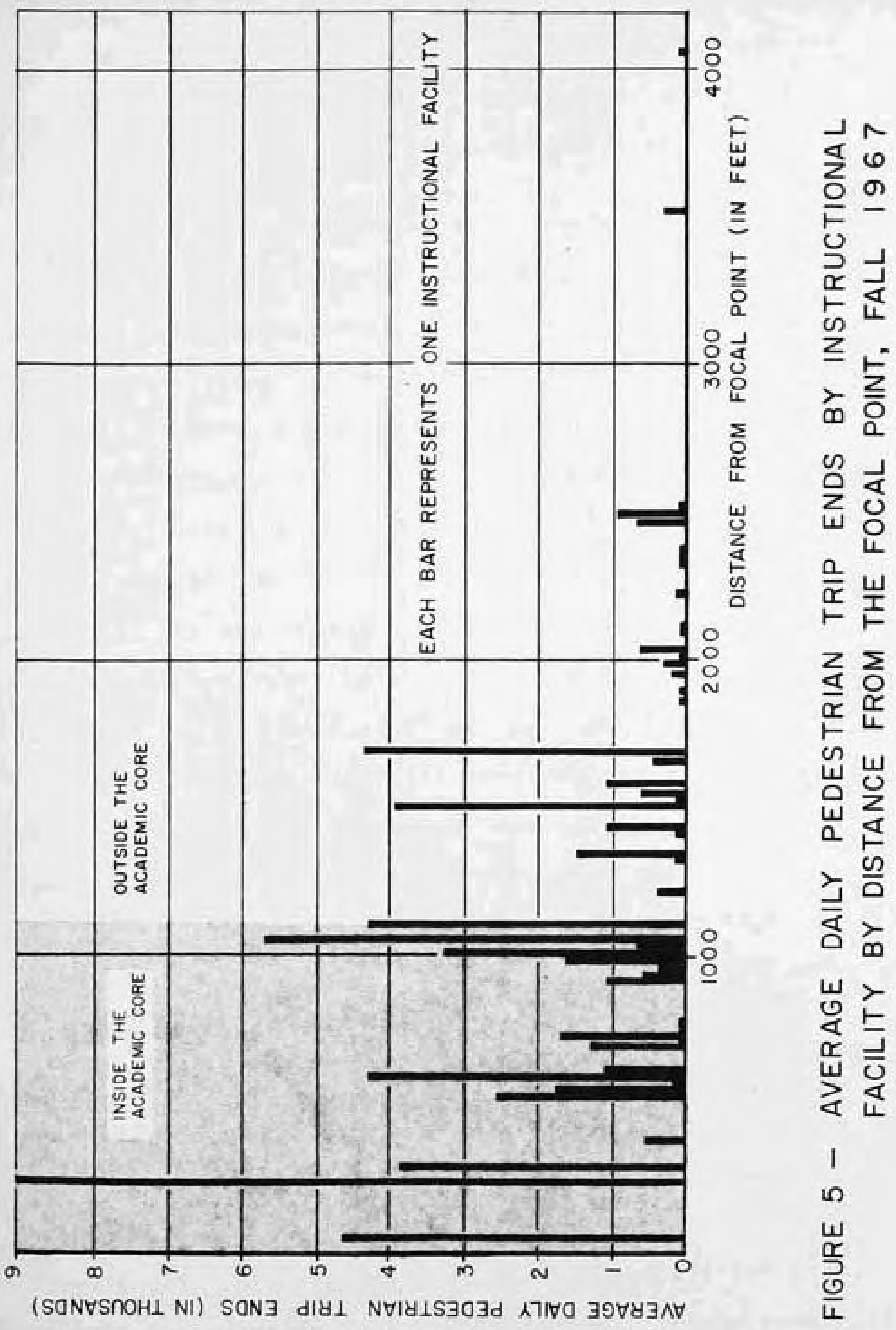


Hall Laboratory building) and some infrequently used instructional facilities (e.g., Pierce Conservatory building and the Aeronautical and Engineering Sciences building).

\section{Pedestrian-Vehicle Conflicts}

The existing network of pedestrian paths in the academic zone was exanined to deteraine the locations of pedestrianvehicle conflicts. Major conflicts take place on state Street. Although fences and signals are provided to control pedestrian crossings between the north and south canpuses, major conflicts still exist in a number of locations such as in front of the Home Economics buildings and the Krannert building. On the north campus, vehicular through traffic is presently discouraged by blocking portions of some internal streets. But a number of problematic points still remain on Oval Drive, Memorial Ma11, Stadium Ma11, Purdue Ma11 and south of the Hall of Music. Pedestrian-vehicle conflicts are almost absent on the south campus. The railroad line that passes through the academic zone does not seem to cause any real problem. However, it is aesthetically incompatible with the acaderic surrounding.

In the future, the volumes of pedestrian traffic will tend to increase in proportion to the expected increase in campus population. This calls for appropriate future actions to minimize the pedestrian-vehicle conflicts pointed out above and to maximize the efficiency of pedestrian circulation in the academic zone. With this in mind, a number of 
alternative circulation plans (in the academic zone) are developed in the next chapter. A number of recommendations concerning the future layout and use of different facflities in the academic zone are also given in Chapter IY.

\section{Commuting to and fron the Acadenic Zone}

In this section, the campus population characteristics infiuencing commuting are first considered. Future commuting demands are then estinated.

\section{Campus Population Characteristics Influencing Commuting}

Data were collected on four characteristics of the canpus population:

1. The size and the composition of the campus population (students, staff, and visitors).

2. The daytime population in the academic zone.

3. The student auto trips (home based).

4. The residential distribution of students on and around the campus.

The first, second, and fourth data items were obtained from the university records $(11,14-19,21-23)$. The third was obtained by direct observation. In several cases, data from past years were used to ascertain whether or not noticeable trends existed.

Analyses were performed on these data to make possible the forecasting of future characteristics of campus population and hence future comuting demands. The results of a faculty questionnaire on policies affecting the development 
of a university master plan was constantiy used for guidance in analysis and forecasting (14).*

\section{Campus Population: Size and Composition. Three prin-} cipal campus population subgroups were considered: students, staff, and visitors. For each, the existing size and conposition are discussed and the future size and composition are estinated.

Students. Students represent the greatest proportion of the campus population. In the Fall of 1967, Purdue enrolled about 23,370 students on the Lafayette campus. Like on many other campuses, enrollment has greatly increased during the past few years. Figure 6 shows the increase in the total enrollment on the Lafayette campus during the period 19561967 (11). In general, evidence indicates that a growing percentage of the population seeks higher education and that this percentage will most likely continue to increase in the future (5). The enrollment on the Lafayette campus is thus expected to grow. The question is not how far it will grow but rather how far it should be allowed to grow. The problem of an optimum enrollment size has repeatediy been raised $(10,12,13)$. Some believe that universities have already exceeded the ranges of optimum enrollment. Others think more students can sti11 be accomnodated. There appears to be no

* A sumnary of the results of this questionnaire appears in Appendix A. 


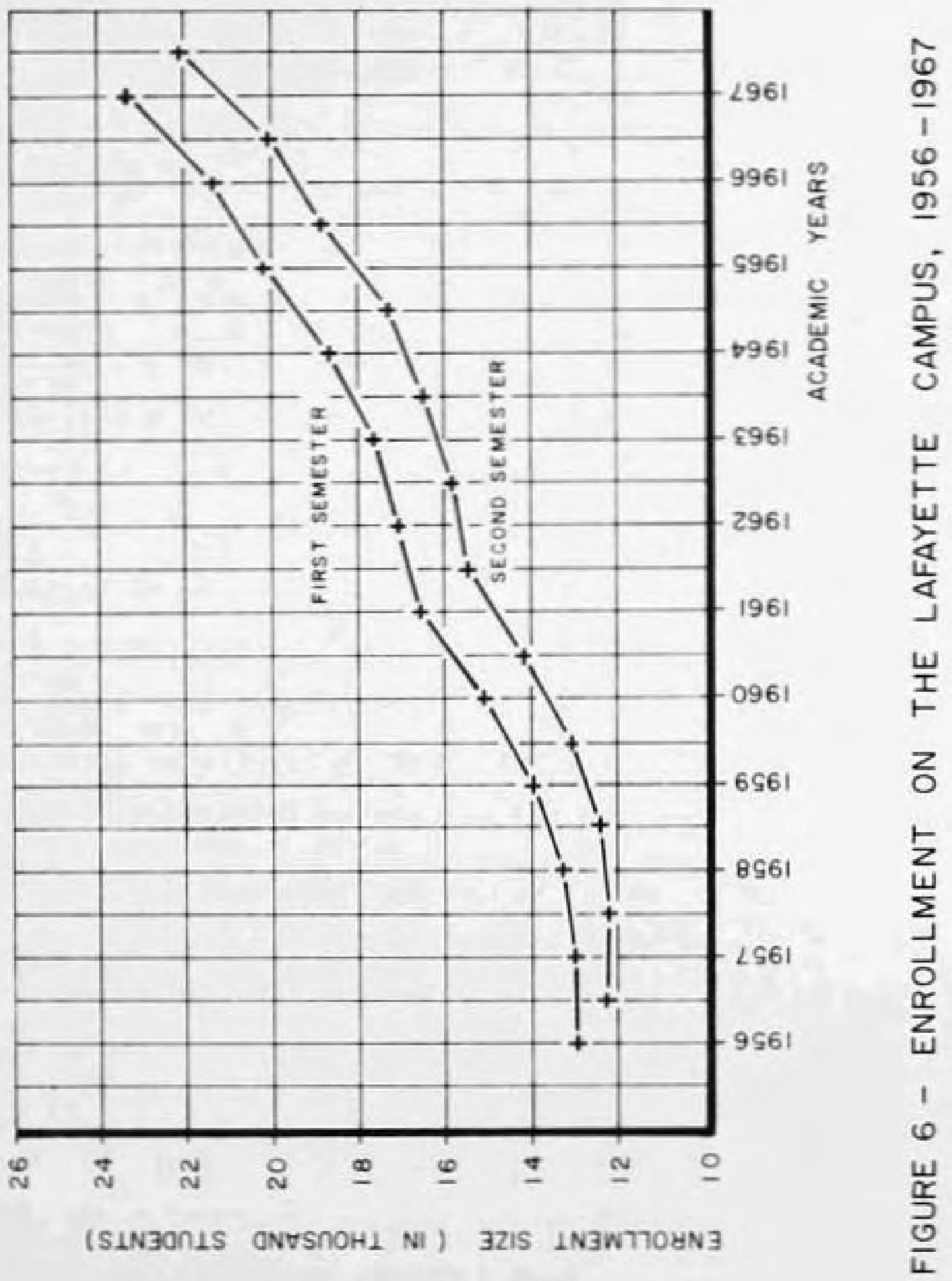


general agreement as to what constitutes an optimum enrollment size.

In this study, the ultimate future enrollnent size was determined on the basis of two criteria: (1) the opinions of university faculty nembers, and (2) the capacity of the existing acadenfic zone. The faculty members seened to reach a concensus of opinion that enrollment on the campus should be 1 imited to 35,000 students (14). Assuming that the present land area of the acadenic zone will renain virtually unchanged in the future, and that the building standards (average number of stories, average land coverage ratios, and average gross built-up area per student) presentiy existing for the university (15) will be applied in the future, it was found that the academic zone can easily accommodate the ultimate enrollment agreed upon by the faculty. The uttimate future enrollment on the Lafayette campus was thus taken as 35,000 students.

From a campus transportation standpoint, two student population characteristics were found to be important: marital status and educational level (graduate or undergraduate). Only these two characteristics were found to correlate with the residential distribution of students and hence influence their choice of mode of travel (autonobile versus walking) to and from the acaderic zone.

In the Fal1 of 1967 , about 52.5 percent of the graduate students and about 10 percent of the undergraduate students were narried. For both subgroups (graduate and undergraduate). 
these percentages remained almost unchanged during the period 1956-1967. For each subgroup, the future percentage of married students was assumed to remain the same as the average percentage of married students during the period 1956-1967; namely, 55 percent for the graduate students and 11 percent for the undergraduates.

To estimate the future total numbers of married students, the proportions of graduate and undergraduate students were examined. Since these proportions depend mainly on the University's educational philosophies, the opinions of faculty members were again consulted. Faculty members tended to agree that, in the future, the proportion of graduate students should be about 35 percent of the total enrollment (compared to about 23 percent in 1967) (14). Knowing that the future total enrollment is expected to reach 35,000 students, that 35 percent of these will be graduate students and that 55 percent of the graduate students and 11 percent of the undergraduates will be married, it was estimated that the number of married students will reach 9,240 students, or about 26.4 percent of the future ultimate enrollment.

Staff. Past trends indicate that the ratio of staff to students is almost entirely a matter of university policy. Therefore, estimatos of the future number of full-time staff members were again based on the opinions of members of the faculty. 
The results of the faculty questionnafre indicated a fairly consistent agreement on a future ratio of 0.27 ful1time employees per student $(14,16)$. Accordingly, it was estinated that, when ultimate enrollment is reached, the university will employ about 9,450 ful1-time staff nembers.

\section{Visftors represented only a small percentage of the} campus population. They are mainly attracted to the campus by special seninars, meetings, conferences, exhibits, and other periodic events conducted in the academic zone. As such, the future numbers of visitors are difficult to estimate. An approximate method, therefore, was used to estimate the future number of visitors parking in the academic zone by observing, for three different years, the ratio between the number of parking spaces (in the acadenic zone) used by visitors and by staff members, and by assuming that the average observed ratio (one parked visitor per 20 parked staff members) will remain almost constant in the future.

Daytime Population in the Academic Zone. The analys is of daytime population deals with the tenporal distribution of the campus population in the acadenic zone. From a campus transportation standpoint, the interest focuses predominantly on periods of peak population concentrations in the academic zone since these peak periods produce parallel peak transportation demands. Besides, more specific aspects related to the concentration of students in the academic zone in 
morning hours are also of interest in determining the expected loads on mass transportation systems that might be developed (as an alternative solution) to students' commuting needs.

students. The numbers of students present in the academic zone at different hours on an average weekday were determined by two factors:

1. The university master schedule assigns the weekdays and the hours on which different courses are given. As such, it determines the total numbers of students using scheduled facilities in the academic zone at different hours.

2. The students use of non-scheduled facilities such as libraries, cafeterias, and student offices determines the total numbers of students present in the academic zone while not attending classes.

Information on the space utilization of different scheduled facilities was obtained from university records in the form of student contact hours (available by day and hour for past semesters)(17). A student contact hour represents one student present in an instructional facility in one class period. By summing these student contact hours for a 11 scheduled facilities in the academic zone by day by hour, the total number of students present in scheduled facilities at different hours was obtained for two Fall semesters (66/67 and $67 / 68)$ and two spring semesters $(66 / 67$ and $67 / 68)$. The proportions these totals represented of the total 
enrollment (for these semesters) were obtained. No significant differences were observed between the results obtained for these four semesters. Their average was used to represent the existing conditions. Figure 7 shows the average percentages of students present in scheduled facilities at different hours on an average weekday for the four senesters.

In the future, these observed percentages were also assumed to apply. Since the master schedule presently used by the university has initially been developed to optimize the use of instructional facilities, any future deviation from it would either mean class conflicts for more students or an inefficient utilization of instructional facilities. Accordingly, the existing percentages of students present in scheduled facilities at different hours on an average weekday (as determined by the master schedule) were assumed to remain almost unchanged for the future.

To estimate the future proportions of students using non-scheduled facilities, past and present data on the use of different 1 ibraries and the meals served in different cafeterias were obtained and analyzed $(18,19)$. The proportions of graduate students present in offices in the acadenic zone were also estinated.

For libraries and cafeterias, two use characteristics were considered: (1) the total numbers of dafly users in relation to the total enrollment, and (2) the proportions of these daily users present in the facilities at different hours 


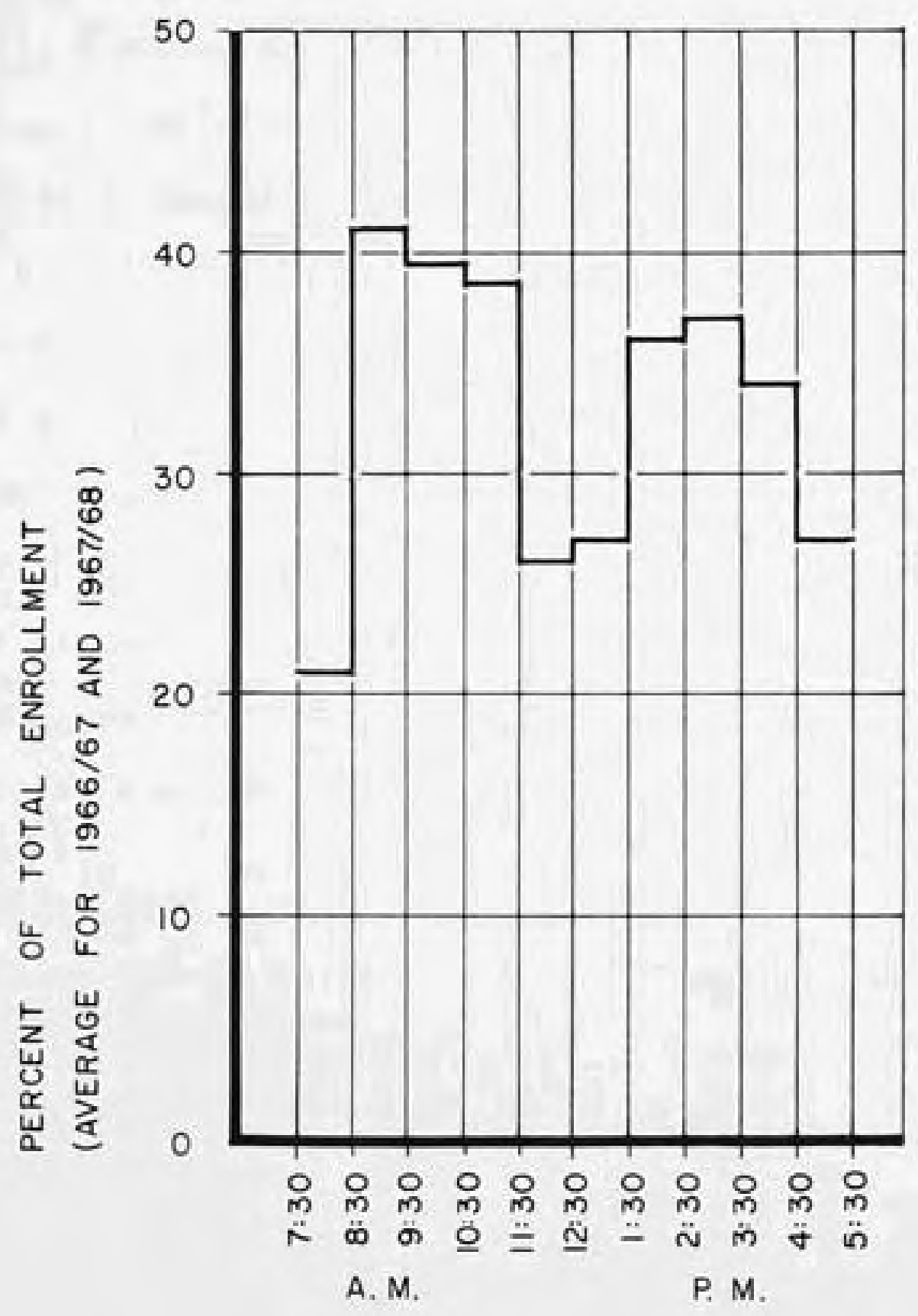

FIGURE 7 - PERCENTAGES OF STUDENTS IN SCHEDULED FACILITIES IN THE ACADEMIC ZONE AT DIFFERENT HOURS ON AN AVERAGE WEEKDAY 
on an average weekday. For both types of facilities, students represented the greatest majority of users. Having established the past trends concerning the two above use characteristics, the expected future use characteristics were projected assuming that the same trends will continue. No conclusive data could be obtained about the percentages of graduate students present in their offices in the acadenic zone at any one time. It was thus assuned that, for both the present and the future, about 30 percent of the nonstaff graduate students are present in their offices on the zorning hours of an average weekday. The results of the above outlined analyses are summarized in Table 1 . The table gives both the existing and the future percentages of students using different facilities in the academic zone at different hours on an average weekday.

Staff and Visitors. Because of the regular work hours during which the majority of staff members are expected to be present in the acadenic zone, the temporal distribution of staff becomes virtually meaningless from the standpoint of this study. A150, because visitors represent only a small fraction of the campus population and because of the unpredictable nature of their temporal concentrations in the academic zone, their daytime population was not considered. For these two groups (staff and visitors), the only estimates of interest were those related to future parking demands in the academic zone. These estimates are discussed later 


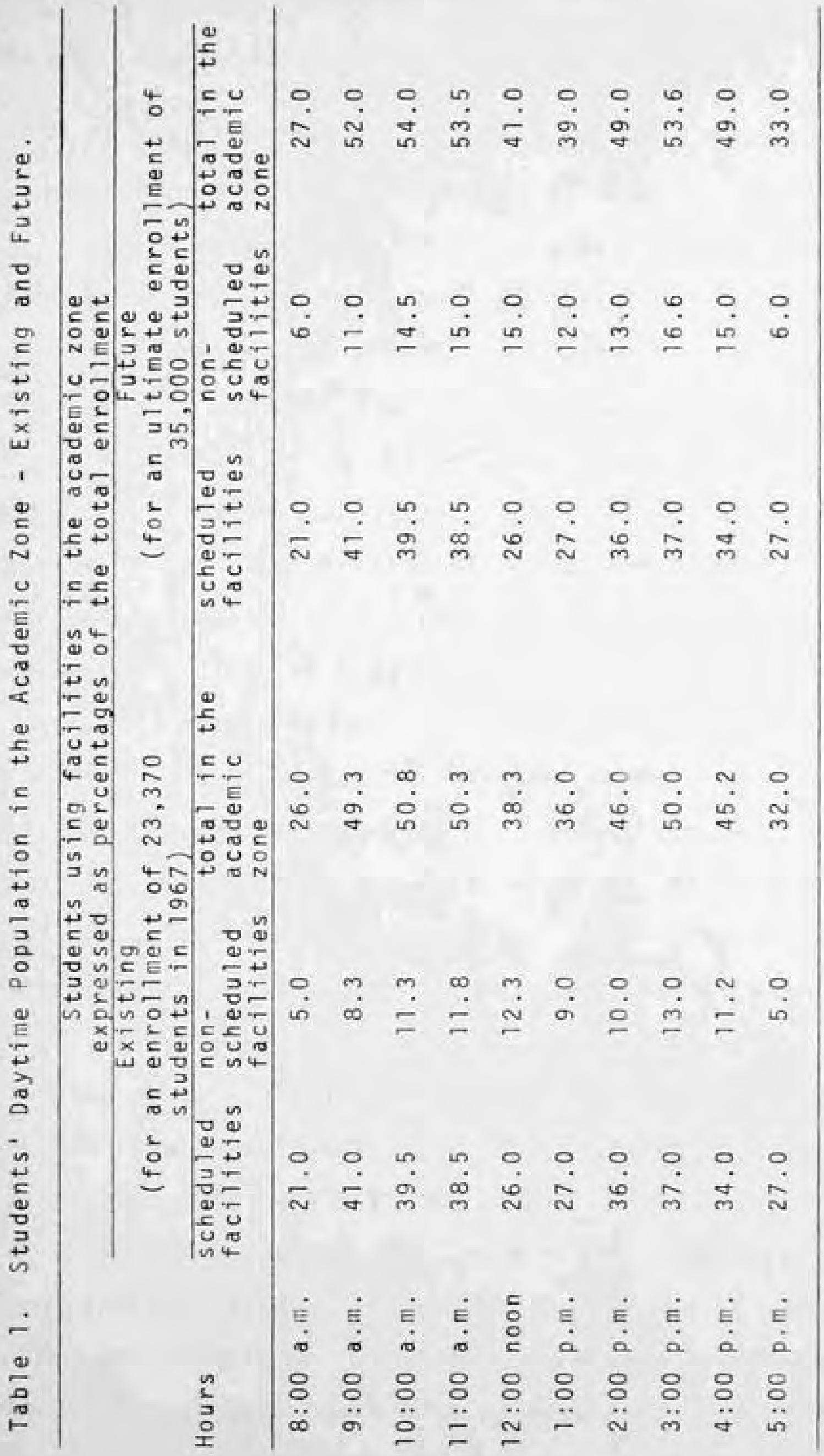


in this chapter.

Student Auto Trips. Student parking demand is generally dependent on the ratio of home based student auto trips (auto trips times occupancy rate) to student trips by all modes to the academic zone. Conceptually, this ratio may be expected to vary in relationship to income, automobile ownership, trip length, availability of parking, and probably climate. Under conditions of relative constant avaflability of parking around the acadenic zone, trip length appears to be the main factor influencing the student's decision to use or not to use his automobile to comnute from home to the acadenic zone. It is conceivable that below a certain minimum trip length, no student auto trips would be made and above a certain maximum trip length, all trips would be rade by the autonobile. Between these mininum and maximum trip lengths, the ratio of student auto trips to student trips by all nodes will vary according to trip length. The relationship between trip length and the percentage of home based student auto trips to the acadenic zone is particularly useful in student parking demand forecasting models. However, to establish such a relationship quantitatively, elaborate origindestination data would be needed.

In this study, and for the purpose of developing a student parking demand forecasting model, a simplified technique based on the observed relationship between trip length and the number of home based student auto trips per student (to 
all destinations including the academic zone) was used. The following is a brief discussion of the procedure applied to establish this relationship. The development of the forecasting model itself is discussed later in this chapter.

Hone based student auto trips were examined in seventeen university residence facilities located at varying distances from the acaderic zone and housing different student subgroups (graduates, undergraduates, single, and married). For each of the exanined facilities, the following data were obtained:

$N$ = the total number of students living in the factitity.

D = fis distance (the actual walking path) from the focal point in the academic zone.

$P_{1}=$ the number of automobiles parked at $6: 00 \mathrm{a} . \mathrm{m}$. In the parking spaces assigned to the facility for obviously used by its residents).*

$P_{2}=$ the number of automobiles parked at 10:00 a.m. in the parking spaces assigned to the facility (or obviously used by its residents).

$P_{3}=$ the number of automobiles parked in the parking spaces assigned to married student apartments (in the facilities to which this iten applies) at $8: 30$ a.m. on a day when the unfversity was in session but classes were not.

* $P_{1}$ was not obtained for facilities housing married students. 
$K$ = average occupancy rate of automobiles leaving the facility.

The choice of 10:00 a.m. to observe the number of automobiles left in the parking lots $\left(P_{2}\right)$ was made on the basis of previous parking studies on the Lafayette campus which indicated that the peak parking in and near the academic zone occurred at this hour $(10: 00 \mathrm{a}, \mathrm{m}).(20)$.

For facilities housing single students, the total number of auto trips made from the facility to all destinations up to 10:00 a.n. $=P_{1}-P_{2}$. The number of student auto trips per resfdent student (to all destinations) up to 10:00 a.m. $=\frac{K\left(P_{1}-P_{2}\right)}{N}$.

For facilities housing married students, the number of student auto trips per resident (to all destinations) up to $10: 00 \mathrm{a} \cdot \mathrm{m} .=\frac{K\left[\left(P_{1}-P_{2}\right)-\left(P_{1}-P_{3}\right)\right]}{N}$ or $=\frac{K\left(P_{3}-P_{2}\right)}{N}$ where $P_{1}-P_{3}$ is the number of auto trips performed by nonstudents (wives or other relatives), most probably work trips.

With this information obtained for each of the examined facilities, a relationship was established between the number of student auto trips per resident student (to all destinations) up to 10:00 a.m. and the trip length from the facility to the focal point in the academic zone.

The seventeen observations were fitted by the "least squares" method. The equation resulting was as follows:

$$
\begin{aligned}
Y=1.045 \times 10^{-8} L^{2}-0.067 \text { for } L \leq 10,105 \\
\text { and } \leq 2,523 \text { feet }
\end{aligned}
$$


where:

$Y=$ the number of student auto trips per resident student to all destinations up to $10: 00 \mathrm{a} . \mathrm{m}$. and,

$L \quad=$ the distance (in feet) between the residence and the focal point in the academic zone (referred to later as trip length).

Figure 8 shows the number of student auto trips per resident student (to al1 destinations) up to 10:00 a.m. in relation to trip length.

In this equation, the high coefficient of multiple deternination $\left(R^{2}=0.93\right)$ confirmed the assumption that the student's decision to use or not to use his automobile to the acadentic zone is greatly influenced by the distance at which he lives from the academic zone. As such, the observed relationship is not expected to change significantly in the future. It was thus used as a basis for developing a student parking demand forecasting model. This was done on the assumption that the relative parking avallability in and near the acadenic zone will renain virtually the same as now for the future.

\section{Residential Distribution of Students. Two character-} istics related to the residential distribution of students were analyzed.

1. The proportions of students using different kinds of residential facilities (university housing, fraternity and scrority houses, cooperatives, and community housing). 


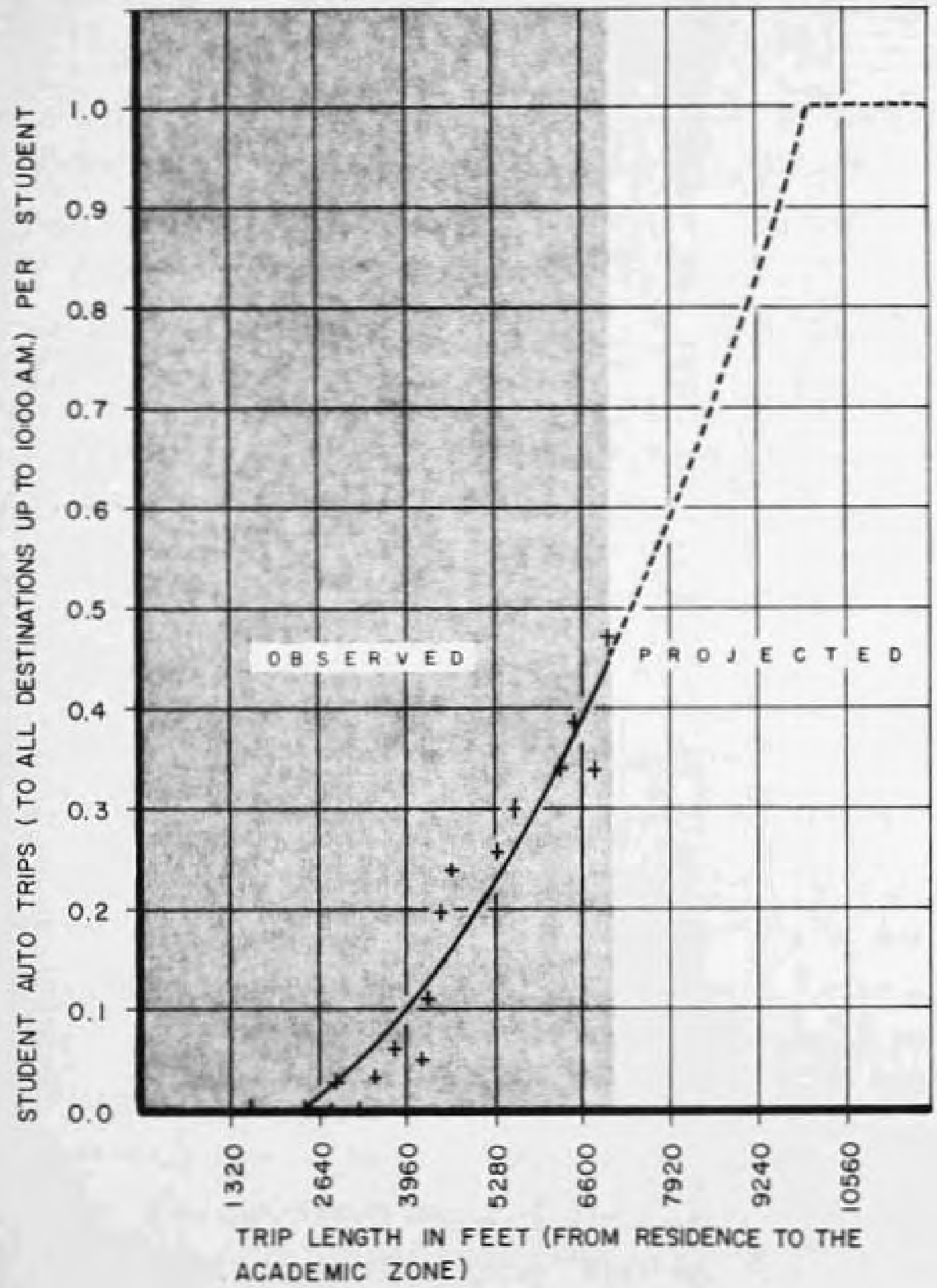

FIGURE 8 - STUDENT AUTO TRIPS PER STUDENT BY TRIP LENGTH 
2. The proportions of students living at different distances from the academic zone.

The population of students was classified into six subgroups: graduate single men, graduate single women, graduate married students, undergraduate single men, undergraduate single women, and undergraduate married students. This classification permits testing the hypotheses that sex, educational level, and marital status influence the student residential distribution. It is also useful in forecasting future changes in such residential distribution since the prospective numbers of students in each of these subgroups can easily be forecasted.

Students: Choice of Residential Facilifties. In analyzing the percentages of students using different kinds of residential facilities, data on the entire population of students for $1967 / 68$ were used. Figure 9 shows the existing university residential facilities, fraternities, sororities, and cooperative houses. Data on the number of students residing in these facilities and on the total enrollment by student subgroups were obtained $(21,11)$. The percentage of students belonging to each subgroup and residing in each kind of facility was established. Table 2 summarizes the findings and Figure 10 fllustrates them. Both educational level and narital status show strong correlations with the choice of the kind of housing facility. On the basis of these observed percentages, the future percentages of students expected to 
PUADUE UNIVERSITY

LAFAYETTE CAMPUS +*

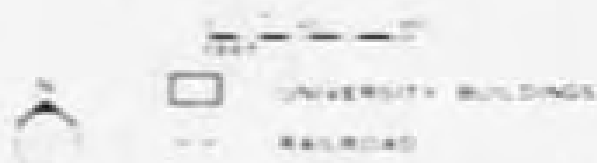

$\square$ ACADENIC zone

W UNIVERSITY HOUSING

E FRATERNITIES A SORORITIES

[III) COOPERATIVE hOUSES

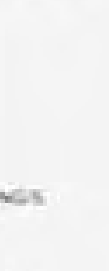

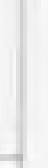
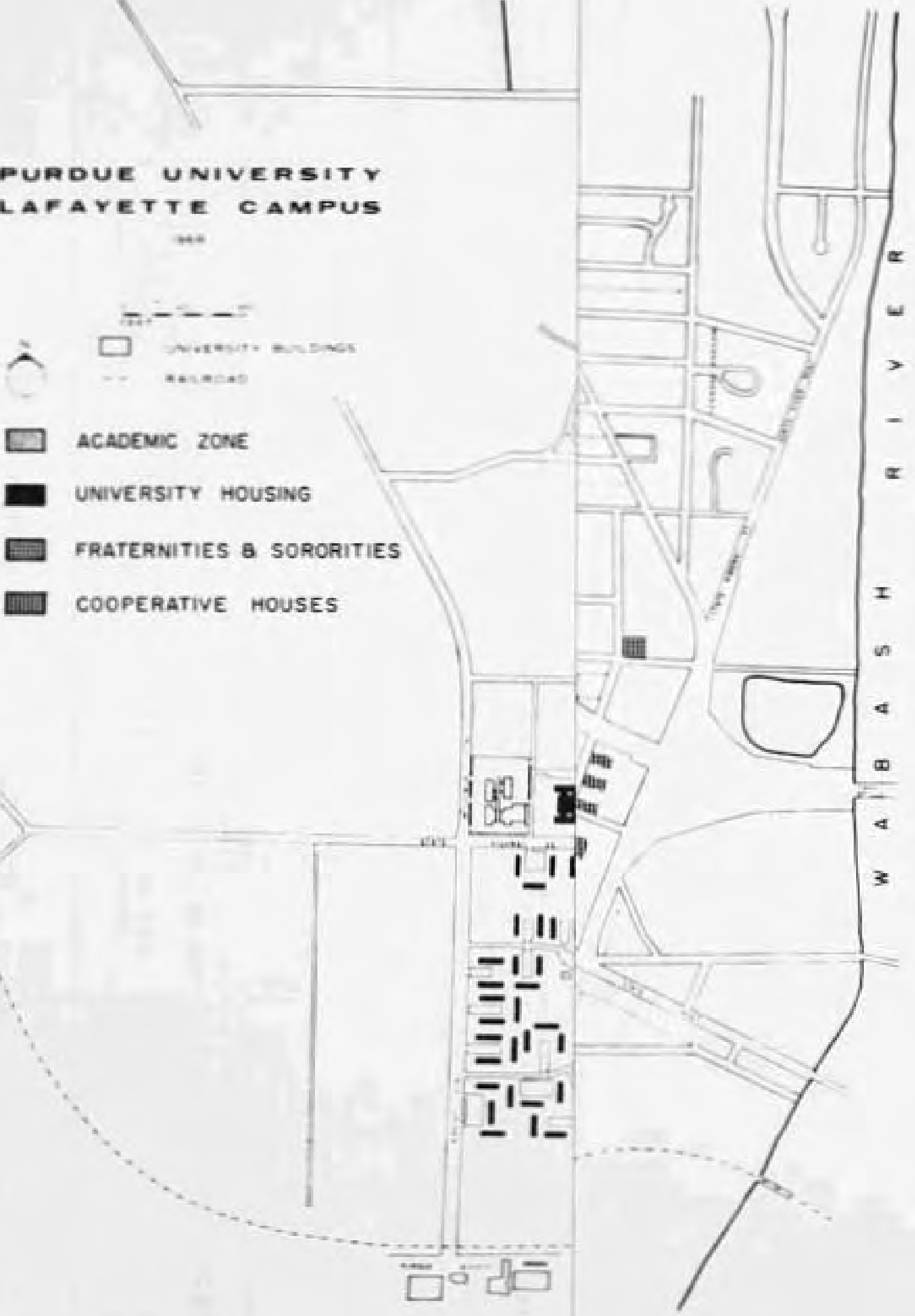

FIGURE 9 - EXISTING STUDENT NG) 


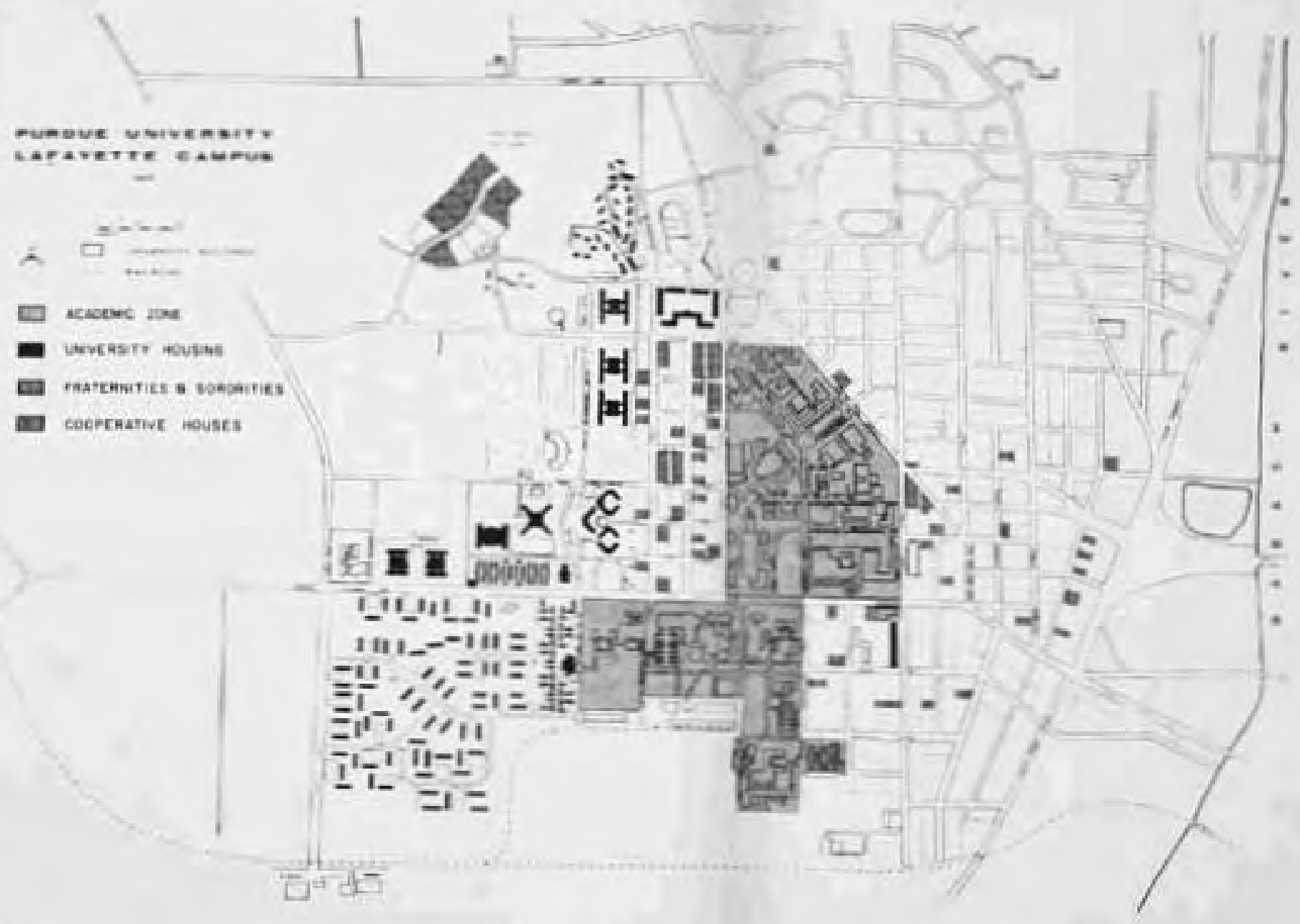

FIGURE 9 - EXISTING STUDENT HOUSING FACILITIES (OTHER THAN COMMUNITY HOUSNG) 


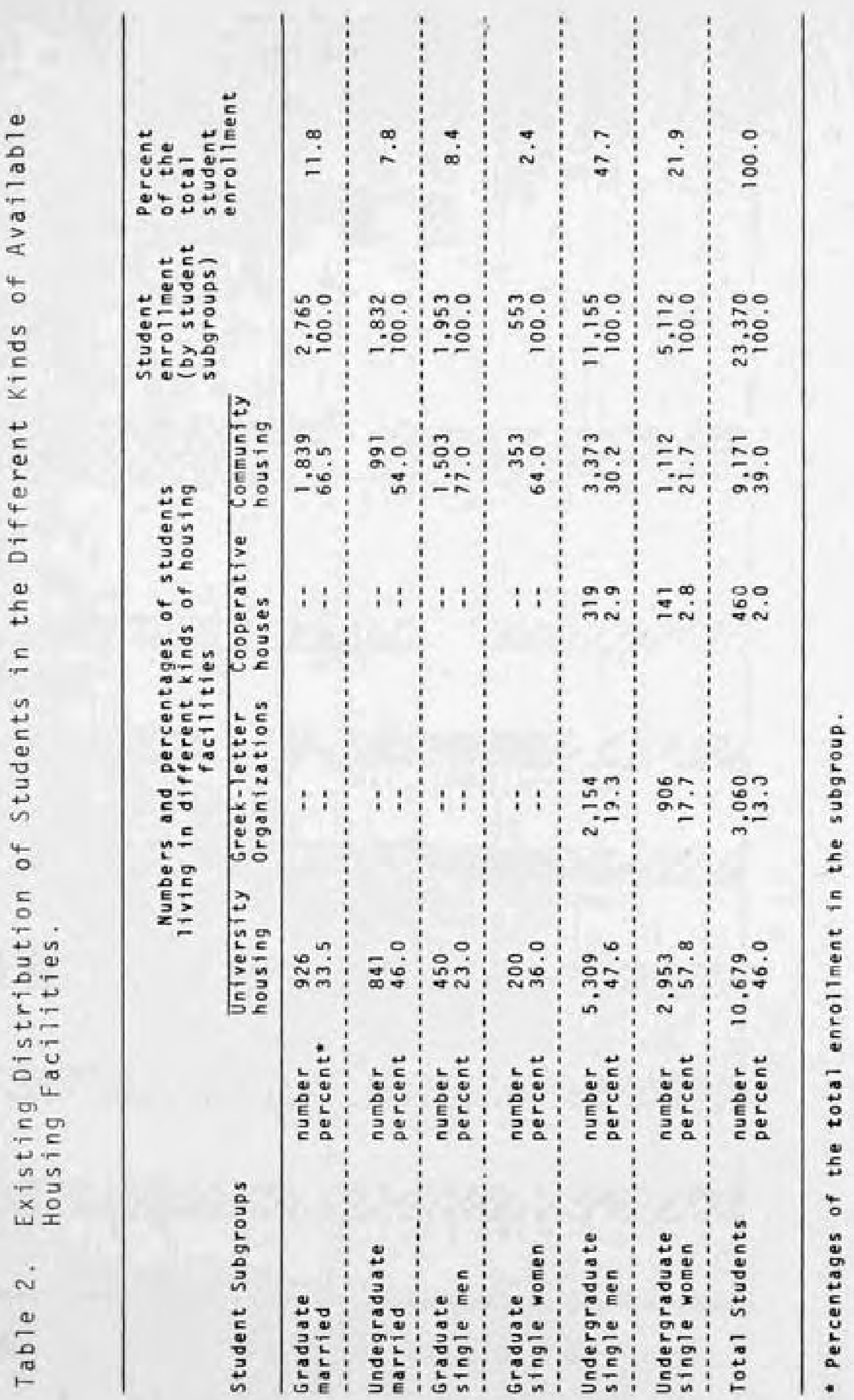




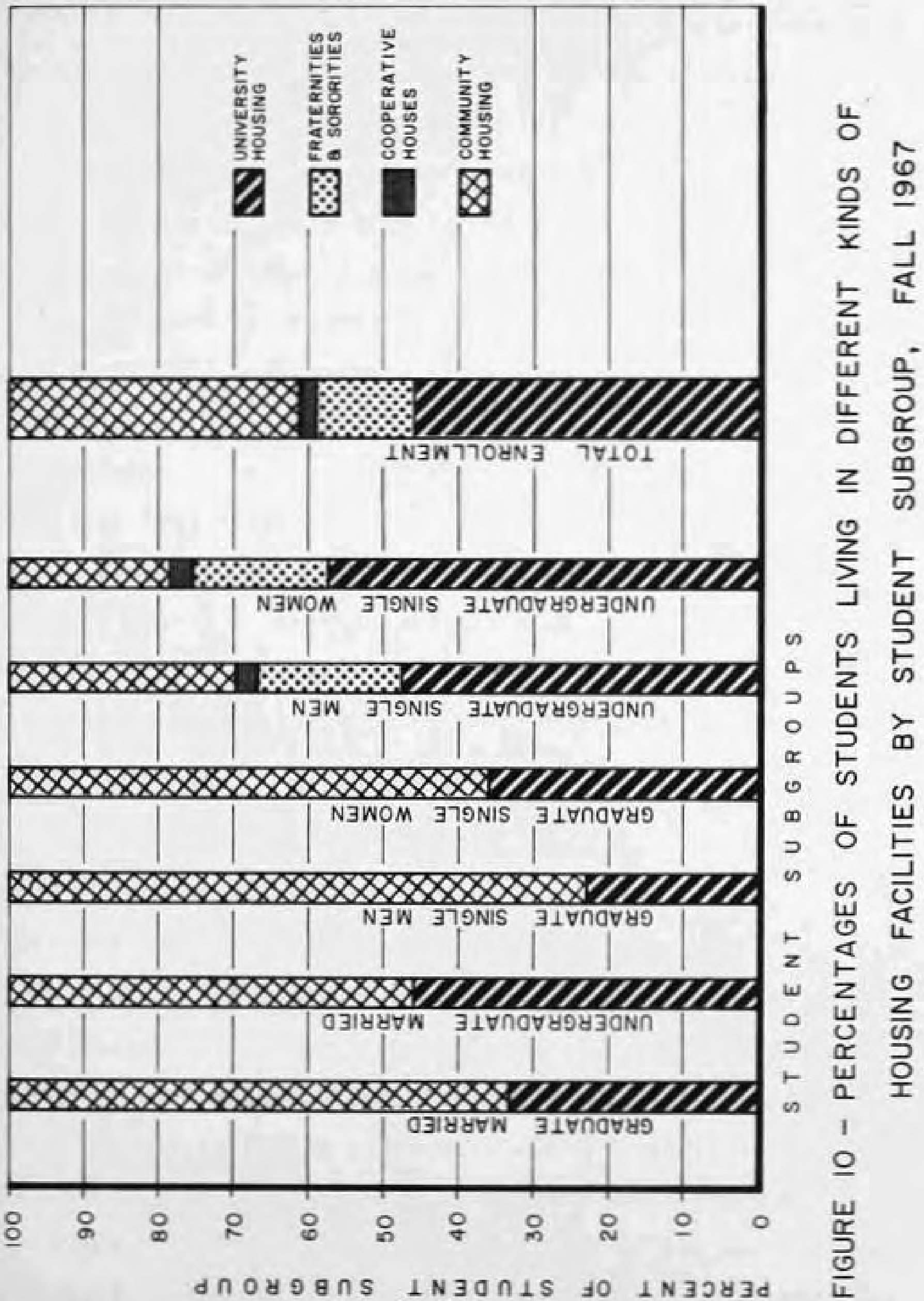


live in different kinds of residential facilities were estimated. Both university housing polfcy and the students potential demand on university housing were considered. The results of the faculty questionnaire indicated an envisaged increase in the proportions of students housed in university housing facilities (14). During the period 1963-1967 students' denand on university housing facilities tended to increase (22). These facilities appear to offer economic advantages (in rents, maintenance, and proxinity to the academic zone) that are difficult to match in community owned housing facilities.

Based on the opinions of faculty members and on the observed trends of student demand on university housing facilities, it was estimated that about 55 percent of the undergraduate single students, 40 percent of the graduate single students, and 40 percent of the married students will be accommodated in university housing facilities in the future.

The Spatial Distribution of Student Residences. As noted previously, the number of student auto trips is highly correlated with the distances at which students live from the academic zone. As such, the spatial distribution of student residences becomes meaningful from the standpoint of campus transportation planning. The following is an analys is of the spatial distribution of the student residences around the acadenic zone. The primary purpose of the analysis is to examine the existing and estimate the future proportions 
of students living at different distances from the academic zone.

Because the composition of the population of students is expected to change in the future, the analysis of the spatial distribution of the student residences should test whether or not future changes in the student population composition would cause changes in the proportions of students living at different distances from the academic zone. In other words, the analysis should test, for each student subgroup (graduates, undergraduates, single, married...etc.), whether or not the proportions of students living at different distances from the academic zone are significantly different from those of other subgroups. Subgroups that show significant differences should, then, be analyzed separately while others can be lumped together. This analysis was performed in two steps:

1. A number of relevant student population subgroups were first tested, in pairs, for significance of differences in the mean distances at which students live from the academic zone and in the variances of these distances from the means. Statistically, subgroups, which have significantly different means and variances should also have significantly different proportions of students living at different distances from the academic zone. Moreover, testing for means and variances is much nore reliable 
and requires relatively smaller sample sizes. By this step, therefore, significantly different subgroups were identified.

2. For each of the identified subgroups, the existing percentages of students living at different distances from the academic zone were statistically estimated and the future percentages then forecasted.

To identify student population subgroups living at significantly different distances from the academic zone (in terms of means and variances) a pilot study on a small sample of students was first undertaken. The preliminary results of this pilot study suggested further testing of five student subgroups: graduate single, graduate married, undergraduate single men, undergraduate single women, and undergraduate married students. The sizes of statistically representative samples of students of these five subgroups were also determined on the basis of this pilot study. From university records, the data obtained gave the student's status (male, or female, single or married, graduate or undergraduate) and his $10 \mathrm{cal}$ address (23). Student addresses were grouped in distance classes (concentric rings around the focal point) with an interval of 0.25 miles. Residences located at distances over four miles from the focal point were not included to avoid distortion of results.

For each of the five subgroups, the means and variances (of the distances of residences from the focal point) were 
obtained and tested, in pairs, for significance of difference. Both the mean and variance of the distance at which single students live (both graduate and undergraduates) were found to be significantly different (on the $0.05 \propto$ clevel) from those for married students (both graduates and undergraduates). No other significant differences were found. Accordingly, for each of these two subgroups, the existing proportions of students living at different distances from the academic zone were statistically estimated. The student addresses were grouped in distance classes with an interval of 0.50 miles (actual walking distance zones). Figure 11 shows the boundaries of these zones. The range of distances covered in the analysis and the class interval used were set on the basis of the observed numbers of student auto trips discussed earlier.

The size of a statistically representative sample of students was set according to maximum allowable estimation errors of \pm 2 percent for single students and \pm 3 percent for married students. By plotting the student addresses (in Spring 1967) on a map, the numbers (and thus the percentages) of residences falling in each distance zone were obtained. The results were tabulated by student subgroup, by distance zone, and by kind of residence facility. Table 3 shows the existing percentates of students living in different kinds of housing facilities at different distances from the academic zone for single students and married students. Figure 12 shows the existing cumulative "less than" 
Lafayette and West Lafayette

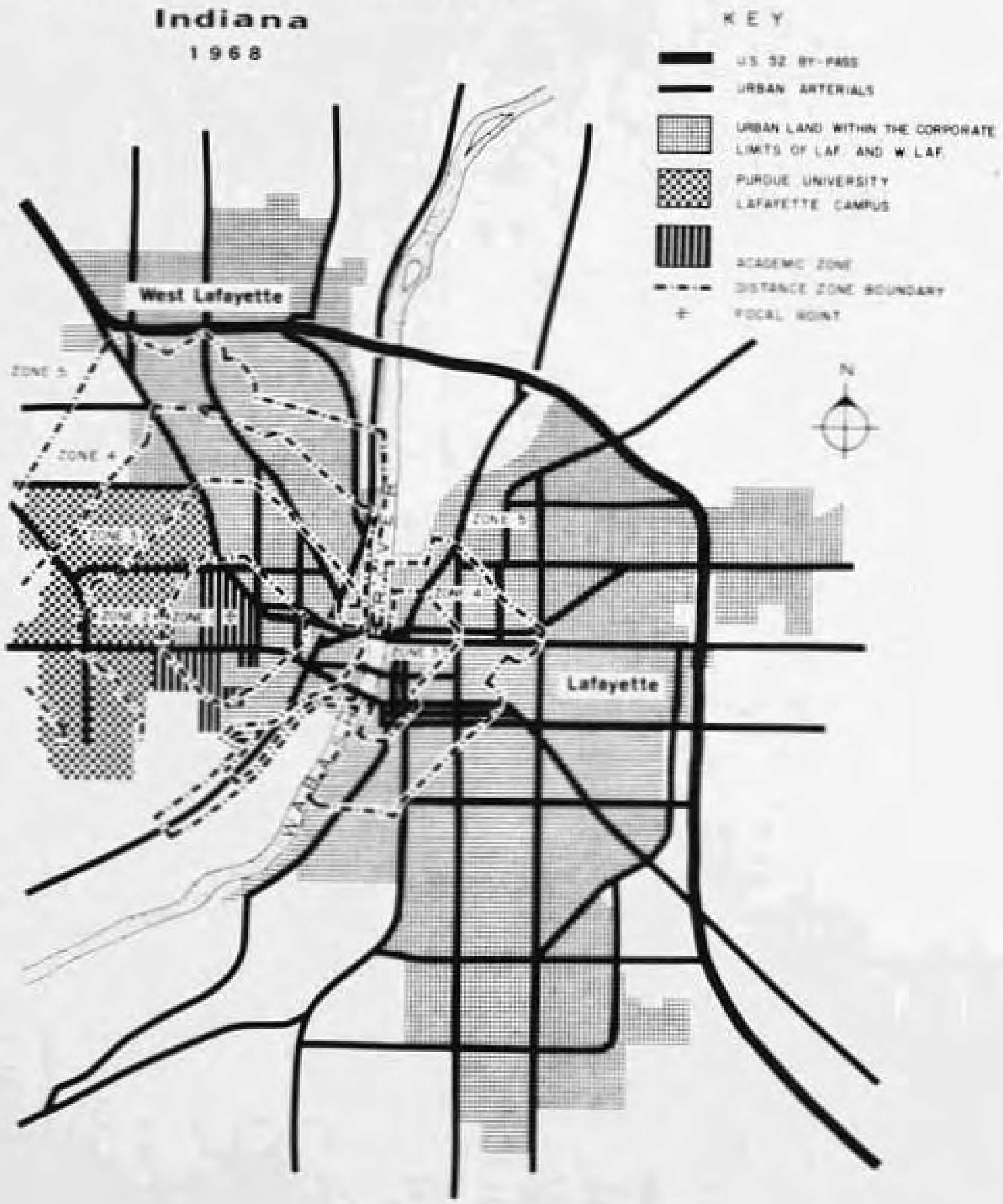

FIGURE II - RESIDENTIAL DISTRIBUTION OF STUDENTS DISTANCE ZONES 


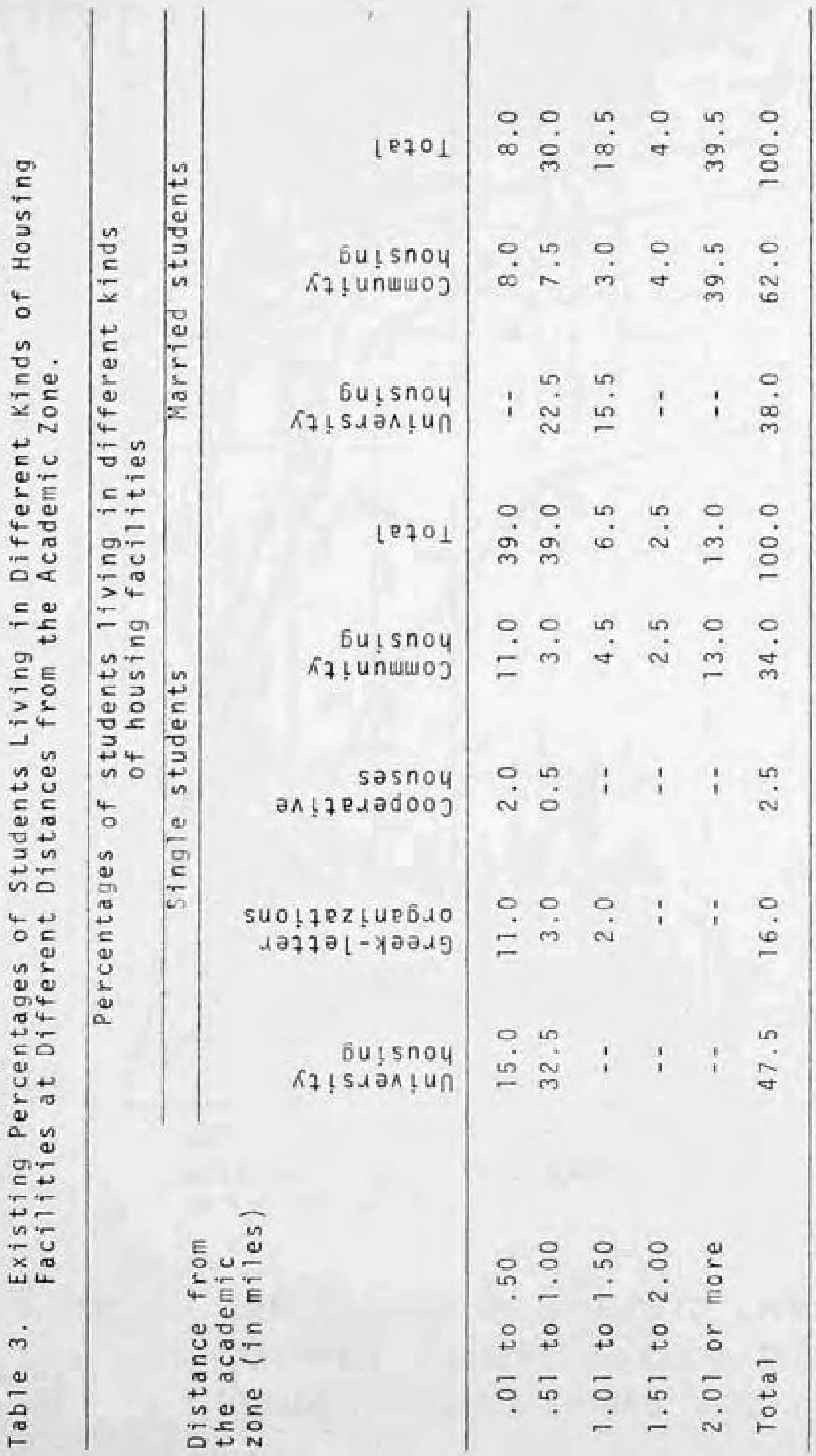




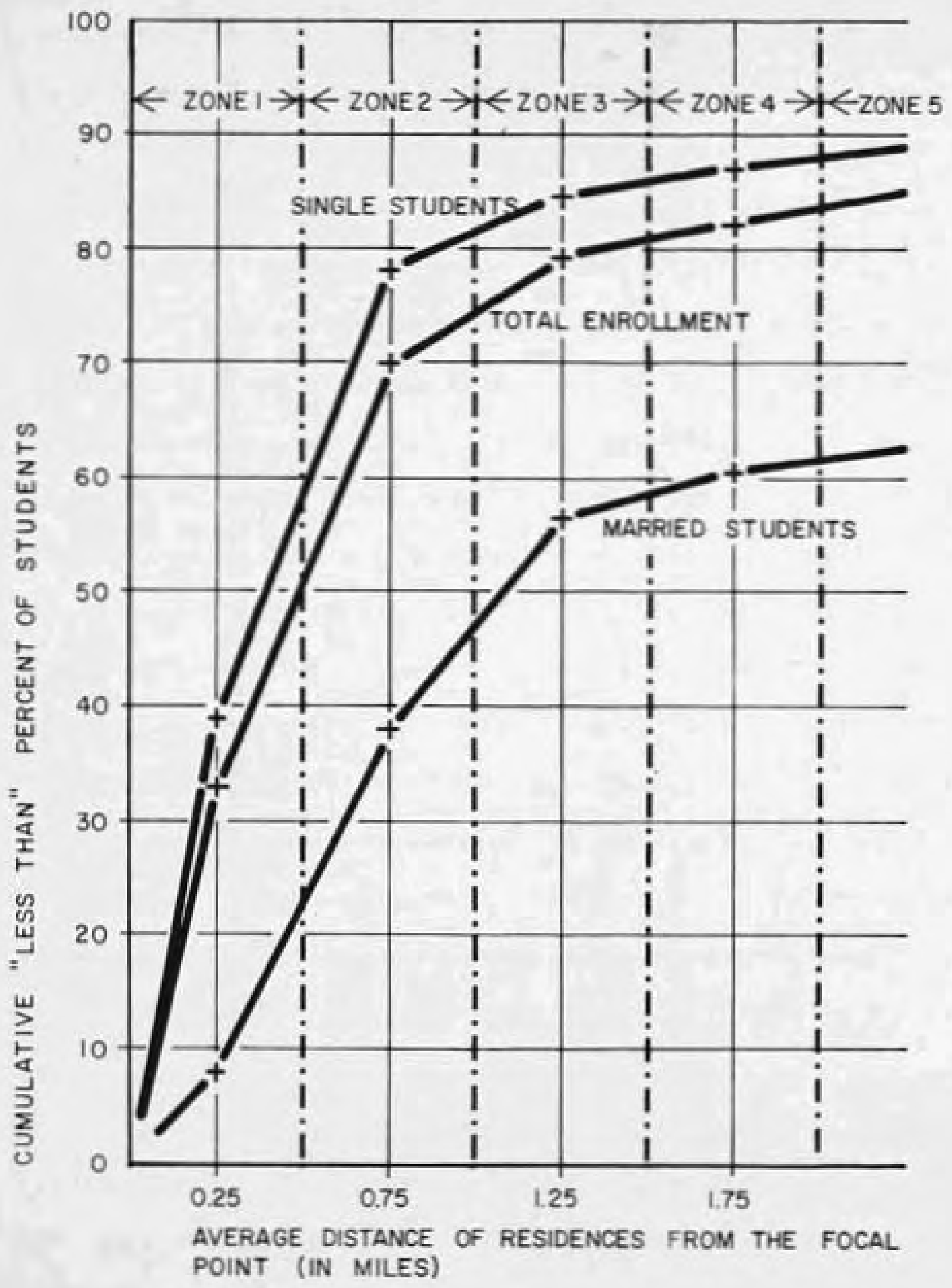

FIGURE I2 - PERCENTAGES OF STUDENTS LIVING AT DIFFERENT DISTANCES FROM THE ACADEMIC ZONE, SPRING 1967 
proportions of students living at different distances from the academic zone for single students, married students, and a11 students.

About 13 percent of the single students and about 39.5 percent of the married students 1 ive at distances over two miles. As expected, the percentage of single students 1iving distant from the academic zone is much less than that of the married students. Single students neither have the need for suburban spacious living nor are willing to sacrifice the proxinfty to the intense social interactions on and around the acadenic zone. High concentrations of both single and married students occur within one mile from the academic zone. This is obviously due to the fact that all university housing facflities are located within this range of distance. About 46 percent of the students 1 ifving in this range live in university facilities. The remaining proportion indicates an undebatable trend of students to live close to the acadenic zone even if they 1 ive in nonuniversity facilities.

These findings and observations provide the bas is for estinating the future distribution of student residences. This was estimated on the basis of three main residential aspects:

1. The estimates of future numbers of students living in different kinds of housing facilities. 
2. The expected future locations of the different kinds of housing facilities.

3. The existing proportions of students living at different distances from the academic zone.

The first and third aspects have already been discussed. The following is a discussion of the second aspect; the expected locations of the different kinds of housing factilities.

Future Greek-letter organizations and cooperative houses are expected to be provided at approximately their present distances from the academic zone. Additional community housing facilities are apt to be provided at distances between 1.5 and 2.5 miles. Little room for expansion at closer distances is available for these facilities. The future locations of university housing facilities are subject to different probable policies. A number of possible alternative layouts of future university housing facilities (based on the existing standards of land coverage and building heights) were developed and examined to determine which would provide maximum future advantages. The layout in which the future housing facilities were most closely located in relation to the academic zone and which still provided flexibility in future land uses was chosen. Figure 13 shows the as sumed locations of future university housing facilities. Accordingly, the future proportions of students living at different distances from the academic zone were estimated. 
PURDUE UNIVERSITY LAFAYETTE CAMPUS

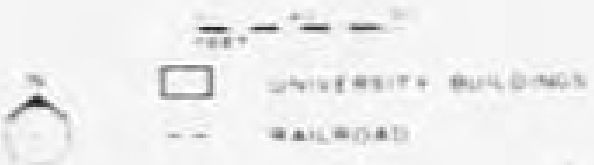

ACADEMIC ZONE

GRADUATE HOUSES

67 undergraduate resioence halls

W MARRIED STUDENT APARTMENTS

LOCATIONS OF FUTURE HOUSING FACILITIES

\begin{tabular}{|c|c|c|c|}
\hline \multirow{2}{*}{ 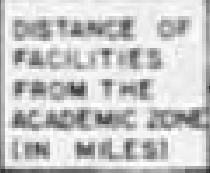 } & \multicolumn{3}{|c|}{ 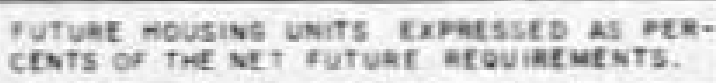 } \\
\hline & $\begin{array}{l}\text { Foh onapuare } \\
\text { singlif stubents }\end{array}$ & $\begin{array}{l}\text { Fon vacengabustr } \\
\text { sintie stuolnts }\end{array}$ & $\begin{array}{l}\text { ron waknico } \\
\text { stubents }\end{array}$ \\
\hline 001 to 0.50 & 100 & 10 & - \\
\hline 0.51 to 1.00 & - & 90 & 20 \\
\hline 1.01 to 1.50 & - & - & 50 \\
\hline 1.51 to 2.00 & - & - & 30 \\
\hline TOTAL & 100 & 100 & 100 \\
\hline
\end{tabular}

एवं हु
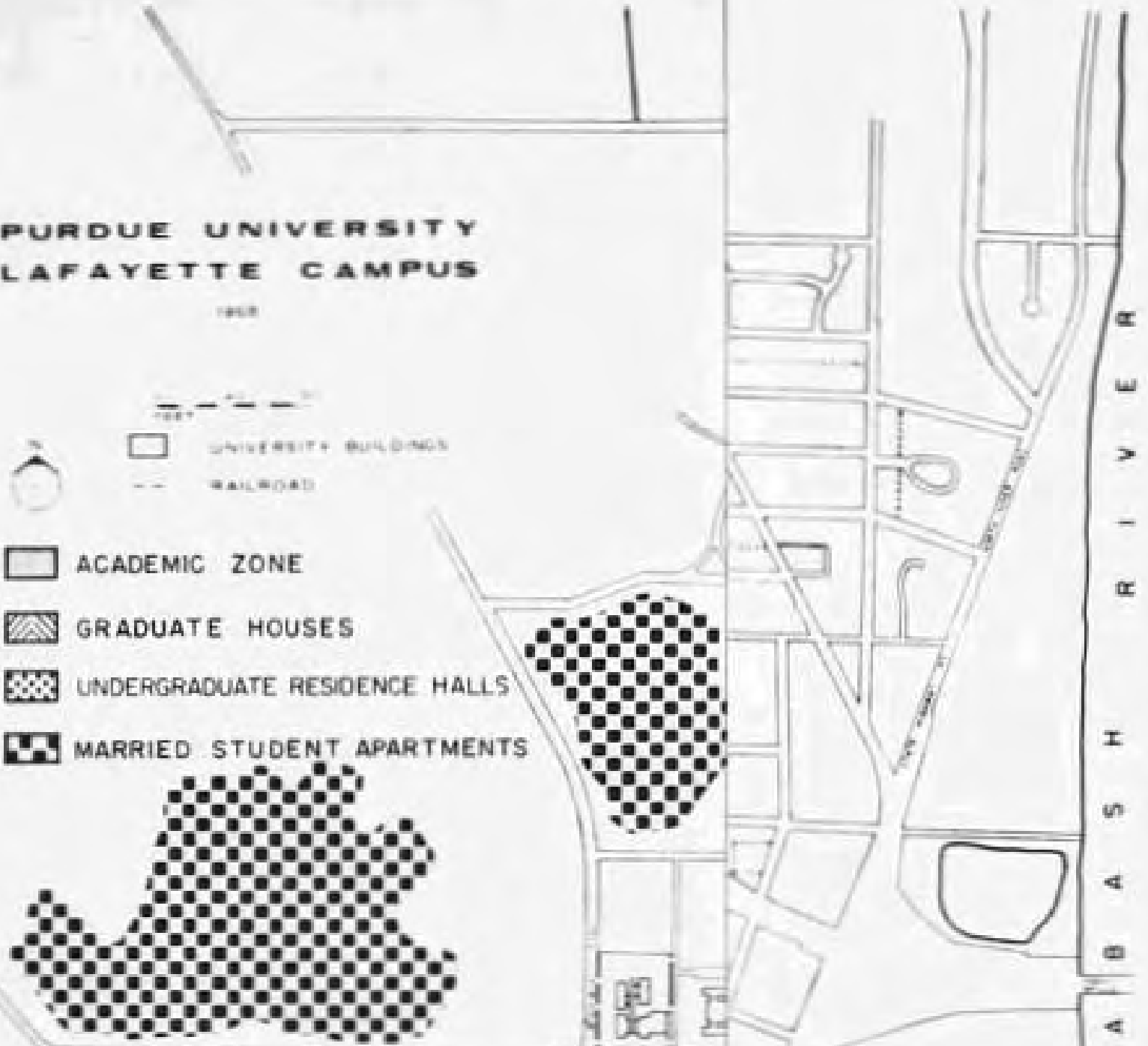

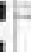
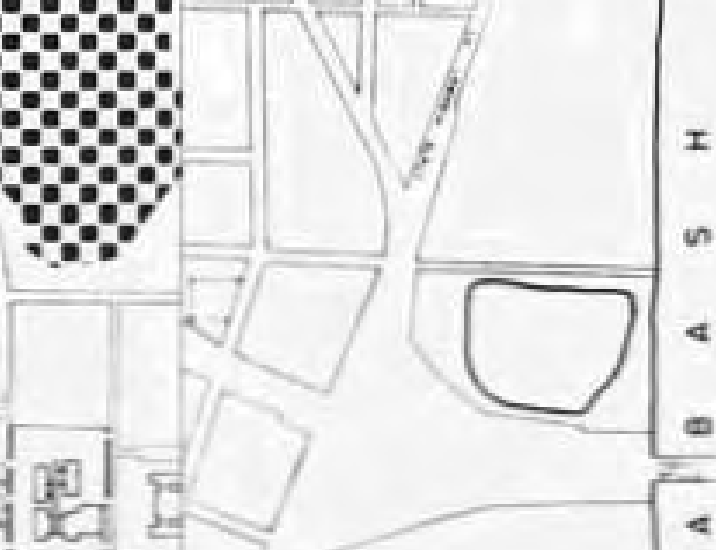

40.

$1=1$
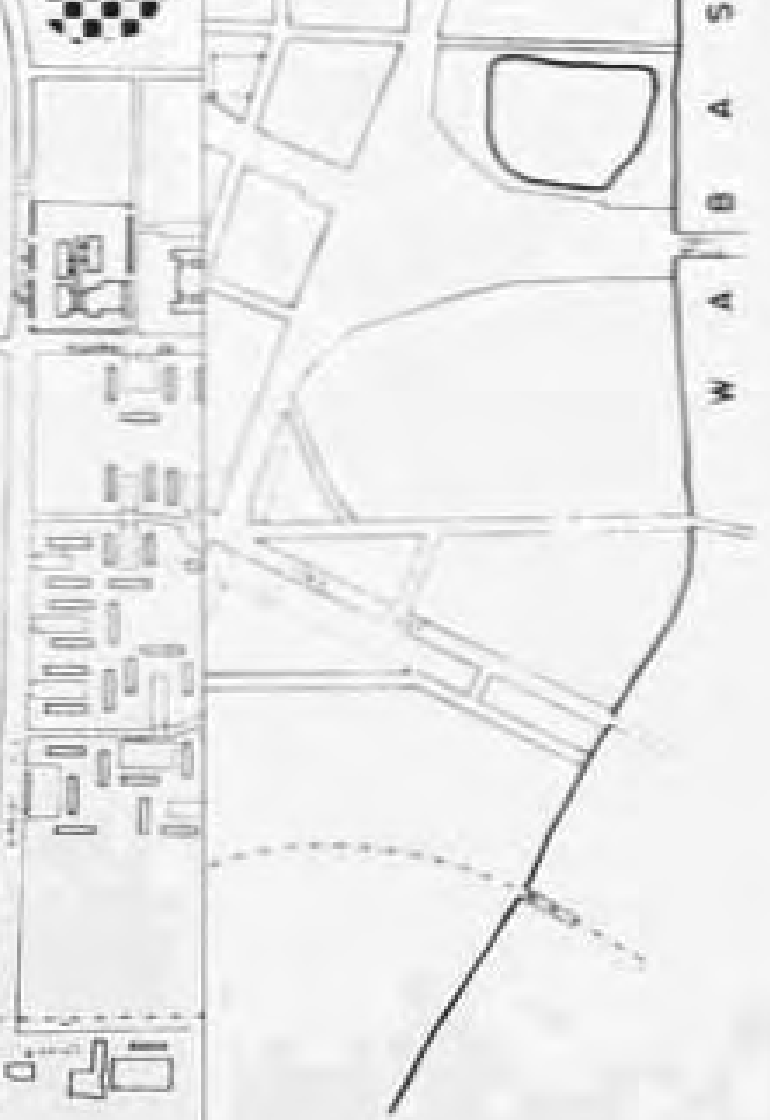

FIGURE 13 - PROBABLE LOCATIONS OI 


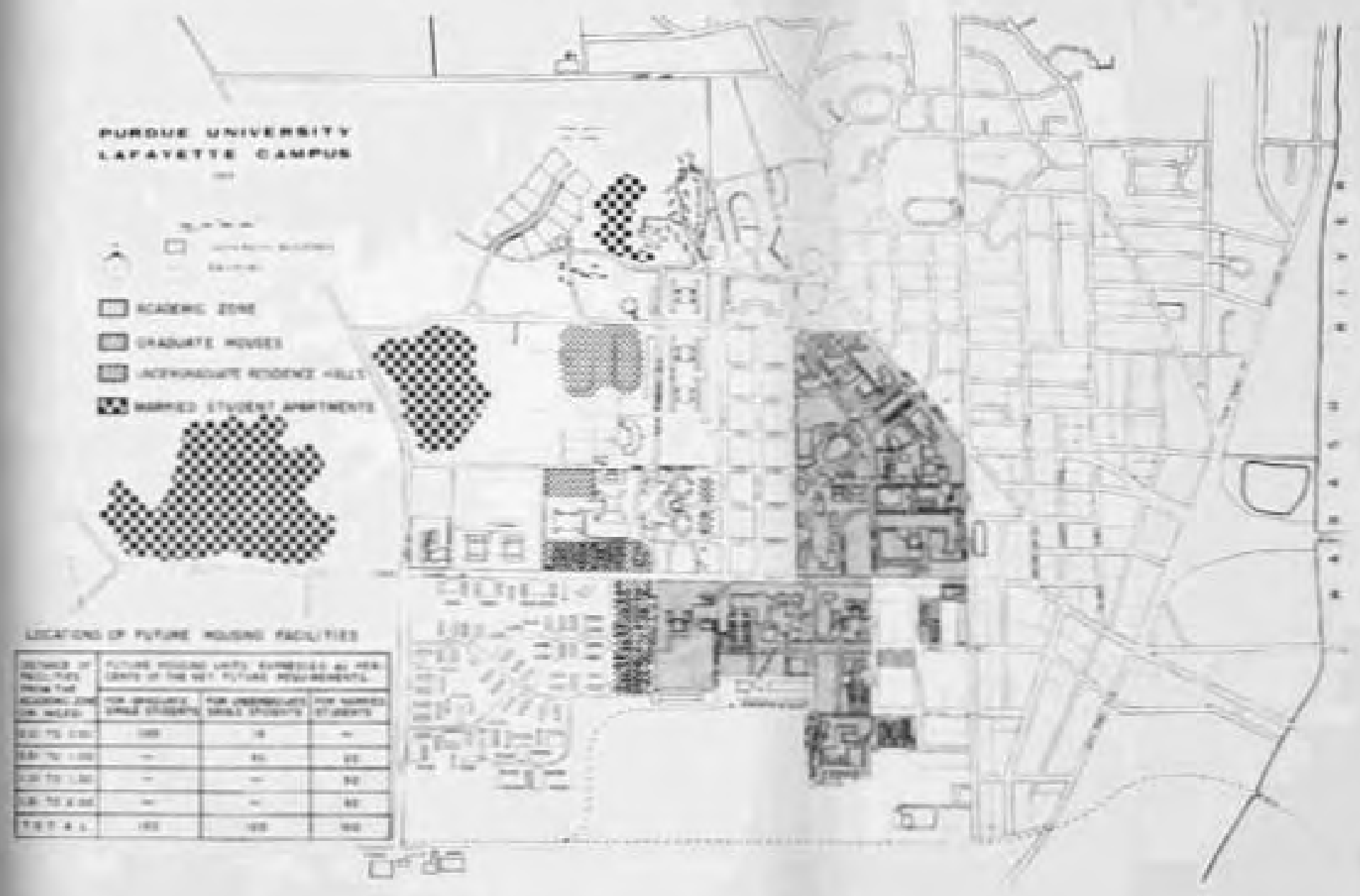

FIGURE I3 - PROBABLE LOCATIONS OF FUTURE UNIVERSITY HOUSING FACILITIES 
Table 4 shows the estimated future percentages of students living in different kinds of housing facilities at different distances from the academic zone.

\section{Future Commuting Demands}

Four campus population characteristics influencing present and future trip productions and trip modes to and from the academic zone have been discussed. In this section, the future demand for commuting to and from the academic zone will be estimated. The magnitude of this demand depends on the size and composition of the campus population and the daytime population in the academic zone. The choice of transportation modes in commuting depends on the patterns of student auto trip productions, on the residential distribution of students, and on the available alternative modes of transportation. Three alternative modes of commuting will be examined: (1) by automobile from residence to parking facilities around the academic zone, (2) by buses either from residence or from remote parking facilities to the academic zone, and (3) on foot.

The importance of considering traffic volumes on the street network surrounding the academic zone and caused by commuting is recognized. In this study, however, the discussion of this aspect is 1 imited to a subjective evaluation of the effects on traffic volumes on the network of some alternative locations, types, and capacities of future university parking facilities in and around the academic zone. To 


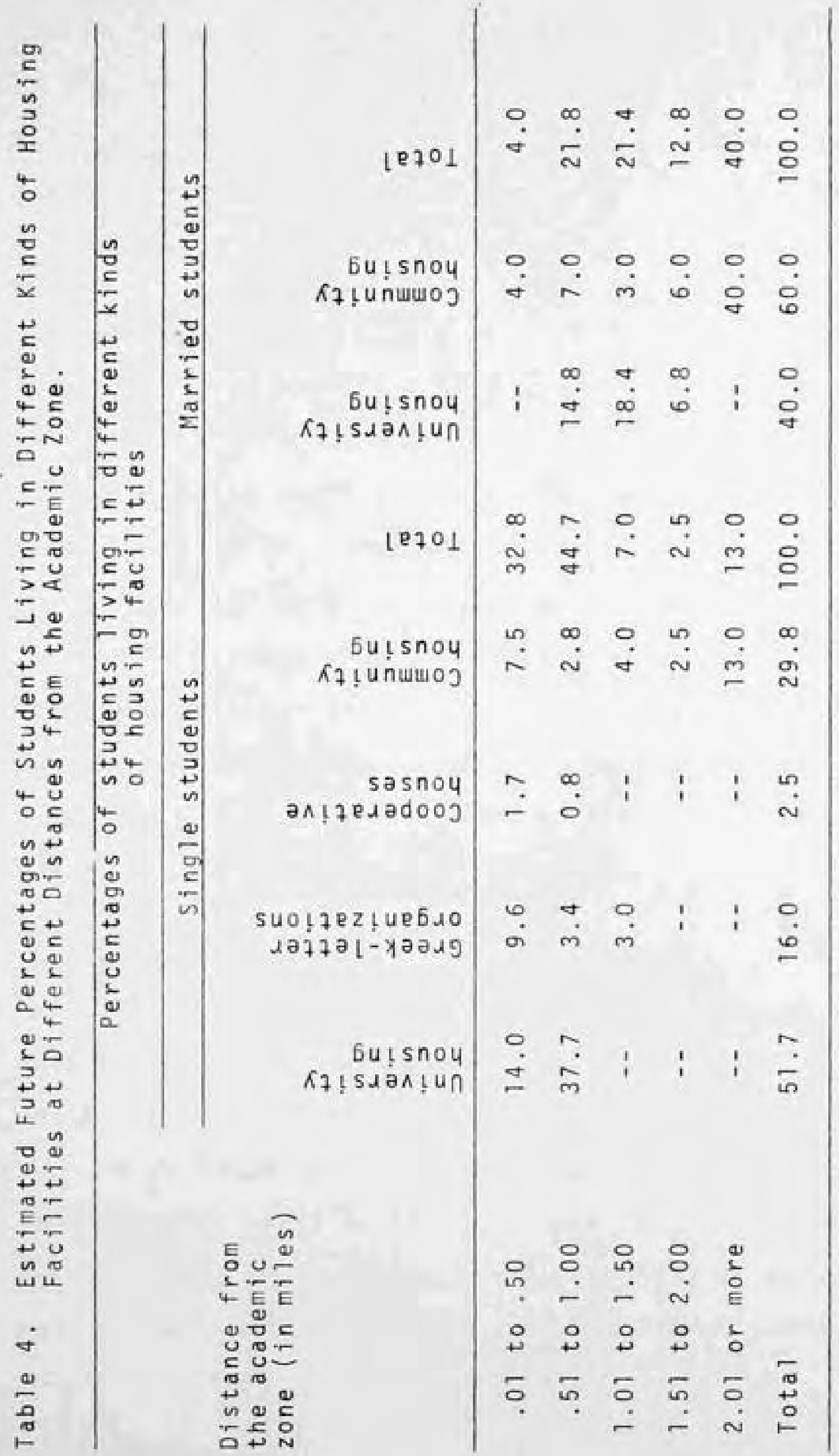


obtain reliable estimates of future average traffic volumes on the street network surrounding the academic zone would require a multiplicity of other input data lother than future locations, types, and capacities of university parking facilities) that are beyond the scope of this study.

Future Parking Demands. In 1968, a total number of about 5630 off-street parking spaces (in and around the academic zone) were provided and operated by the university. The majority of these spaces are provided for full-time staff members. A relatively limited number of spaces are assigned to commuter students and visitors. Besides, on-street free parking is available around the academic zone. For the future, the relative availability of parking was assumed to remain virtually unchanged. The future parking demands were estimated accordingly. Demands by students, staff, and visitors were estimated separately.

Students. The relationship between trip length (from residence to the academic zone) and the number of student auto trips per resident student (to all destinations) up to 10:00 a.m. was established earlier. Based on this relationship, a students' parking demand forecasting model was developed. The total number of student automobiles actually parked around the academic zone at 10:00 a.m. on an average week day was assumed representative of the student parking 
demand.*

Let:

$i=$ zones of different ranges of trip lengths where $i=1,2, \ldots, 5$ (see Figure 11).

$A_{i}=$ total number of student auto trips from zone $i$ to all destinations up to 10:00 a.m.

$z_{i}=$ total number of student auto trips from zone $i$ to the academic zone up to $10: 00 \mathrm{a} \cdot \mathrm{m}$.

$M_{i}=$ total number of student trips by all modes from zone $i$ to the academic zone up to $10: 00 \mathrm{a} \cdot \mathrm{m}$.

$L_{i}=$ average trip length from residences in zone $i$ to the focal point in the academic zone (in feet).

$N_{i}=$ total number of students living in zone $i$.

$K_{i}=$ average auto occupancy rate for trips from residences in zone $i$ to the academic zone. **

$C=$ percent of students living in zone $i$ and expected to be present in the academic zone up to 10:00 a.m. " $C$ " is assumed constant for all values of $i$ since the master schedule of the university on the basis of which student class schedules are determined

* The area referred to as "around the academic zone" is that used in a study on future traffic facilities for the Lafayette campus and includes three rows of blocks around the academic zone (20).

** For married students, average auto occupancy was estimated to be 1.1 students per auto for all zones. For single students, average auto occupancy was estimated to be 2.5 for zone 2 and was accordingly assumed to be $2.2,1.8$, and 1.3 students per auto for zones 3,4 and 5 respectively. 
(and hence the hours at which they should be present in the academic zone) is not "biased" by marital status (and thus not "biased" by distance of residence).

$T_{1}=$ number of student auto trips to the acadenic zone per student trip by all modes to the acadenic zone up to 10:00 a.m.

therefore

$$
T_{i}=\frac{z_{i}}{M_{i}}
$$

In terms of $A_{i}$ and $N_{i}$, this can be expressed as follows:

$$
T_{i}=\frac{A_{i}}{N_{i}} \times \frac{\frac{Z_{i}}{A_{i}}}{\frac{M_{i}}{N_{i}}}
$$

but $\frac{A_{1}}{N_{i}}=Y_{1}=$ number of sutdent auto trips per resident student (in zone i) to all destinations up to $10: 00$ a.m.

therefore

$$
T_{i}=Y_{i} \cdot q_{i}
$$

where

$$
q_{i}=\frac{\frac{z_{i}}{A_{i}}}{\frac{n_{i}}{N_{i}}}=\frac{\frac{z_{i}}{M_{i}}}{\frac{A_{i}}{N_{i}}}
$$

It can be shown mathenatically that if $Z_{i}$ is equal to $A_{i}, q$ is independent of $i$. In this case, it can be safely 
assumed that $Z_{i}=A_{i}$ since the great majority of student auto trips up to 10:00 a.m. are expected to end around the acadenic zone. Therefore, $q$ is assumed constant for all values of $i$.

If $P_{S}$ is the total number of student automobiles parked around the academic zone at 10:00 a.m. on an average weekday, then

$$
P_{s}=\sum_{i=1}^{5} c \cdot N_{i} \cdot \frac{T_{i}}{R_{i}}=\sum_{i=1}^{5} c \cdot N_{i} \cdot \frac{\gamma_{i} \times q}{K_{i}}
$$

or

$$
P_{S}=C \cdot q \cdot \sum_{i=1}^{5} \frac{N_{i} Y_{i}}{K_{i}}
$$

but $Y_{i}$ has previously been shown to have the following value:

$$
Y_{i}=1.045 \times 10^{-8} L^{2}-0.067 \text { for } L \leq 10,105 \text { and } \leq 2,523 \text { feet }
$$

In this modeT, the future values of the independent variables $\left(C, N_{i}, Y_{i}\right)$ were estimated earlier in the discussion of the population characteristics influencing commuting. " $C$ " was estimated from the analysis of the student daytime population in the acadenic zone, $N_{i}$ was estimated from the analy5 is of the student residential distribution, and $Y_{i}$ was established by direct observation. Values of $k_{i}$ for zone 2 (for single and married students) were estimated by direct observation while those for zones 3 through 5 were subjectively assumed accordingly. 
To establish the value of the constant $q$ in this model, the result of an actual count of student automobiles parked around the academic zone at 10:00 a.m. in the Spring of 1968 (1650 automobiles) was used for calibration (20). The value of $q$ was found to be equal to 0.7 . The accuracy of the model was then tested by comparing the total number of student automobiles parked around the academic zone at 10:00 a.m. in the Spring of 1962 as obtained by an actual count and as replicated by the model. The actual count in 1962 was 1150 automobiles while the total as replicated by the model was 1077 automobiles. The error is acceptable for the purpose of this study.

Accordingly, for the ultimate enrollment, the future student peak parking demand (at 10:00 a.m.) is estimated to be about 3,316 parking spaces. This estimate was increased to 3,685 parking spaces since on ly 90 percent of available parking spaces can be used efficiently during periods of peak parking demand. Of these, about 600 parking spaces are expected to be required by students living in university housing facilities (married student residents, McCutcheon Hal1, etc.).

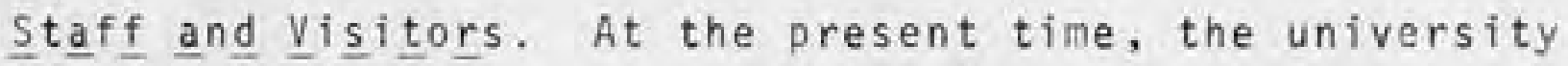
operates sufficient parking for all full-time staff members. It was assumed that this policy will remain unchanged in the future. To estimate future staff parking demand, a relationship was established, on the basis of data obtained 
from university records for the years 1963 through 1967, between the number of staff parking spaces provided by the university in the academic zone and the total number of fulltime staff members working there (20). Knowing that the number of staff parking spaces provided in these past years by the university in the academic zone proved adequate, the established relationship was thus used to estimate the future staff parking demand.

In establishing this relationship, the ratio of the number of full-time staff members working in the academic zone to the total number of full-time staff members (on the whole campus) was determined for 1962 and assumed constant in the future.* Figure 14 shows the observed and projected relationship between the number of staff parking spaces provided by the university in the academic zone and the number of full-time staff members working there. In this figure, the observations obtained for the five past years (1963 through 1967) were fitted by using the "least squares" method. The resulting straight line relationship was:

$$
P_{F}=1.17 F_{a}-2958.7 \quad\left(R^{2}=0.96\right)
$$

where $P_{F}=$ number of staff parking spaces provided in the academic zone (including an allowance of 10 percent for peak hour vacancies), and $F_{a}=$ number of full-time staff members working in the academic zone.

* Data were not available for any other years. 


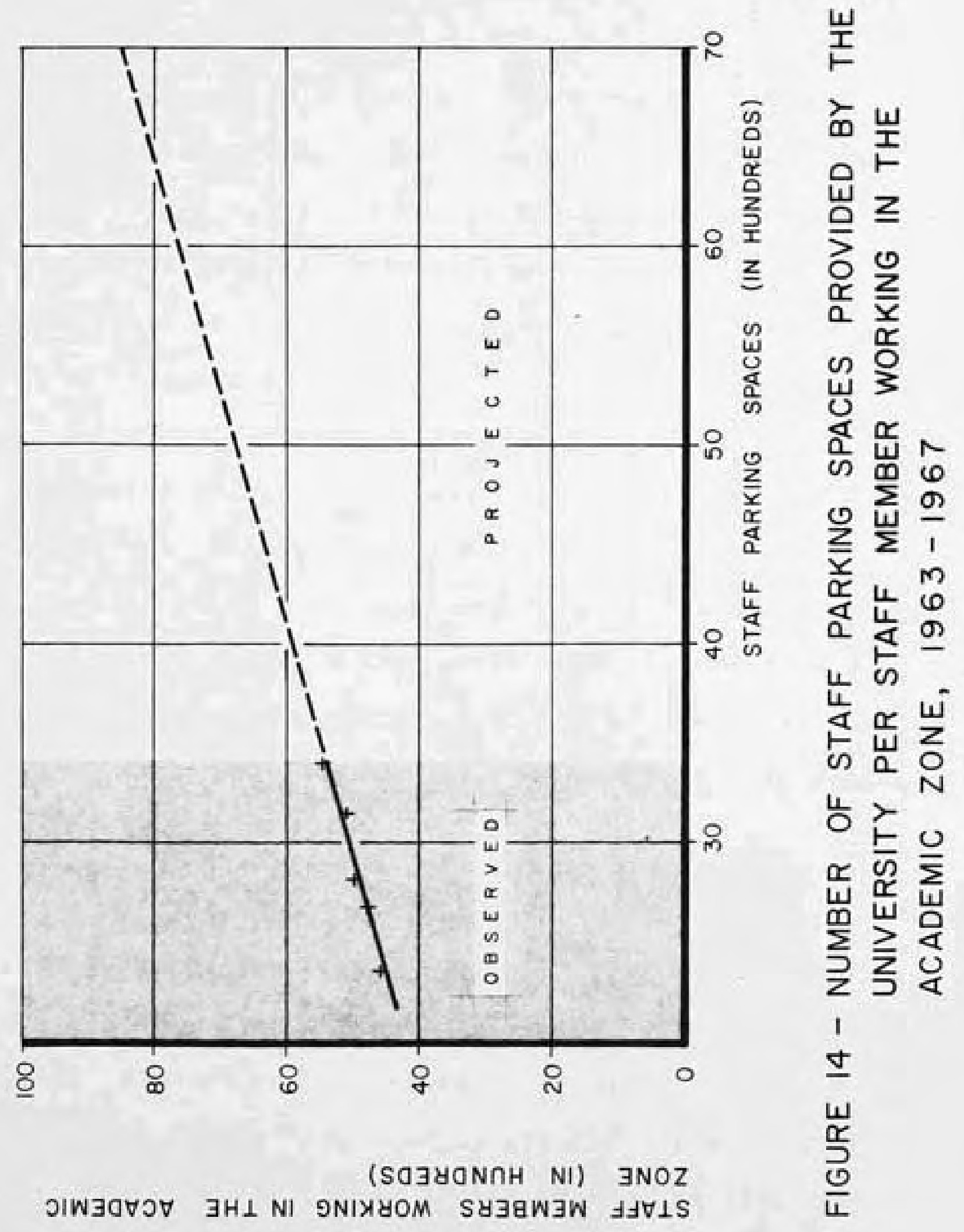


It is recognized that this formula has the limitation of being based on a relatively small number of observations. However, for the purpose of estimating future staff parking demand, the formula gives reasonable accuracy. For the ultimate campus population, about $8,210 \mathrm{staff}$ nembers are expected to be working in the academic zone $(0.87$ of the total number of staff members on the campus). Future staff parking demand at ultimate enroliment was thus estimated (on the basis of the established relationship) to be about 6,650 parking spaces.

In estimating future visitor parking demand, the ratio of the number of parking spaces (in the academic zone) used by visitors to that used by staff members was observed for 1965 through 1967. The ratio was found to be about 0.05 . It was assumed that, in the future, the university will still provide visitor parking for about 0.05 of the staff parking demand. Thus, the ultimate future visitor parking demand was estinated to be about 330 spaces.

Future Provision of Bus Systems. The future provision of bus systems as an alternative mode of commuting to the academic zone was considered. Buses, if used, should be basically planned to meet student commuting demands. Staff and visitors are not expected to use the systen in the periods of peak student loads. Buses can be operated from renote parking facilities and/or university housing facilities to the academic zone and vice versa. They can thus 
substitute for part of the need for parking around the academic zone and/or commuting by automobile from university housing facilities. As such, the student loads expected on a bus system around a given time depend on the number of student auto trips expected to be made to the academic zone around the same time.

The expected future student load on a bus system was estimated as follows. Of the existing on-street free parking spaces around the academic zone, about 1000 spaces were assumed to remain used in the future. Analys is of the daytime population shows that about 27 percent of the student population are expected to be present in the academic zone at $7: 30 \mathrm{a} \cdot \mathrm{m}$. These students are a 150 expected to make about 1658 auto trips to the academic zone shortly before this time. Due to the favorable locations of the parking spaces around the academic zone, these will probably be almost entirely occupied by $7: 30$ a.m. Remote parking facilities and the bus system (if this combination is provided) will then start to accommodate the overflow. But at $8: 30 \mathrm{a} \cdot \mathrm{m} ., 52$ percent of the students are expected to be present in the academic zone. If $i t$ is assumed that not more than 2 percent of the student population return to their residences after the $7: 30$ a.m. class, then not more than 27 percent of the student population will have to commute to the academic zone between $7: 30$ and $8: 30 \mathrm{a} . \mathrm{m}$. These will have little choice but to use 
remote parking facilities and the bus system or to walk. As such, these constitute the probable peak student load on the system since analysis of other daytime populations does not suggest the probability of higher peaks at any one time after $8: 30$ a.m.*

Accordingly, the expected future number of student auto trips made to the academic zone around $8: 30$ a.m. was estimated and assumed equal to the expected peak student load on the bus system. This estimate was arrived at by using the student parking demand forecasting model. The value of " $\mathrm{C}$ " used in this case was 0.27 (the percent of students expected to commute to the academic zone around $8: 30 \mathrm{a}, \mathrm{m}$.$) .$ It was thus estimated that if a bus system (or systems) is used, it could have a peak load of 2150 students around $8: 30$ a, m. Of these, about 430 students are expected to be 1 iving in university housing facilities.

Pedestrian Commuting. Most of the pedestrian trips made to the acadenic zone are generated by university housing facilities and fraternities, sororities, and cooperative houses located in the vicinity of the academic zone. In the future, commuting from these kinds of residential facilities is expected to remain predominantly pedestrian. The following is an analysis of the existing as well as the expected

* To obtain accurate estimates of the expected student loads on a bus system at different hours would require the use of sophisticated data on the probable frequencies of student trips from the academic zone back and forth to their residences between classes. 
pedestrian-vehicle conflicts resulting from pedestrian commuting to the academic zone.

The actual frequencies and paths of pedestrian trips made from origins outside of the academic zone to destinations within it are difficult to plot; more so to forecast. However, by plotting and examining schematic pedestrian desire lines based on estimates of pedestrian trips generated by different housing facilities and hypothetically attracted to the focal point in the academic zone, the locations of heavy pedestrian movements to and from the academic zone can be identified. Figure 15 shows a schematic configuration of the existing pedestrian desire lines to and from the academic zone. The heaviest pedestrian traffic approaches the academic zone from the west and the north; especially through First, Second, and Third Streets. In the future, the same pattern is expected to remain, probably with increasing pedestrian traffic approaching the academic zone from the south (due to the expected provision of additional graduate housing facilities south of State street).

Existing volumes of vehicular traffic around the academic zone are shown in Figure $16(24)$. Northwestern Avenue and State street are the main approaches to the academic zone. Other surrounding streets carry much less vehicular traffic. These serve to distribute traffic to the parking facilities in and around the academic zone. Short of drastic changes in the street network around the academic zone, the same 
PURDUE UNIVERSITY

LAFATETTE CAMPUS

set

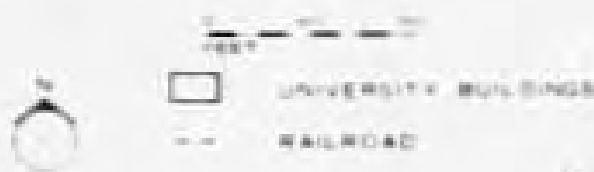

$\square$ ACADEMIC ZONE

PEDESTRIAN TRIPS

4,000

1.500

500,100

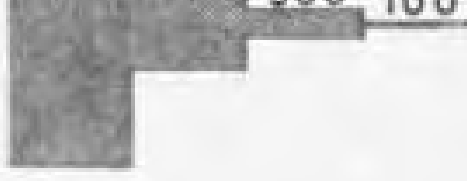

口゙व
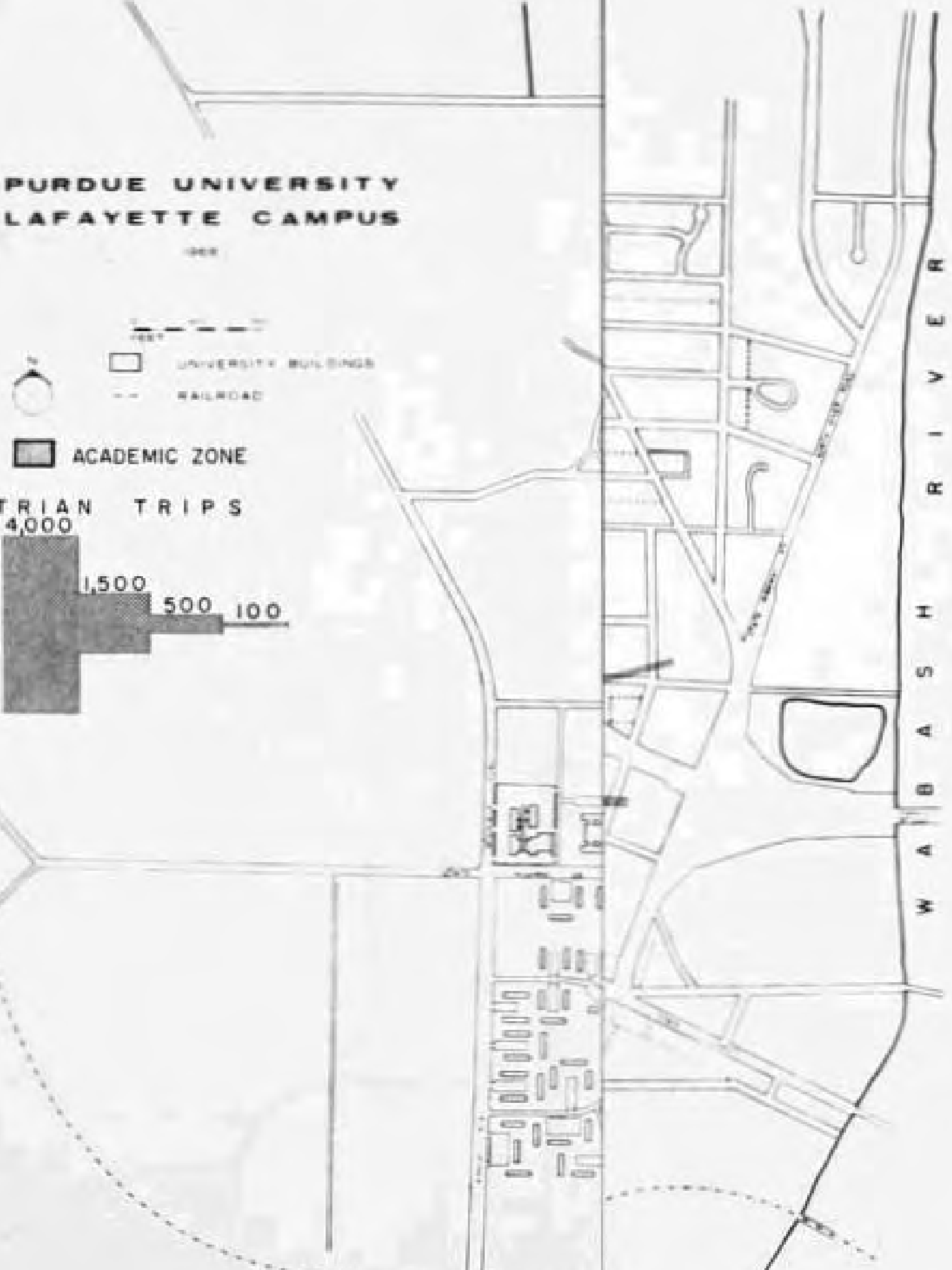

1 政

$\frac{\sqrt{2}}{10 i 1}$
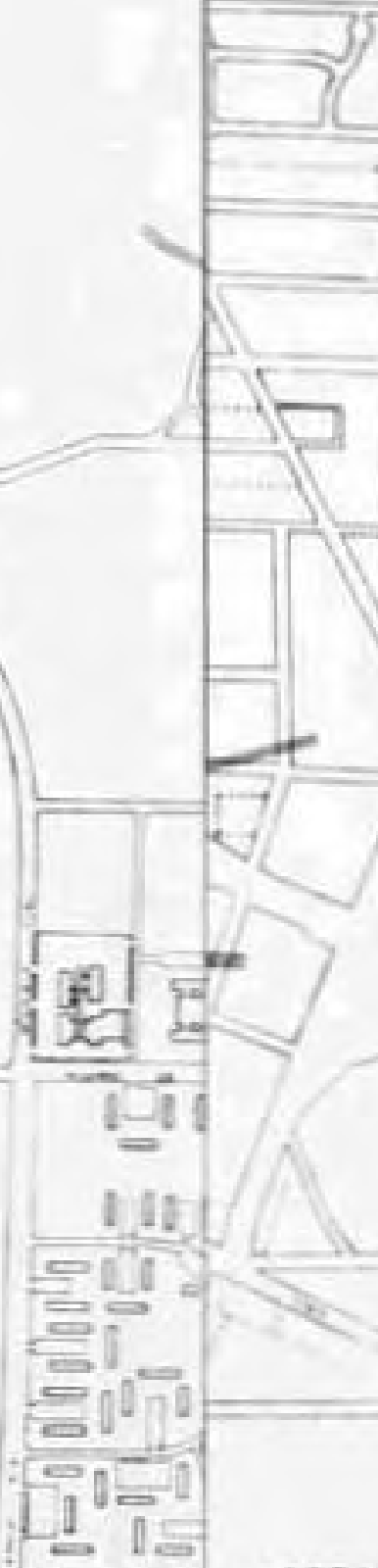

$x$

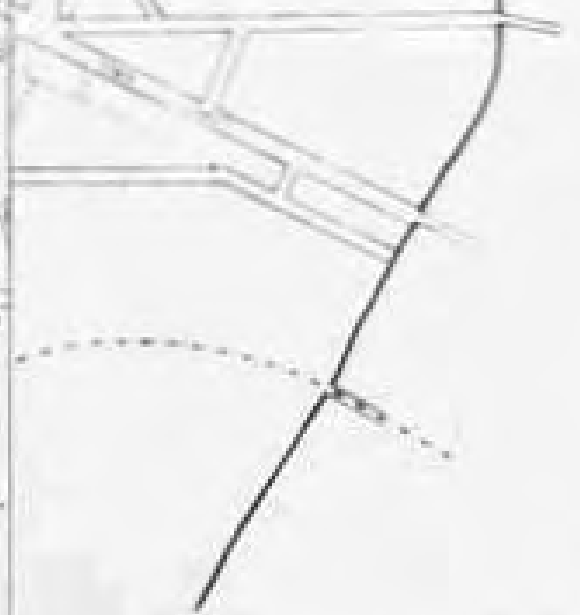

FIGURE 15 - SCHEMATIC CONFIGURATI THE ACADEMIC ZONE, 


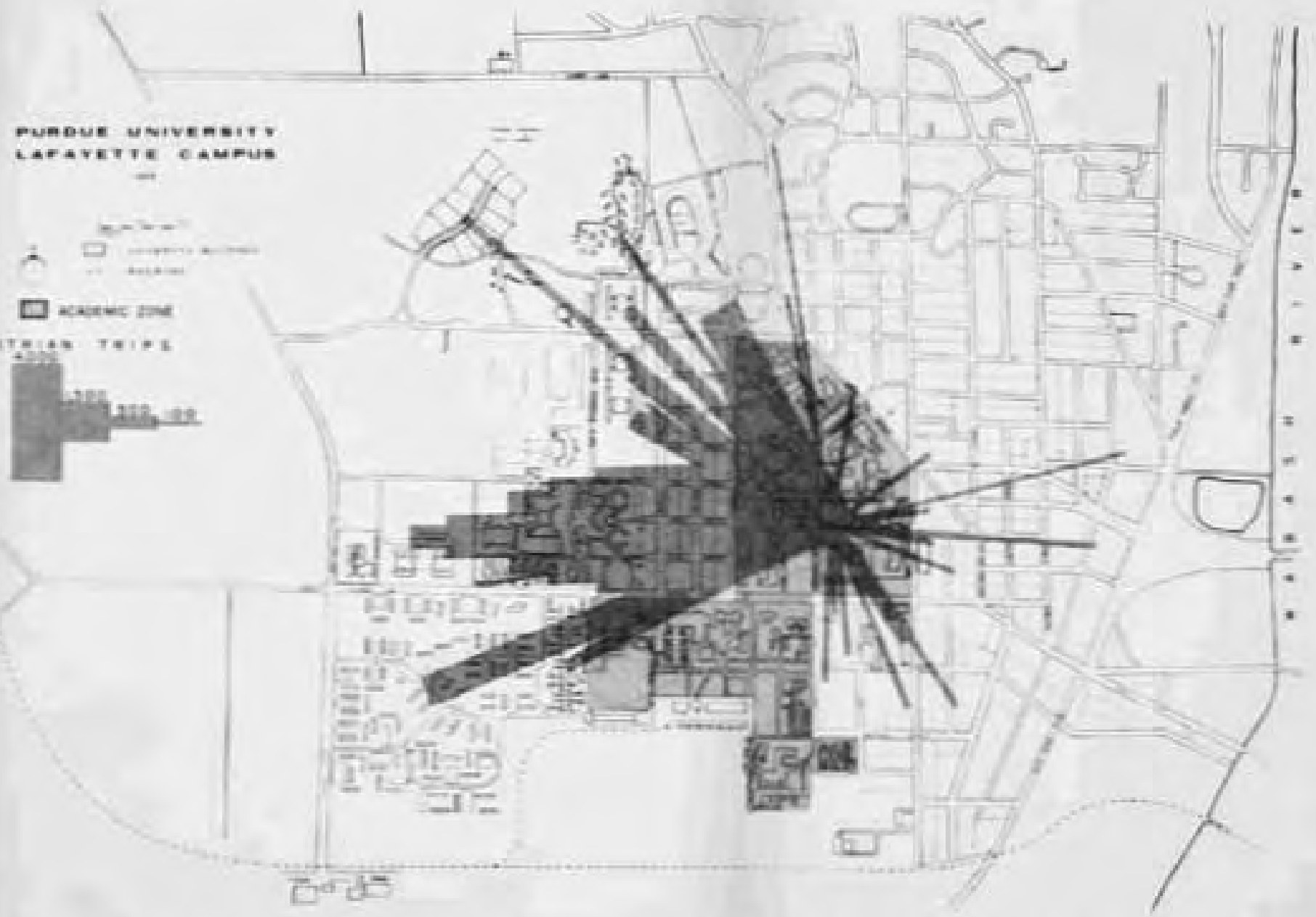

FIGURE 15 - SCHEMATIC CONFIGURATION OF PEDESTRIAN DESIRE LINES TO ANO FROM THE ACADEMIC ZONE, FALL 1967 


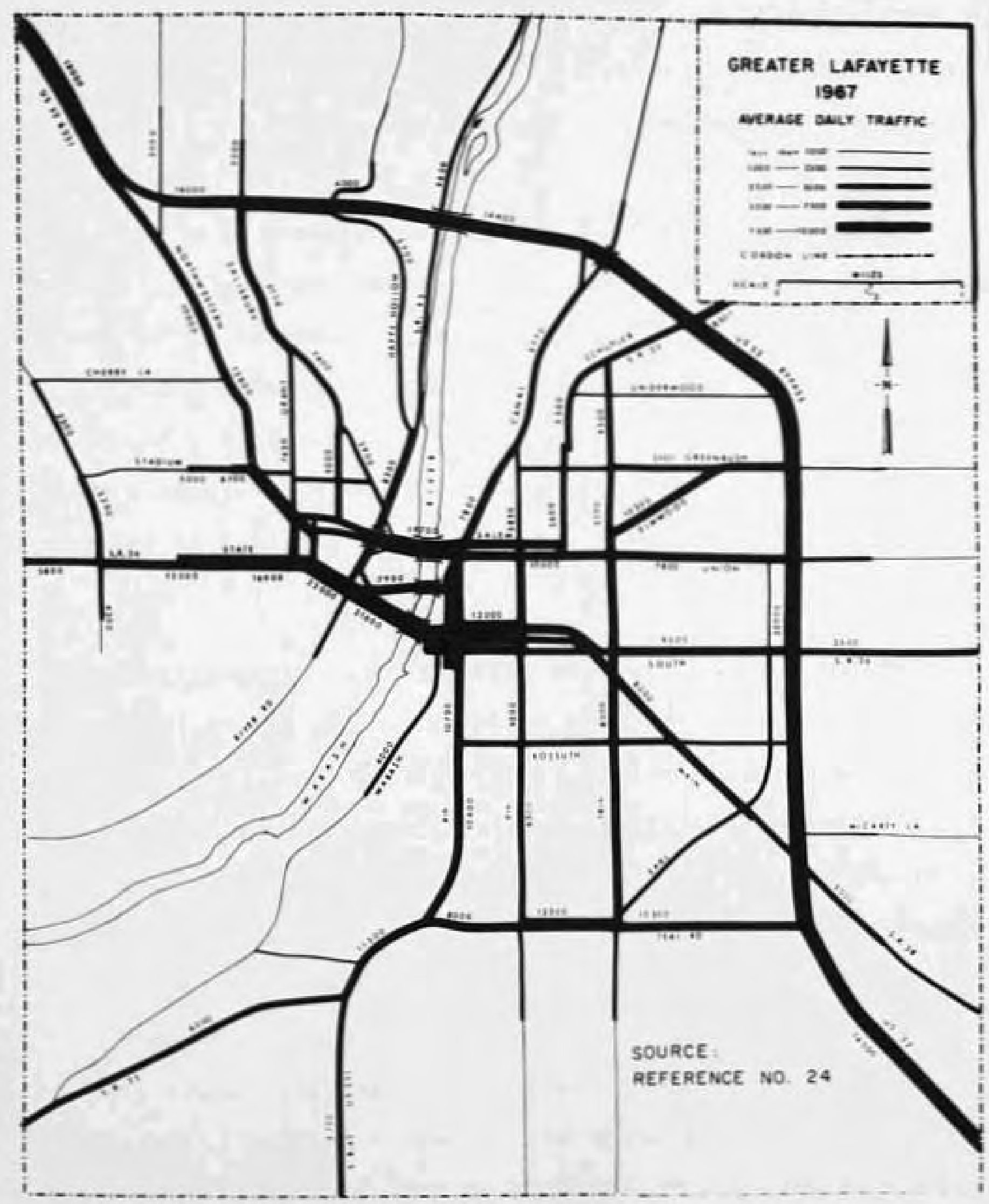

FIGURE 16 - AVERAGE DAILY TRAFFIC VOLUME MAP, 1967 
traffic pattern is expected to remain unchanged in the future. Volumes of traffic, however, will obviously increase. By examining the patterns of pedestrian traffic and vehicular traffic together, existing and expected pedestrianvehicle conflicts can be located. Such conflicts presently occur and will tend to increase on Stadium Avenue, along University, Maldron, and Russell Streets, and most inportantly on State Street. No significant conflicts seem to occur along Northwestern Avenue. Fortunately, peak vehicular traffic does not concur with peak pedestrian traffic. As such, pedestrian-vehicle conflicts around the academic zone may be subject to possible solutions.

\section{Summary}

This chapter discussed data collection, data analysis, and forecasting. The patterns of movement in the academic zone were analyzed, the efficiency of the present layout of facilities was evaluated, and the pedestrian-vehicle conflicts in the acadenic zone were located. Future expected conditions in the academic zone were discussed. Commuting to and from the academic zone was also examined. Data on the campus population characteristics influencing commuting were collected and analyzed. Expected future population characteristics were estimated and techniques for forecasting commuting denands were developed. Thus future parking demands and the peak student load on a possible bus system that might be used as an alternative mode of conmuting to 
and from the academic zone were estimated. Finally, pedestrian-vehicle conflicts around the academic zone were examined.

The results arrived at in this chapter provide the factual bases on which a number of alternative circulation and commuting plans are developed in the next chapter. 
CHAPTER III. ALTERNATIVE PLANS FOR CIRCULATION AND COMMUTING

The existing conditions relative to circulation in the acadesic zone and commuting to and from it were analyzed. Deficiencies were noted and future demands were estimated. A number of alternative plans were developed to overcome the existing deficiencies and meet the future demands. These were then evaluated in terms of their capabilities to fulfill objectives and in terms of their annual costs. The following are the objectives set for these alternatives and the criteria by which they were evaluated.

\section{Objectives and Criteria}

Objectives

In his general discussion of campus circulation systems, Dober proposed a number of objectives (5). On the basis of these, specific objectives were formulated to suit the purpose and scope of this study. The alternative plans for circulation and commuting were developed with the following objectives:

1. To create, whenever practicable, traffic-free pedestrian precincts in the acadenic zone.

2. To separate the channels of movenent of inconpatible modes of transportation. 
3. To provide logical connections in traffic flow.

4. To meet, as adequately as feasible, the demand for parking.

5. To choose, within the 1 imitations of land availability and uses, convenient locations for parking.

6. To provide for the appropriate servicing of buildings.

7. To create an aesthetically pleasing environment on the campus.

\section{Criteria}

Circulation and commuting plans were evaluated in terms of the following criteria: (1) continutty of the circulation system and clarity of destinations, (2) safety for both pedestrians and drivers, (3) convenience in driving and walking, (4) enjoyment of an aesthetically pleasing environment especially in walking, and (5) cost.

\section{Alternative Circulation Plans (In the Academic Zone)}

Analysis of pedestrian circulation in the academic zone indicated the presence of pedestrian-vehicle conflicts in a number of locations. Three alternative plans were developed to minimize these conflicts. In the first (alternative 1/1) the conflicts are almost entirely elininated. In the second and third (alternatives $1 / 2$ and $I / 3$ ) the conflicts are partially eliminated with varying degrees. In all three alternatives, most parking facilities presently available on 
the periphery of the academic zone are kept in use. Buildings are serviced through these parking facilities. Whenever through vehicular traffic is eliminated by vacating or dead-ending internal streets, provision can be made for emergency vehicles to use pedestrian walkways for access. In all three alternatives, the railroad line is removed on the assumption that the existing power plant on the north campus will be relocated.

\section{Alternative $1 / 1$}

In this alternative, through traffic was completely eliminated from the academic zone. Pedestrian circulation is given prime importance while vehicular traffic is strictly kept to a minimum. Figure 17 shows alternative plan $1 / 1$. On the north campus, vehicular traffic was eliminated on Oval Drive, on Memorial Ma11, south of the Chemistry building, on Central Drive, around the Hall of Music, on Purdue Mall, and on Stadium Ma11. This was done to minimize the interference, in these locations, between vehicular traffic and the heavy concentrations of pedestrians. On the south campus, pedestrian-vehicle conflicts are as yet relatively less noticeable. However, a few changes were made in the existing vehicle circulation system to minimize increases in such conflicts in the future. Thus vehicular traffic was eliminated south of the Life Science Small Animal building, east of the Agricultural Engineering building, west of the Horticulture building, and west of the Agricultural Hall. 


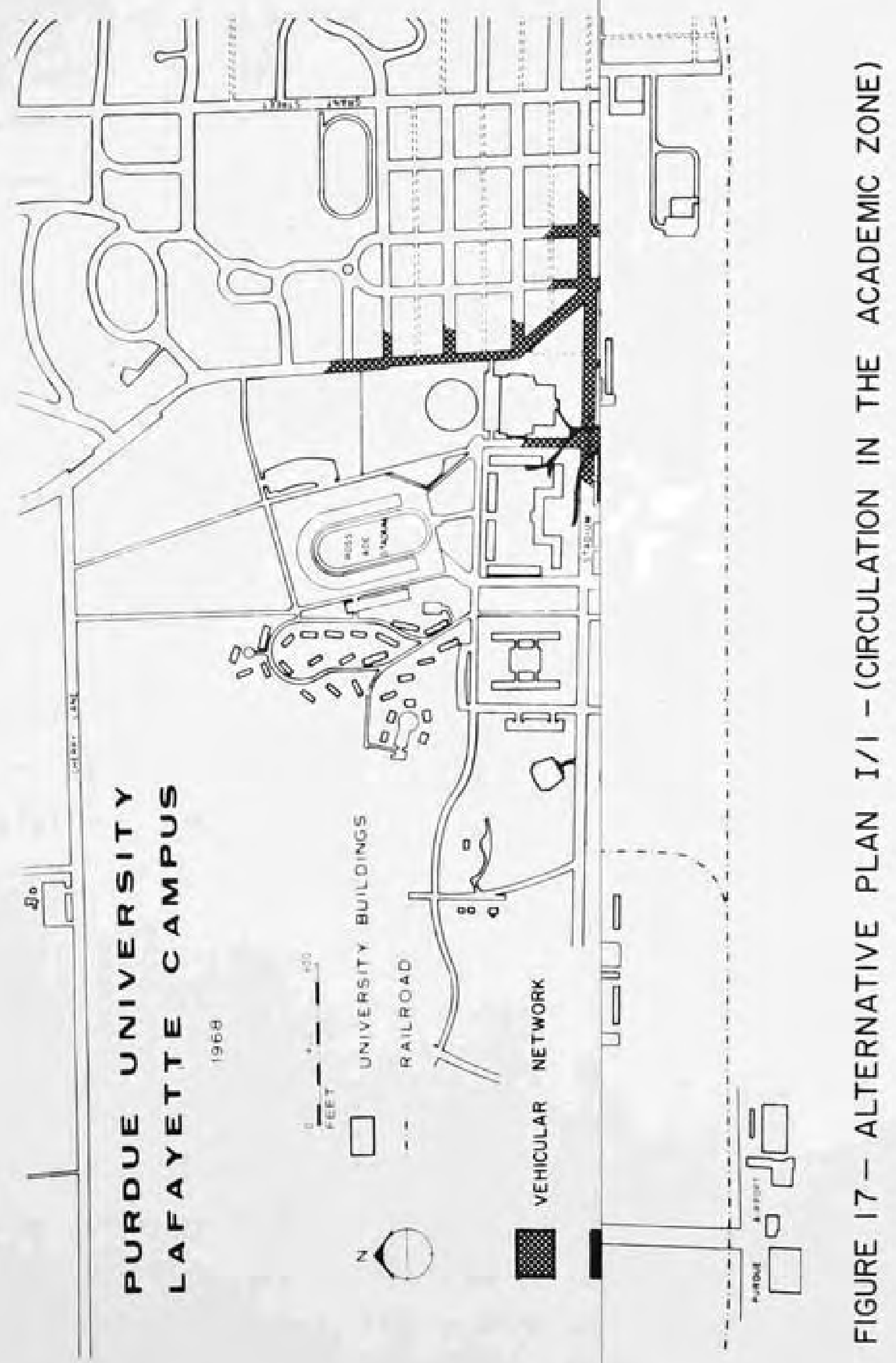




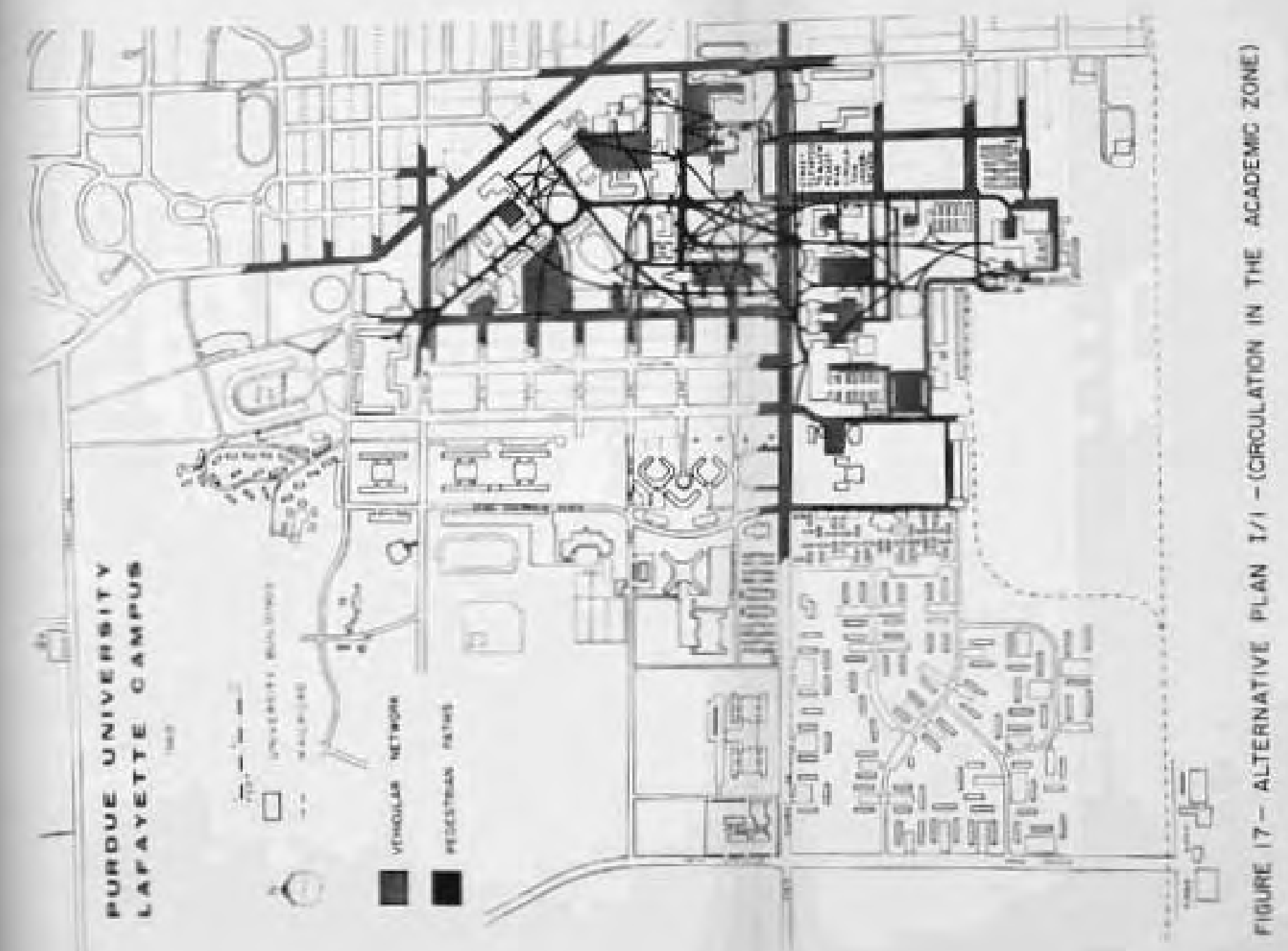


It was recognized that the penetration of state Street into the campus creates one of the major pedestrian-vehicle conflicts in the acaderic zone, a conflict that is likely to increase considerably in the future. In this alternative, the solution proposed to overcome this conflict is based on the concept of complete integration of the south and north campuses. This is achieved by slightly raising the level of the stretch of State Street west of Memorial Mall and east of the Home Economics Administration building, and by slightly lowering the level of the open spaces north and south of this raised portion of state Street just enough to allow pedestrian movement underneath State Street (Figure 18). Continuity can thus be achieved in the flow of open spaces and in pedestrian circulation between the north and south campuses. The solution, however, requires considerable change in the design of the intersection of state street with Marsteller street.

\section{Alternative $1 / 2$}

Figure 19 shows alternative plan $1 / 2$. In this alternative, through traffic is also eliminated on the north campus. Peripheral parking facilities which do not conflict with major pedestrian paths are kept in use. The parking on Purdue Ma11, northeast of the Music Hall, and north of the Memorial Center and Memorial Union are left unchanged. Major pedestrianvehicle conflicts are minimized by converting Stadium Mall, Oval Drive, and Memorial Mall into pedestrian walkways. On the south 


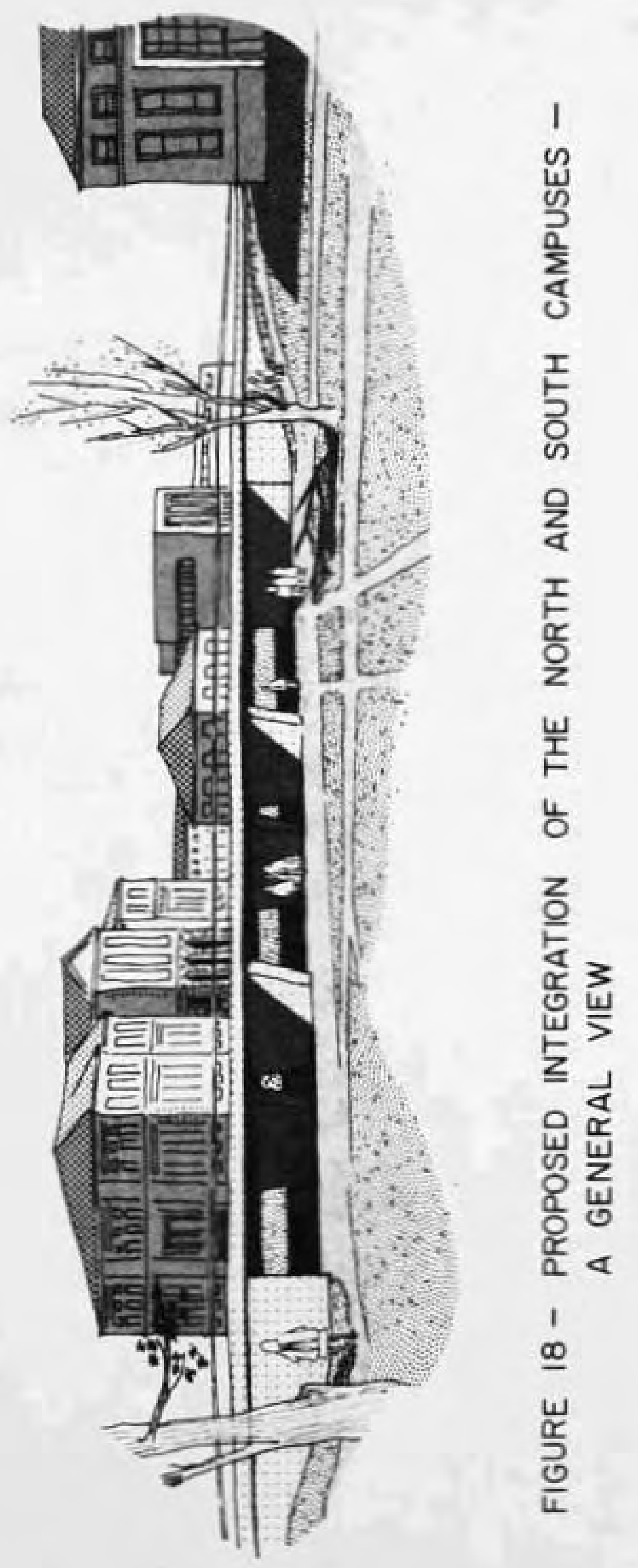




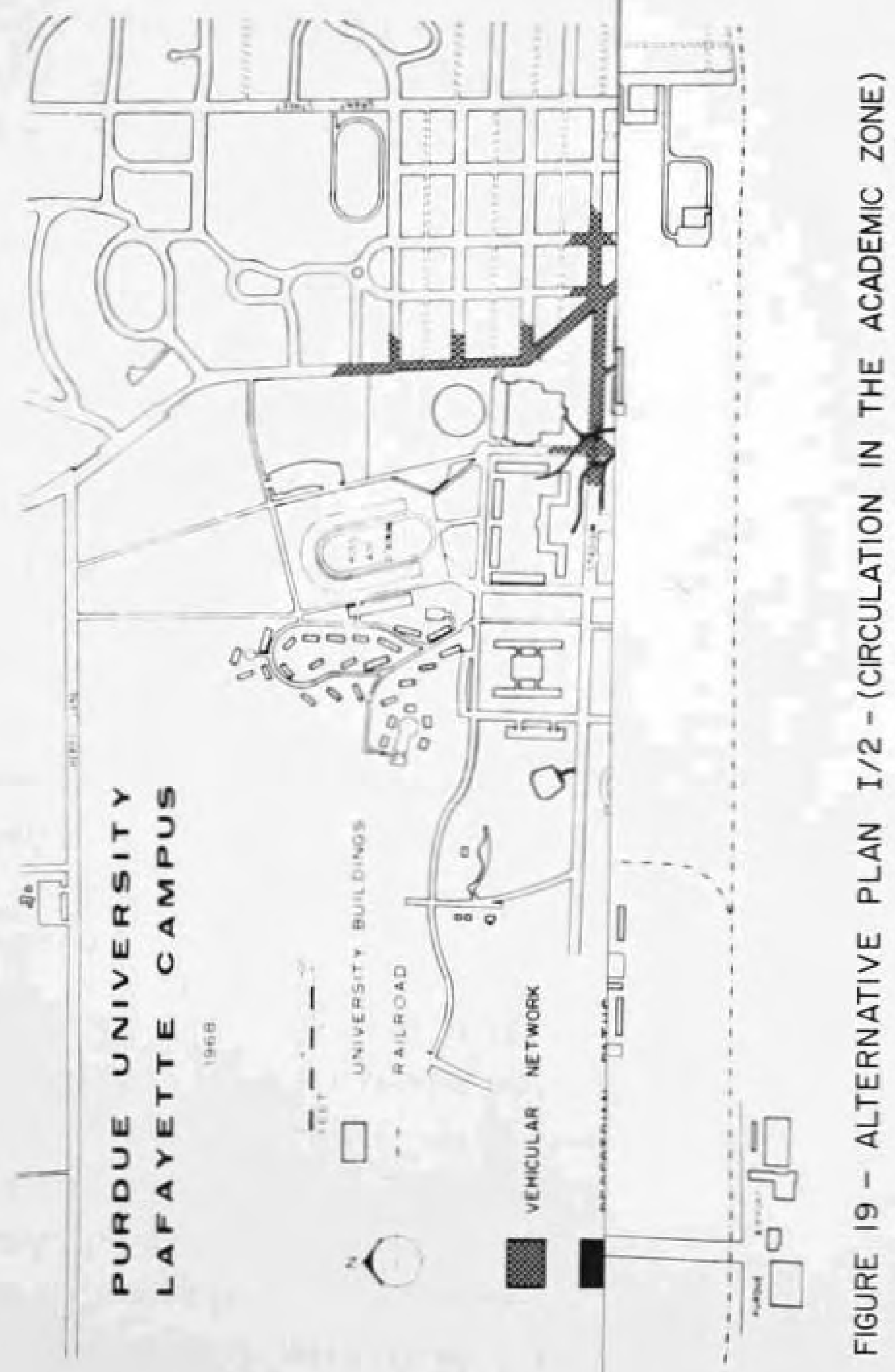




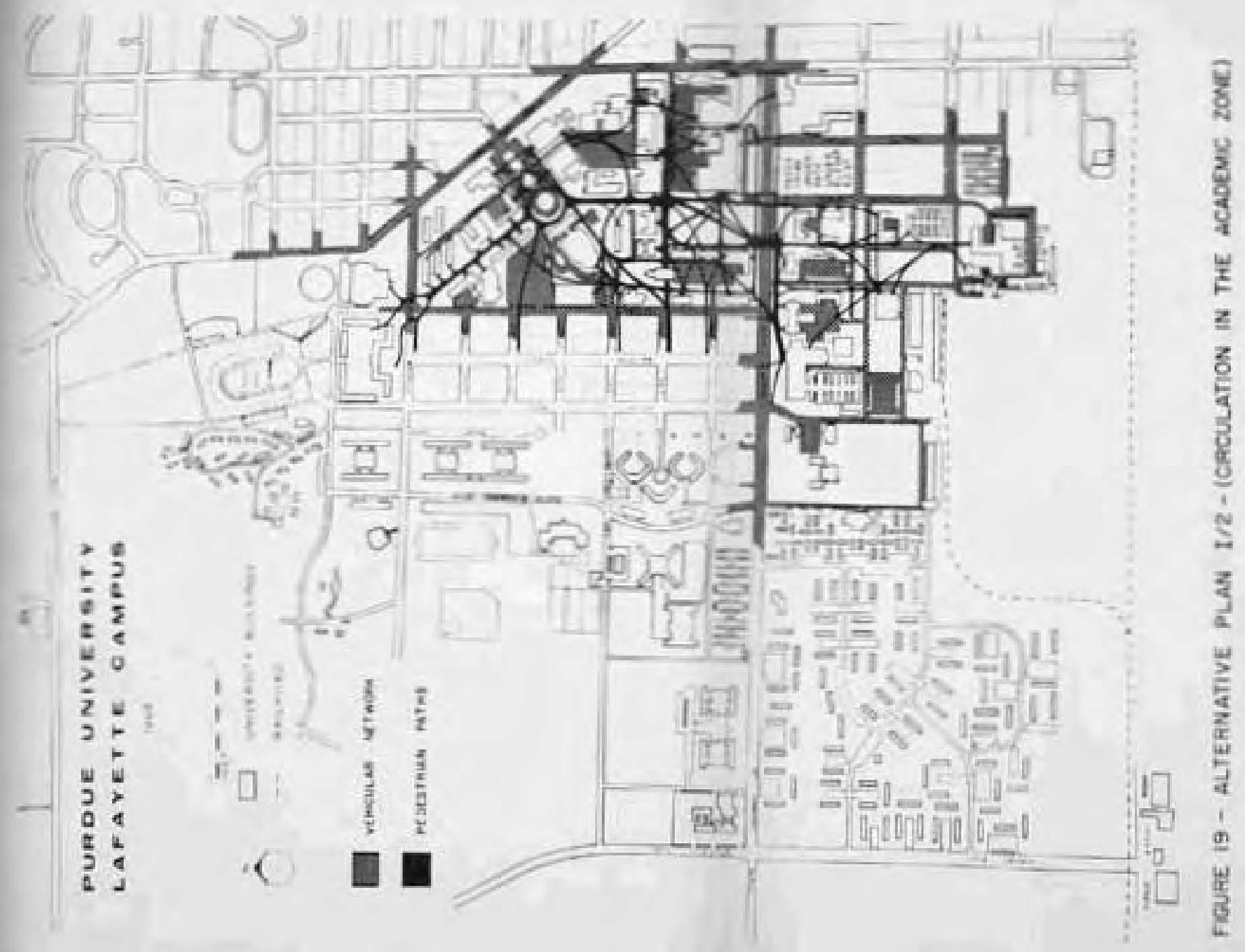


campus, no changes are made in the circulation system. If the existing pattern of dead-end streets is maintained in the future, no major pedestrian-vehicle conflicts are likely to arise in the south campus.

To overcome the pedestrian-vehicle conflict on State Street, an open pedestrian underpass is proposed (Figure 20). In choosing the location of the underpass, the points at which the greatest concentrations of students cross State Street between classes were repeatedly observed. According$1 y$, it was felt that the underpass would be nost intensely used if located east of the Home Economics Administration building. Also, by slightly raising the level of State Street at this location and by slightly lowering the level of the proposed underpass (just enough to allow pedestrian movement), no major changes will be required in the adjacent intersections. The solution provides only partial integration of the north and south campuses but satisfactorily eliminates the major pedestrian-vehicle conflict on State Street.

\section{Alternative $1 / 3$}

Figure 21 shows alternative plan $1 / 3$. Unlike alternatives $1 / 1$ and $1 / 2$, this alternative seeks only to minimize (and not completely elininate) through traffic on the north campus. Parts of Oval Drive, Central Drive, and Memorial Mall are closed to vehicular traffic. Stadiun Mall is used for one-way traffic (going south) leading to the parking 


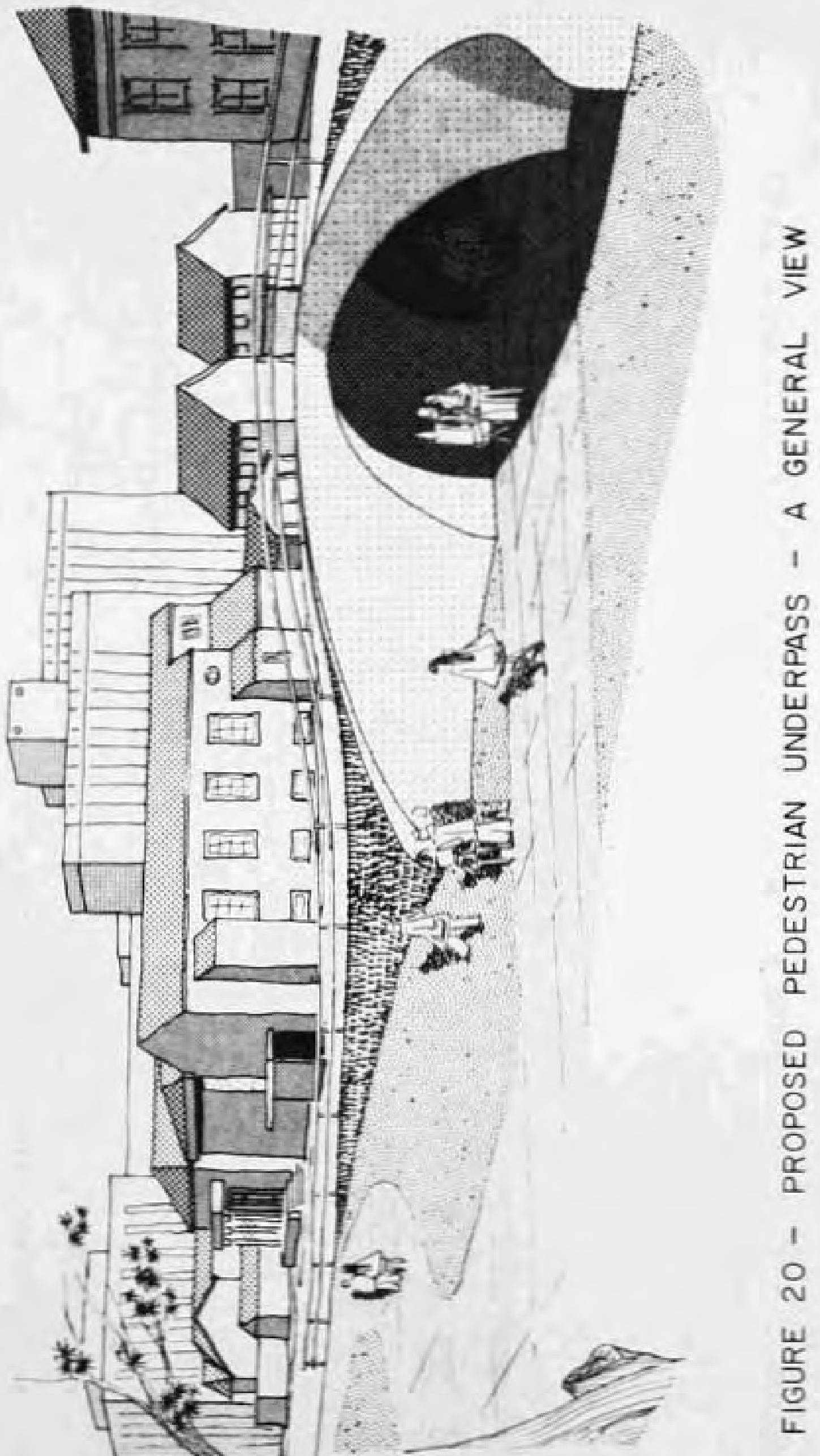




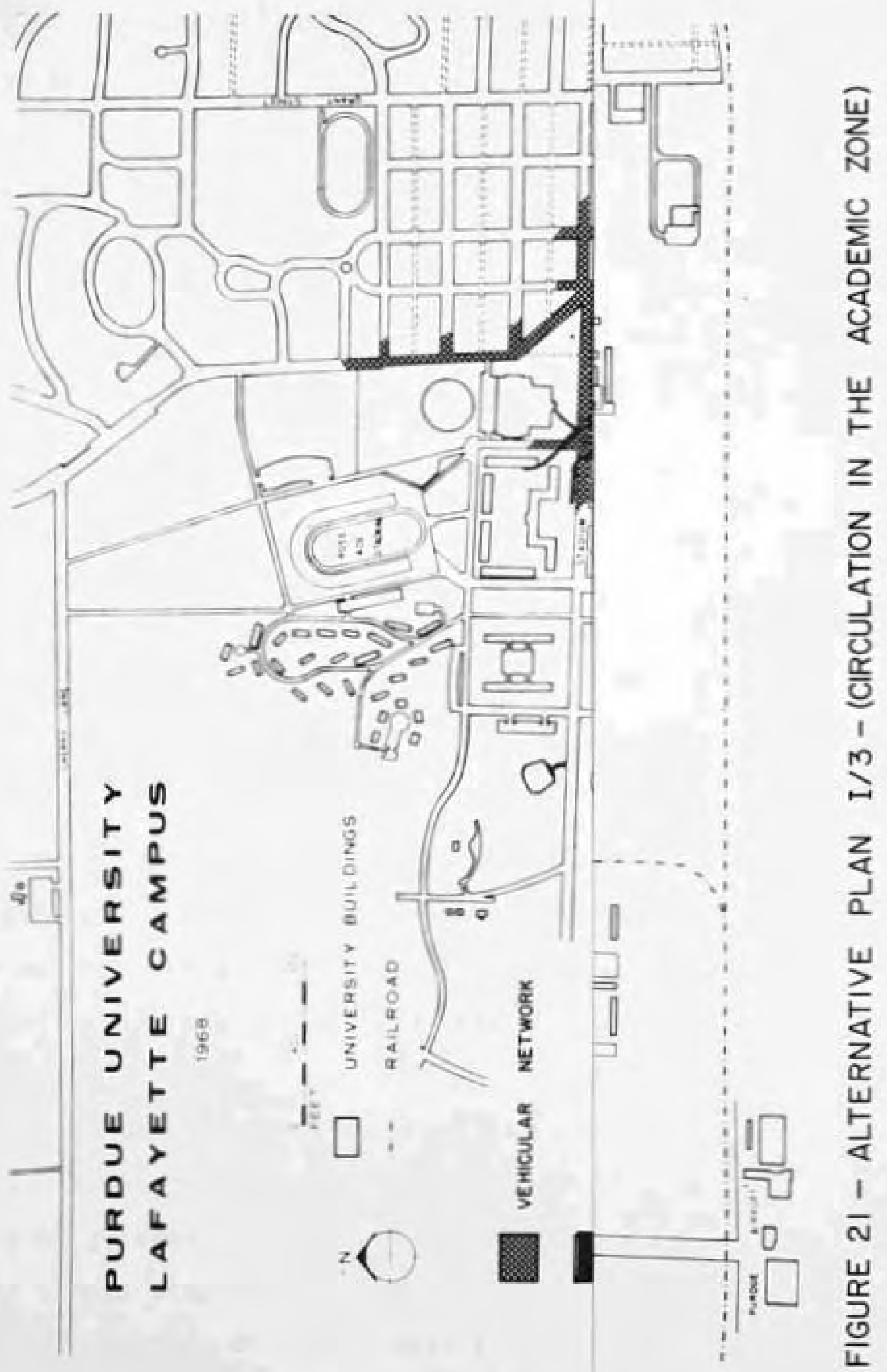




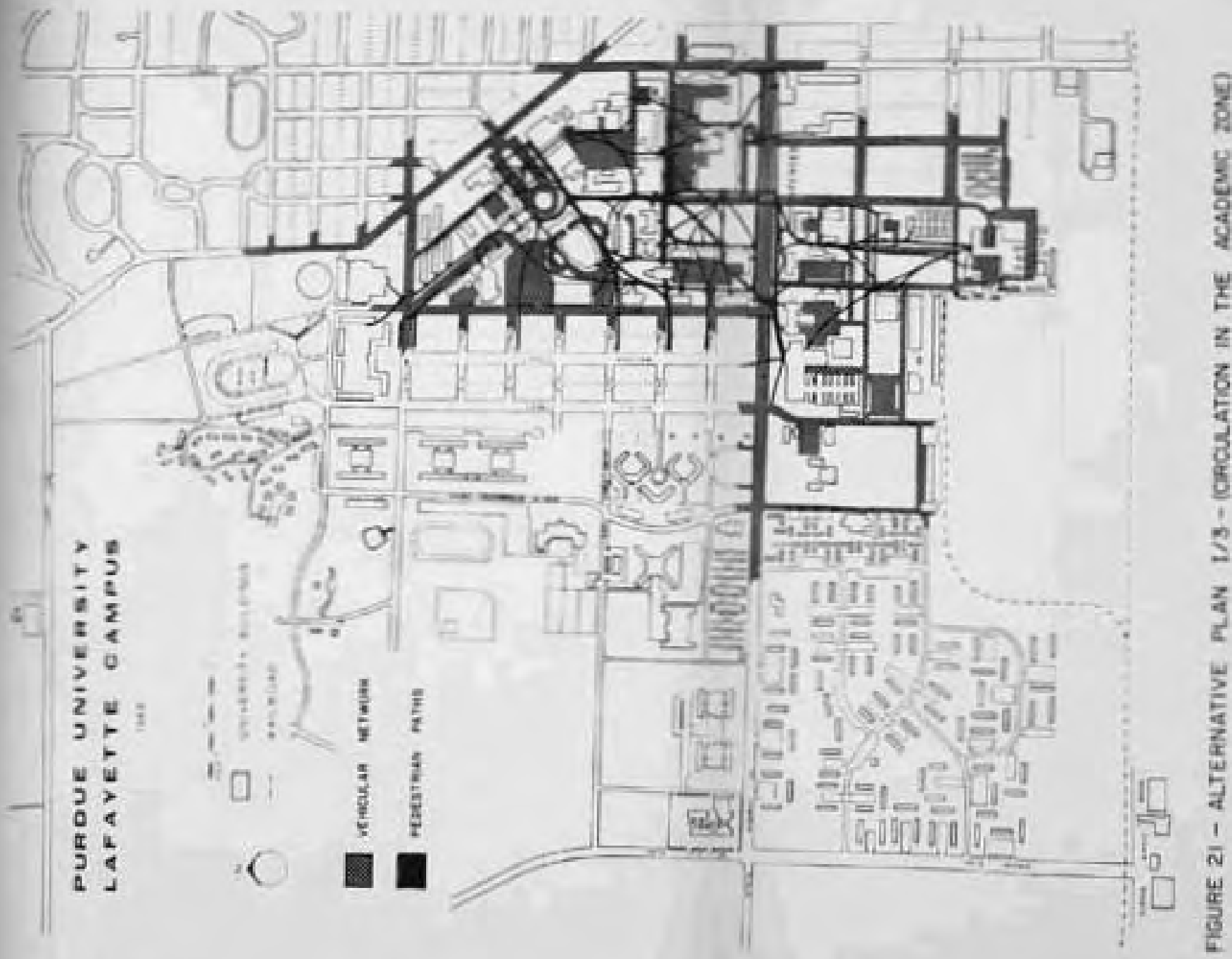


lot abbuting University Street (Figure 21). As in alternative $I / 2$, no changes are made on the south campus. The pedestrian-vehicle conflict on State street is reduced by using a more complete system of decorative fences along the street to 1 imft the points of crossing and by providing traffic controls at these points.

\section{Evaluation of Alternatives}

The following is a subjective evaluation of the three alternative circulation plans in terms of the criteria outlined earlier in this section. The evaluation is subjective in the sense that it does not attempt to quantify the attributes and characteristics of each alternative, but instead, discusses then qualitatively.

In both alternatives $I / 1$ and $1 / 2$, continuity is fully achieved in both vehicular and pedestrian circulation. In alternative $1 / 3$, pedestrian circulation is interrupted, at a number of points, by vehicular traffic. In terms of safety, both alternatives $1 / 1$ and $I / 2$ succeed in elfminating the major hazards caused by pedestrian-vehicle conflicts, but in aiternative $1 / 3$ the conflict on State Street is not fully overcome.

In all three alternatives, driver convenience is reduced (to varying degrees) by elininating access to parking facilities from internal streets (in the acadenic zone) and by limiting this access to single points on the surrounding streets. Not only will this mean longer trips in some cases 
(by automobile and on foot), but it inight also create some mild traffic congestion on the surrounding streets during peak hours. Access for service and emergency vehicles can be adequately provided in all three alternatives.

Aesthetically, the potential exists in all three alternatives for creating pleasing visual relationships in the acadenic zone. In alternatives $I / 1$ and $1 / 2$, the grade separation of pedestrians and vehicular traffic on State Street creates wide possibilities of landscaping and open space organization.

For this evaluation, cost was found to result primarily from two measures: (1) the number of parking spaces in the acadenic zone that would be lost due to the proposed changes, and (2) the extensiveness of the proposed changes. Alternative $I / 1$ has the greatest reduction in the number of parking spaces (about 766 spaces). Of the three alternatives, it also proposes the most extensive changes in the existing conditions. As such, it will undoubtedly prove to be the most expensive to implement. Conversely, alternative $I / 3$ wit1 result in reducing the number of the existing parking spaces in the academic zone by only about 142 spaces and will require the least extensive changes. Alternative $1 / 21$ ies between the two extrenes; it involves the reduction of about 302 parking spaces and requires moderate changes in the existing conditions.

On the basis of this evaluation, it seems justified to conclude that, of the three proposed alternatives, 
alternativ $1 / 2$ would be most acceptable. It will minimize the major pedestrian-vehicle conflicts in the academic zone; it will reasonably link the north and south campuses; and it would require only moderate costs to effect necessary changes in the existing conditions. Alternative $I / 2$ is consequently used as the basis for developing alternative commuting plans.

\section{$\frac{\text { Alternative Commuting Plans (To and From }}{\text { the Acadenic Zone) }}$}

Commuting to and from the academic zone and circulation in the academic zone, although examined separately, are interrelated. Both are phases of an integral canpus transportation system. The alternative commuting plans proposed in this section, therefore, are developed in connection with the selected circulation plan (alternative 1/2). However, few changes are expected to arise lespecially in future parking demands) if some other circulation plan (in the academic zone) is selected.

Three alternative commuting plans are proposed. In the first (alternative 11/1), it is assumed that a11 expected auto trips to the acadenic zone will terninate in or around it. Therefore, all future parking denand (for students, staff, and visitors) is provided in and around the acadenic zone. The second (alternative $I I / 2$ ) uses a combination of parking facilities around the academic zone and a bus system to move students from university housing facilities to the academic zone. The third and last (alternative 11/3) is based 
on the concept of providing parking factlities in relatively remote locations and moving commuters from these parking lots to the academic zone by mass transportation. Two types of mass transportation systems are compared. In subalternative $11 / 3-A$, a street bus systen is proposed and in sub-alternative $11 / 3-B$, the possibility of using a skybus systen operating on an elevated roadway is discussed.

In a 11 three alternatives, no additional parking is provided on the north campus. Of the existing on-street free parking around the academic zone, 1000 spaces are assumed to be available for commuter parking in the future. In addition to these and the existing parking spaces in the academic zone, it was estimated that, to meet the future commuting demands of students, staff, and visitors, about 4330 additional spaces will either have to be provided or some other mode of commuting to the academic zone will have to be developed, * In developing the alternative commuting plans, due consideration was given to pedestrian commuting. Locations of future parking facilities were chosen so as to minimize pedestrian-vehicle conflicts and to allow for appropriate traffic controls at major pedestrian crossing points.

* For the details of this estinate, see Appendix B - Section 2. 


\section{A1ternative $11 / 1$}

In this alternative, future commuting demands are met by providing parking facilities around the academic zone. Figure 22 shows alternative plan 11/1. A number of possible kinds and locations of parking facilities were examined. A comparison was nade between the annual costs of different kinds of parking facflities such as underground garages, multi-story above ground garages, and surface parking. The costs of providing parking facilities on university owned 1 and and on non-university owned land were also compared. Appendix B - section 1 shows a detailed comparison of the annual costs of four kinds of parking facilities. Underground parking in the academic zone was discarded because of its relatively high costs. Surface parking on close-by locations around the academic zone in most cases was rejected because of the limited availability of usable land in general and university owned land in specific. The provision of parking in multi-story above ground garages around the academic zone was found to be the least expensive and the most appropriate from a land use and pedestrian circulation point of view. On the fringes of the south campus, however, surface parking is most economical because of university owned 1 and.

In deciding upon the locations of future parking facilities (Figure 22), a number of factors were taken into consideration: 
Cumeut univensit?

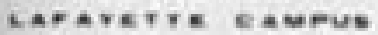
$=$

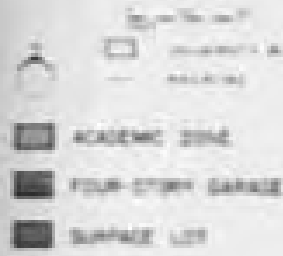

$+\frac{1}{2+1}$

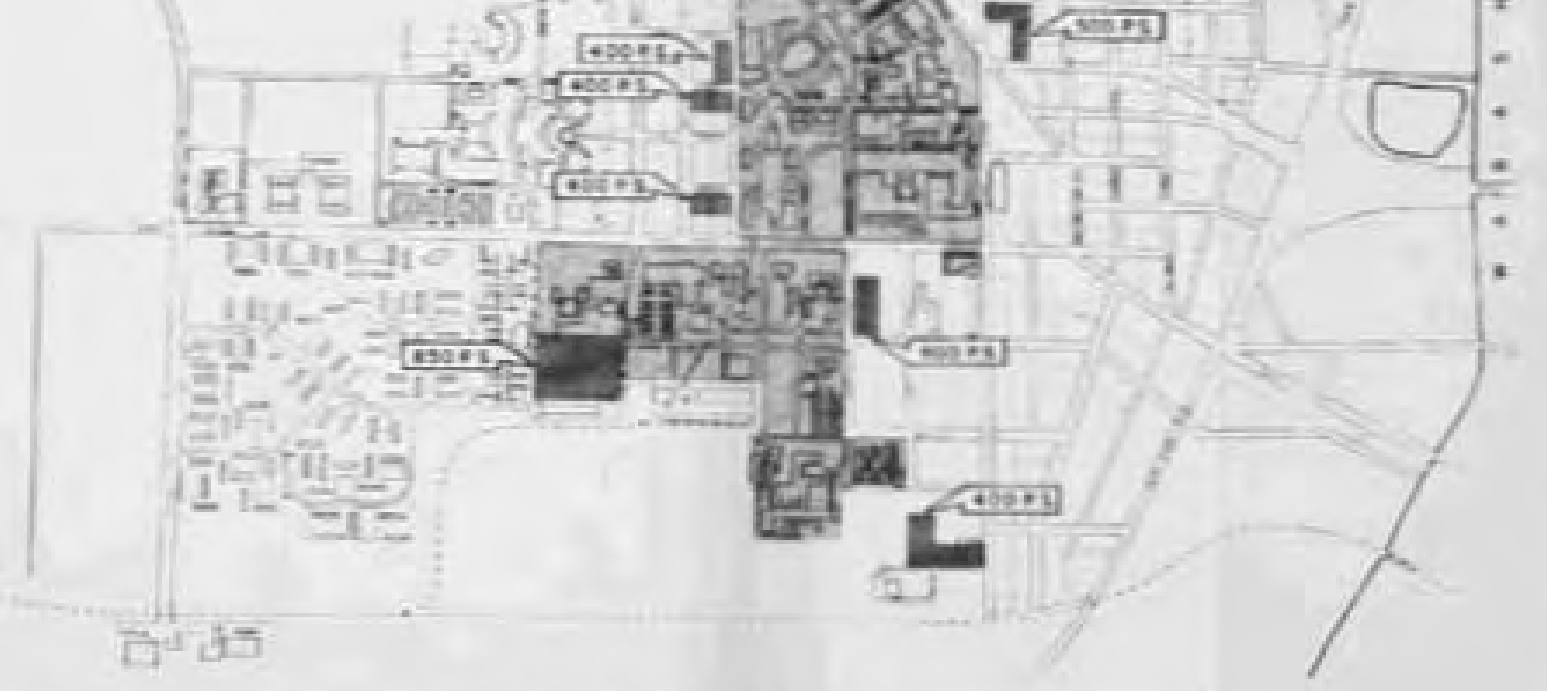

FIGURE 22 - ALTERNATIVE PLAN II/I-(COMMUTING TO AND FROM THE ACADEMIC ZONE) 
1. Parking facilities should be located, whenever possible, near the major traffic approaches to the acadenic zone. This enhances driver convenience and mininizes unnecessary vehicular movement around the acadenic zone. Thus, locations on Northwestern Avenue, University Street, Grant Street, Fowler Street and Wood Street were chosen for multi-story garages.

2. Location of parking facilities should minimize conflict at points of major pedestrian crossings. The entrances and exits of such facilities should be carefully designed to minimize pedestrian-vehicle conflicts. Thus, parking facilities on University Street were not located adjacent to second Street because of the expected heavy pedestrian use of this street. However, if a pedestrian ramp along Second Street with a separated crossing of University street were to be integrally constructed as a part of a garage on the south side of Second street between Waldron and University Streets, separation of pedestrians and vehicles would be better accomplished.

3. In choosing parking locations, proximity to intensely used facilities in the acadenic zone secures pedestrian convenience. Multi-story garages were, therefore, located as close as possible to the ain instructional facilfties in the academic zone. 
Along these 1 ines, alterntative $I I / 1$ provides about 1250 parking spaces in surface lots on the south campus and about 3400 parking spaces in multi-story garages around the academic zone (Figure 22). The annual cost involved in implementing this alternative is estinated in Appendix B section 2.

\section{Alternative II/2}

This alternative is developed on the basis of providing a combination of parking facilities around the acadenic zone and a bus systen. Two possible systems were considered:

(1) a bus system connecting the academic zone to the principal apartment complexes in West Lafayette and to the university housing facilities, and (2) a bus system connecting the academic zone to the university housing facilities only. The first was discarded because of the excessively long trip involved and the long time required to make such a trip by bus. The second was used as a basis for developing this alternative.

Since this proposed bus system is operated only between the acadenic zone and university housing facilities, it likely will substitute for only a fraction of the need for auto trips. The systen is thus combined with parking facilities around the acadenic zone to meet the future commuting desand. Figure 23 shows alternative plan $11 / 2$. The figure gives the proposed bus route as well as the types and locations of the parking facilities around the acadenic zone. 
PURDUE UNIVERSITY

LAFAYETTE CAMPUS

+en

m.- - -

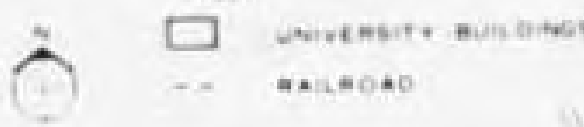

ACADEMIC ZONE

FOUR-STCRY GARAGE

D SURFACE LOT

$\because$ RESIDENTIAL FACILITIES SERVEO BY THE BUS SYSTEM

- Bus station

Y BUS ROUTE

4

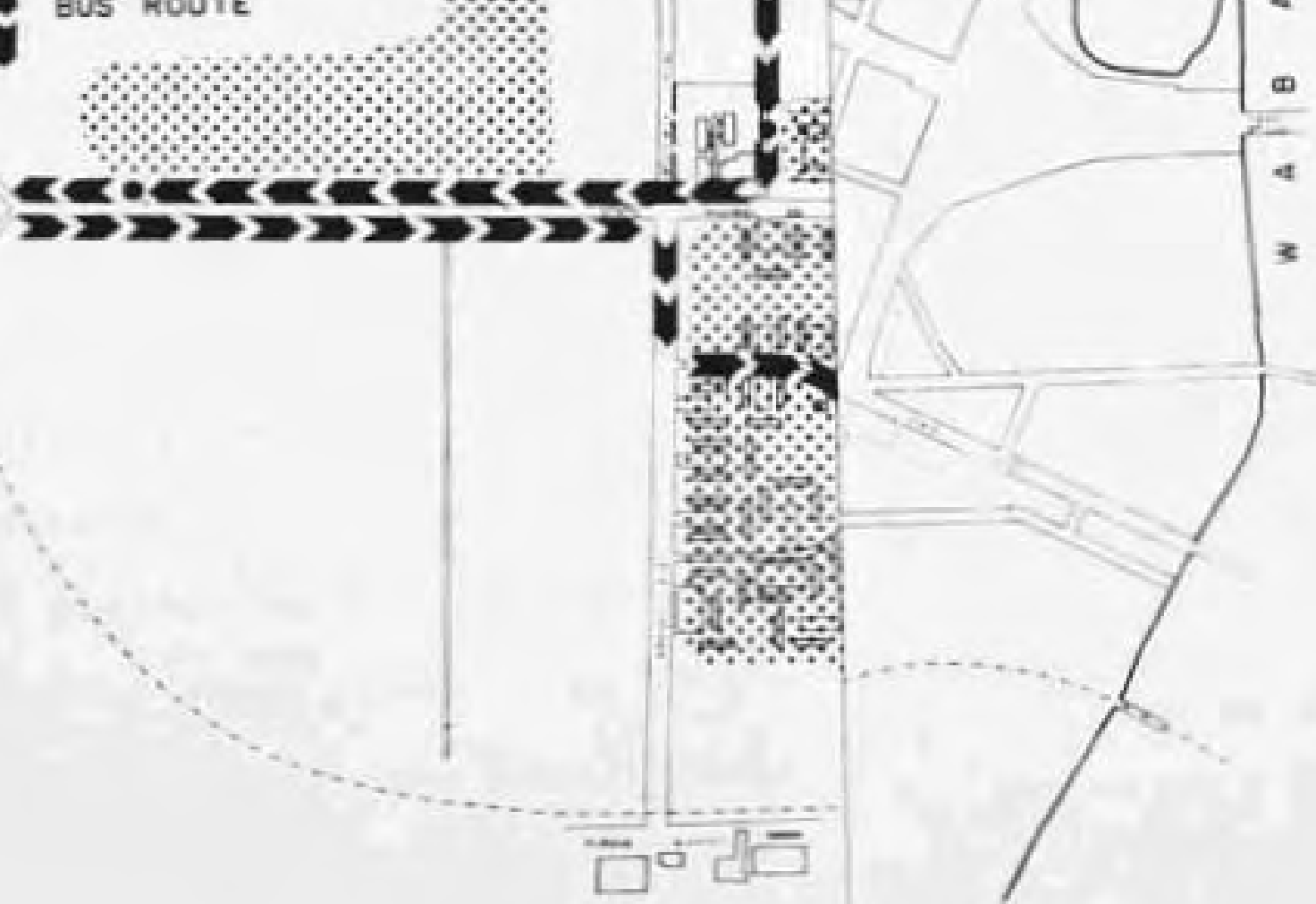

FIGURE 23 - ALTERNATIVE PLANNE) 


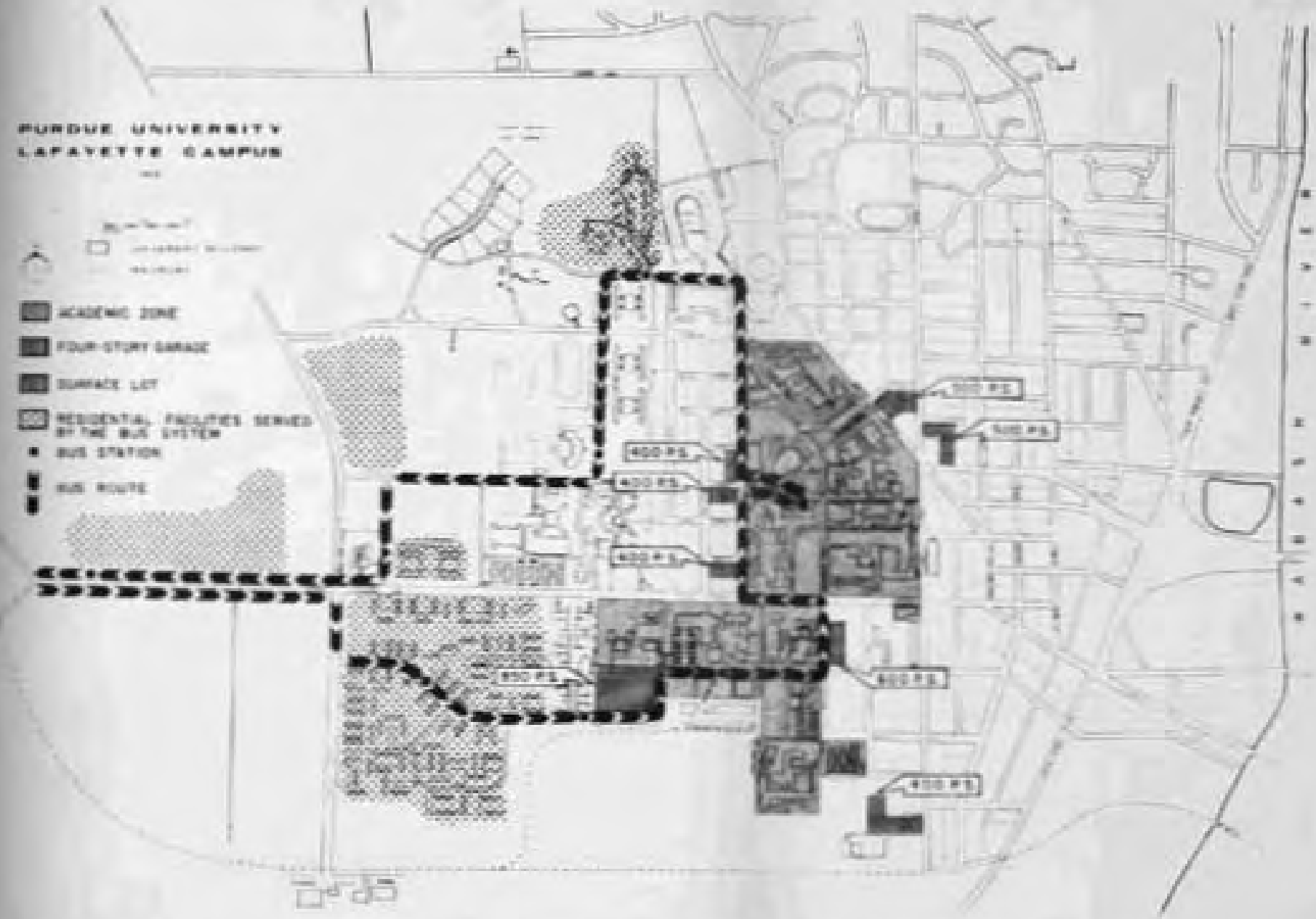

FIGURE 23 - ALTERNATIVE PLAN II/2 - (COMMUTING TO AND FROM THE ACADEMIC ZONE) 
According to this bus route, the round trip would be about five miles long. The types and locations of the parking facilities provided around the academfc zone are not much different from those proposed in alternative $11 / 1$. Their capacities, however, are reduced by about 600 spaces assuming that all peak-hour non-pedestrian commuters living in university housing facilities will use the proposed bus syster to the academic zone instead of their private autonobiles. The peak load on the bus system is estimated as equal to the number of student auto trips nade by students living in university housing facilities to the academic zone around $8: 30$ a.m.* This peak $10 a d$ was found to be about 430 passengers and is expected to occur shortly before $8: 30 \mathrm{a}, \mathrm{m}$.

The requirements of the bus system were estimated on the basis of the following operational criteria:

1. The system should be able to move a peak load of about 430 passengers from university housing facilities to the acadenic zone in not more than twenty minutes.

2. A minimum headway of about three minutes and a maximum of about ten minutes were allowed.

3. The systen is used fron 7:00 a.m. til1 6:00 p.m. on average weekdays and from 7:00 a,m. to 12:00 noon on Saturdays and only on days when classes are in session.

* Estimation of the peak load on the bus system is discussed in detail in Chapter II. 
4. The average speed of the bus on the round trip is about eight miles per hour including stops and time allowed between trips (determined by field tests over the proposed route with reasonable loading, unloading, and terninal stops).

5. The peak occupancy of the bus is about seventy passengers (25).

On the basis of these criteria and the estimated peak load, nine bus units would be needed. The detailed estimates of the requirements of the system and the annual cost of implementing alternative $11 / 2$ appear in Appendix B section 3 .

\section{Alternative $1 \mathrm{I} / 3$}

Unlike alternatives $11 / 1$ and $11 / 2$, in this alternative, no additional parking facilities are provided around the academic zone. Instead, parking is provided in relatively remote locations and bus systems are operated to move parkers from these renote parking facilities to the academic zone. Two types of bus systems were compared: (1) a regu1 ar street bus system, and (2) a new transportation device known as the skybus. Sub-alternative $11 / 3-A$ proposes two renote parking facilities both connected to the acadenic zone by neans of street bus systems. Sub-alternative $11 / 3-B$ proposes the same parking facilities. Of these, one is connected to the acadenic zone by a street bus syster while the other is connected by a skybus system. The two 
sub-alternatives (A and $B$ ) are developed primarily to compare the two types of bus systems.

In choosing the locations of remote parking facilities, several sites were considered: (1) the Ross Ade Stadium parking lot, (2) the gravel pit south of the academic zone, (3) the intramural field west of the acadenic zone, and (4) the open space at the corner of Afrport Road and State Street west of the earried students courts. The gravel pit was discarded quickly because of its poor access and since its use would require a large amount of fill. Also to preserve the continuity of open spaces north of the single student housing facilities on state street, the intramural field was not chosen for use as a parking facility. Thus the Ross Ade Stadfut and the Airport Road locations were chosen. These locations have two advantages: (1) they abut the two main traffic approaches to the academic zone; namely, Northwestern Avenue and State Street, and (2) their proximity to university housing facilities (especially married students' housing) will probably encourage residents of these facilities to commute by the connecting buses and thus reduce the student demand on parking around the academic zone (and in the remote parking facilities). In deciding on which kind of parking facilities to provide at these locations the assumption was made that since these sites are presently owned by the university, their use would require no land cost. Under this assumption, surface parking was found to 
be the least expensive and was thus used.

It was earlier estimated that, in the future, 4330 parking spaces will have to be provided to meet the denand for commuting to the academic zone. If all non-pedestrian conmuters living in university housing facilities use the bus systens connecting the remote parking facilities to the acadenic zone, this estinate is expected to be reduced to 3730 parking spaces. These were distributed between the two remote parking facilities in such a way that both of the bus systems connecting these factlities to the academic zone vould carry an equal peak student load. Thus 2100 parking spaces were provideci in the Ross Ade Stadium parking facility and 1630 in the Airport Road facility.

The expected peak student load on both bus systems was earlier estimated to be about 2150 students* (around $8: 30$ a.m.). In this alternative, each system carries a peak student load of about 1075 students. Having chosen the 10cations of the remote parking facilities, determined the capacity of each, and established the peak load on the bus systems connecting them to the academic zone, the two types of bus systems were compared.

Sub-Alternative II/3-A. In this sub-alternative, two street bus systens were provided between the remote parking facilities and the acadenic zone. Figure 24 shows the

* Estination of the peak load on the bus systens is discussed in detail in Chapter II. 
PURDUE UNIVERSITY LAFAYETTE CAMPUS

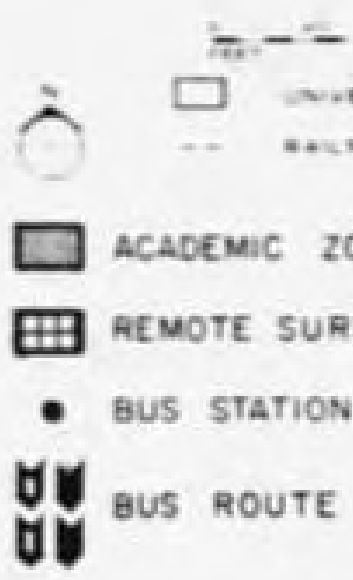

- Bus station.

UY BUS ROUTE dy

\section{ONE}

RFACE LOT

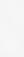



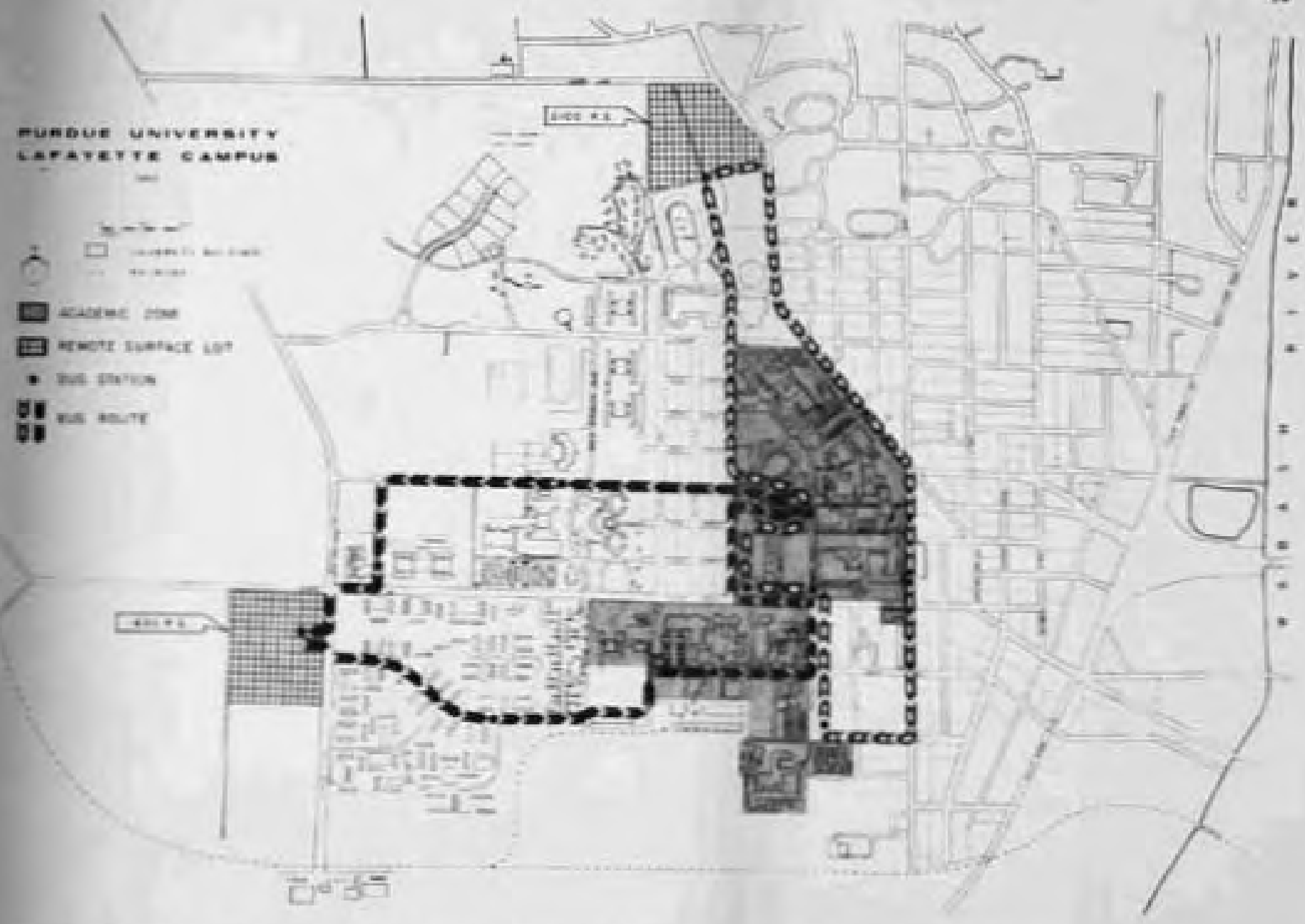

FIOURE 24 - SUE-NLTERNATIVE II/3-A - (COMMUTING TO AND FROM THE ACADEMIC ZONE) 
locations of the parking facilities and the proposed bus routes. In both bus systems, the round trip length is about 3.2 miles. The requirments of each of these systems were estinated on the basis of the following operational criteria.

1. The system needed to move a peak load of about 1075 passengers from the parking facility and from the university housing facilities located along its route to the acadenic zone in not more than thirty ninutes.

2. A minimum headway of about two minutes and a maximum of about five minutes are allowed.

3. The system is used from 7:00 a.m. till 6:00 p.m. on average weekdays and from $7: 00$ a.m. t 111 12:00 noon on Saturdays when classes are in session, and from $7: 30 \mathrm{a} . \mathrm{m}$. to $5: 30 \mathrm{p}, \mathrm{m}$. On average weekdays when classes are not in session.

4. The average speed of the bus on the round trip is about eight miles per hour including stops and time allowed between trips.

5. The peak occupancy of the bus is about seventy passengers (25).

On the basis of these criteria and the estimated peak load, thirteen bus units would be needed for each system. The detalled estinates of the requirenents of the bus systems and the annual cost of inplementing sub-alternative $11 / 3-A$ appear in Appendix B - section 4. 
Sub-A1ternative $11 / 3-B$. A number of new intraurban transportation devices are presently being developed and tried. Questions are often raised as to their efficiency, economy, and advantages. This sub-alternative used an elevated skybus systen to connect the Ross Ade Stadiun parking Tot to the acadenic zone. In this way, the sub-alternative provided a basis for evaluating the advantages of the device in meeting future demand for commuting to the academic zone. The skybus is basically a bus running on an exclusive elevated roadway. The operation of the system is fully automatic. Its vehicles can be run singly or in trains (26). The system was selected from anong a number of other new transportation devices (e.g., moving sidewalks and carveyors) as its operational characteristics were found suitable for the situation at hand.

Figure 25 shows sub-alternative plan $11 / 3-B$. Apart from the proposed roadway for the elevated skybus system connecting the Ross Ade Stadium parking lot to the acaderic zone, all other elements of this plan are identical to those of sub-alternative $11 / 3-A$. In Figure 25 , the skybus round trip is about $2.6 \mathrm{miles}$ long. The requirements of the system were estimated on the basis of a peak load of 1075 passengers and according to the following operational criteria:

1. The systen should be able to move a peak load of about 1075 passengers from the Ross Ade Stadiun parking lot to the acadenic zone in not more than twenty minutes. 
PURDUE UNIVERSITY

LAFAYETTE CAMPUS

an:

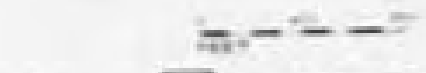

$8 \square$ antests

ACADENIC ZONE

E\# REMOTE SURFACE LOT

- bus station

y bus route

a SKYBUS STATION

SKYBUS ROUTE
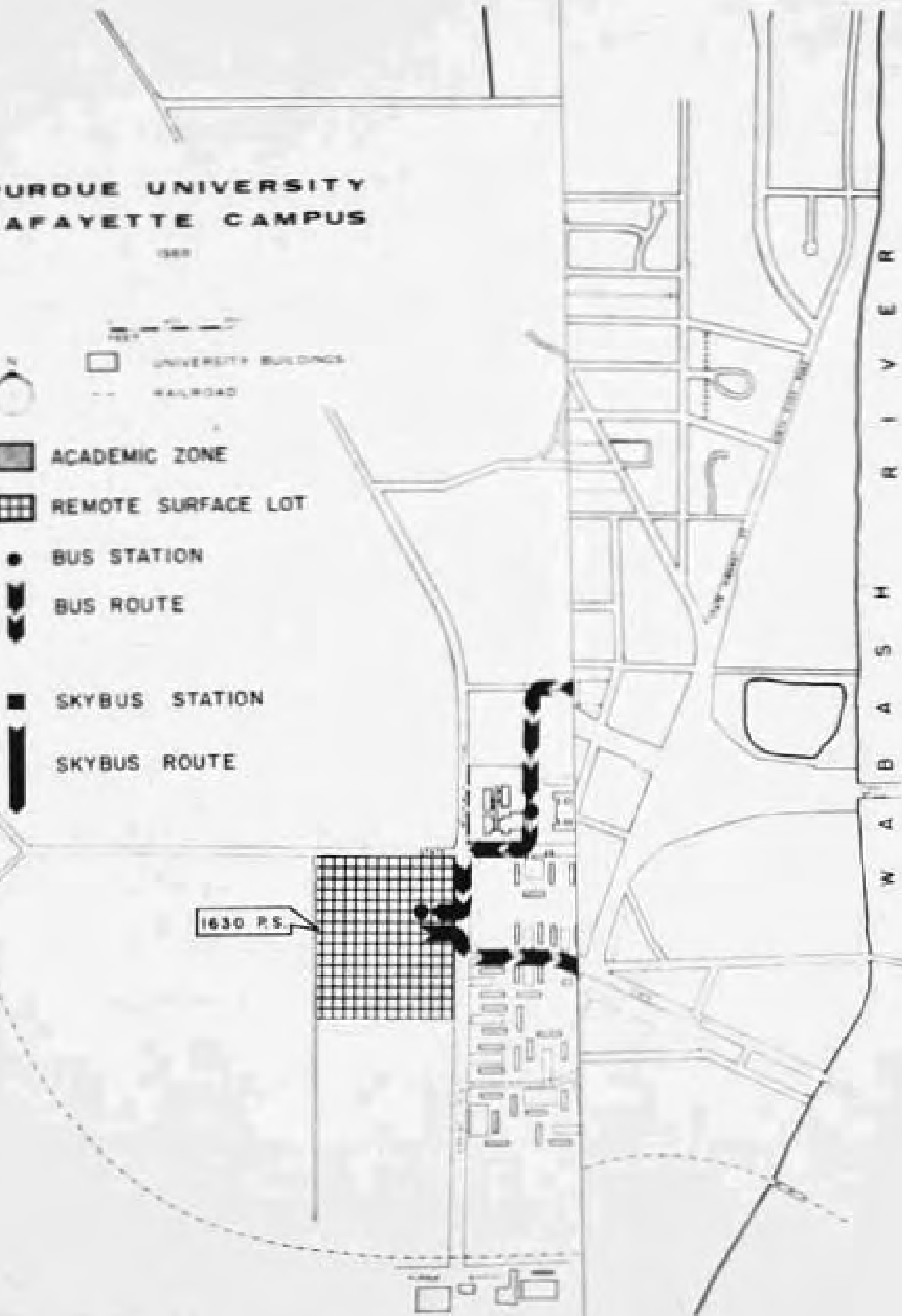

prenses
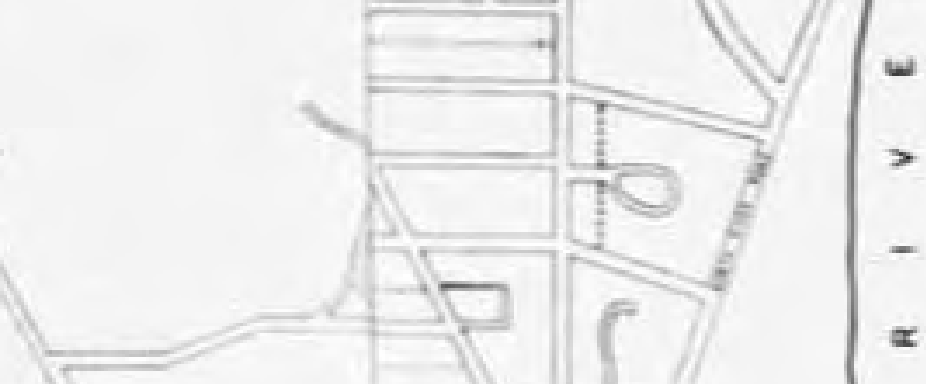

i 


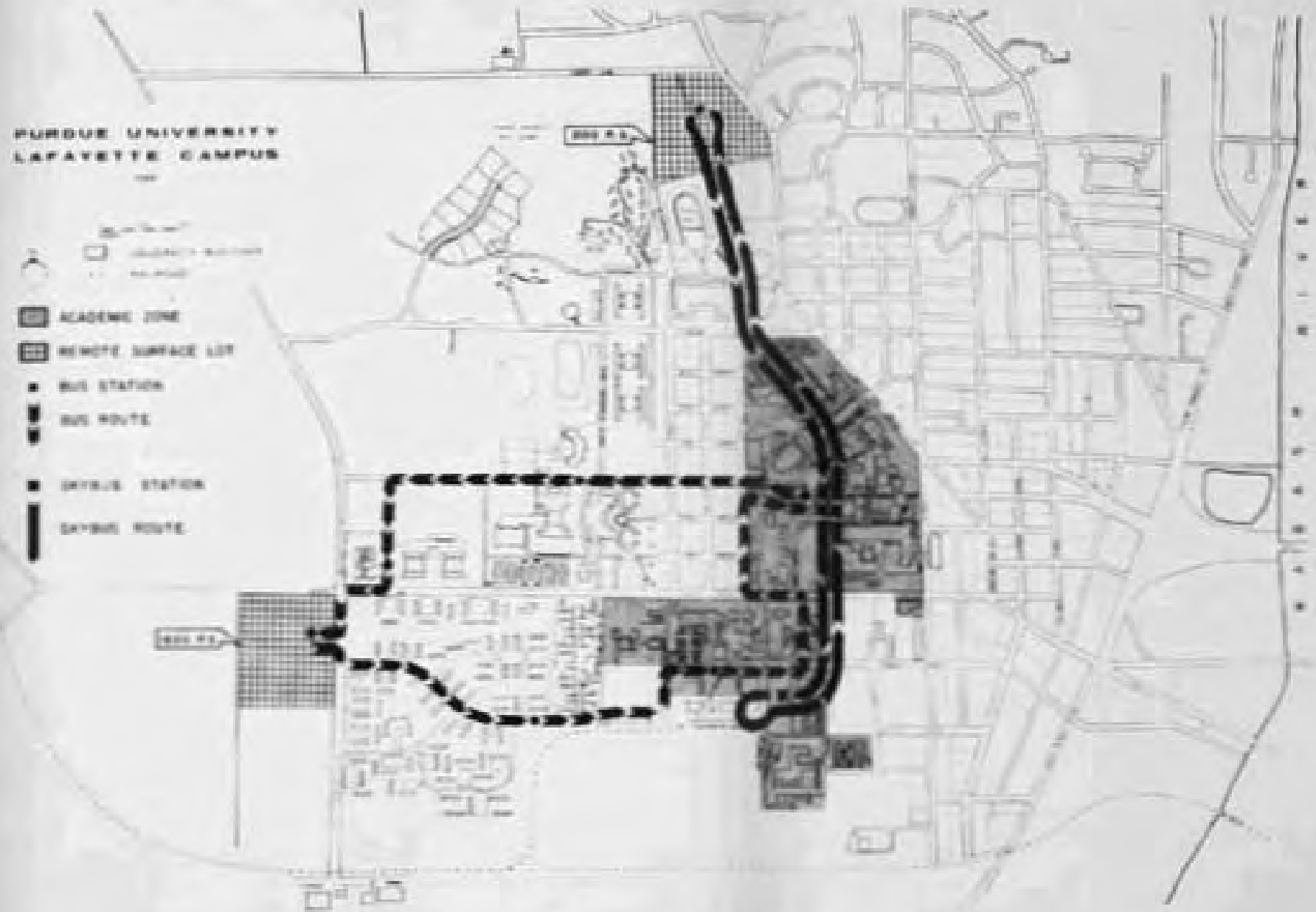

FIGURE 25 - SUB-ALTERNATIVE PLAN II/3-B - ICOMMUTING TO AND FROM THE ACADEMIC ZONE) 
2. A minimum headway of about two minutes and a maximum of about three minutes are allowed.

3. Two vehicles per train are used during peak use and only one during off-peak use.

4. The syster is used from 7:00 a.m. to $6: 00 \mathrm{p} . \mathrm{m}$. on average weekdays and from 7:00 a.m. to 12:00 noon on Saturdays when classes are in session, and from $7: 30 \mathrm{a} \cdot \mathrm{m}$. to $5: 30 \mathrm{p} . \mathrm{m}$. On average weekdays when classes are not in session.

5. The average speed of the skybus train is about 25 miles per hour including stops (26).

6. The peak occupancy per vehicle is about 50 passengers (26).

On the basis of these criteria and the estimated peak load, seven skybus vehicles would be needed. The detailed estimates of the requirements of the skybus system and the annual cost of fmplementing sub-alternative $11 / 3-B$ appear in Appendix B - section 4 .

Evaluation of Alternatives

In the following evaluation, two criteria are considered: convenience and cost. Because continuity in the circulation systerl, safety, and the potential for developing an aesthetically pleasing environment are about equally satisfactory in each of the alternatives, these criteria were not considered in the evaluation. 
Convenience was measured in terms of three factors:

1. the average trip time from parking facilities to the academic zone. In estimating these averages, the focal point on the acadenic zone was taken as the hypothetical destination of all trips.

2. the average trip time from university housing facilitfes to the academic zone (focal point) if the mode of transportation fs other than walking the total distance.

3. the maximum delay expected in bus and skybus trips. In bus and skybus systems, headways cannot be reduced below a certain minimum, and vehicle occupancies cannot be raised above a certain maximum. Therefore, a certain period of time is required to move all passengers to their destinations during the peak hours. This period of time is here referred to as the maximum expected delay. Students, in order to reach their classes in time, have to start their trips from residences early enough to allow for at least a portion of this maximum expected delay. Obviously, the higher this maximum expected delay, the less convenient the system becomes.

The alternatives are also evaluated in terms of their annual costs. This includes the annual costs of investment (construction and equipnent) as well as the annual costs of 
maintenance and operation. The detailed estimates of these annual costs appear in Appendix B. Table 5 gives, for each alternative, the average trip time from parking facilities to the acadenic zone, the average trip time from university housing facilities to the acadenic zone, the maximum expected delay, and the estinated annual cost.

In terms of the three measures of convenience used in this evaluation, alternative $11 / 1$ appears to be the most convenfent, and sub-alternative $I I / 3-A$ the least convenient. Unlike what is generally believed, the use of the skybus in sub-alternative $11 / 3-B$ was not as convenient as parking near destinations but was more convenient than the ordinary bus system. The inefficiency of providing intermediate stops along the roadway, however, requires that students living in university housing facilities walk to the terminal point to be able to use the system. Because of this, the system tends to lose one of its basic advantages, namely, high speed for residents of university facilities. From Table 5, it can also be noted that in alternatives $11 / 2$ and $11 / 3$, the possible maxfmum delays expected in bus and skybus trips represent a definite inconvenience. This inconvenience is totally absent in alternative $I I / 1$ (assuming adequate parking space is provided). In terms of cost, Table 5 shows that subalternative $11 / 3-A$ has the lowest estimated annual cost while sub-alternative $I 1 / 3-B$ has the highest. However, alternatives $11 / 1$ and $11 / 2$ are very close, in annual cost, to alternate $11 / 3-A$. 


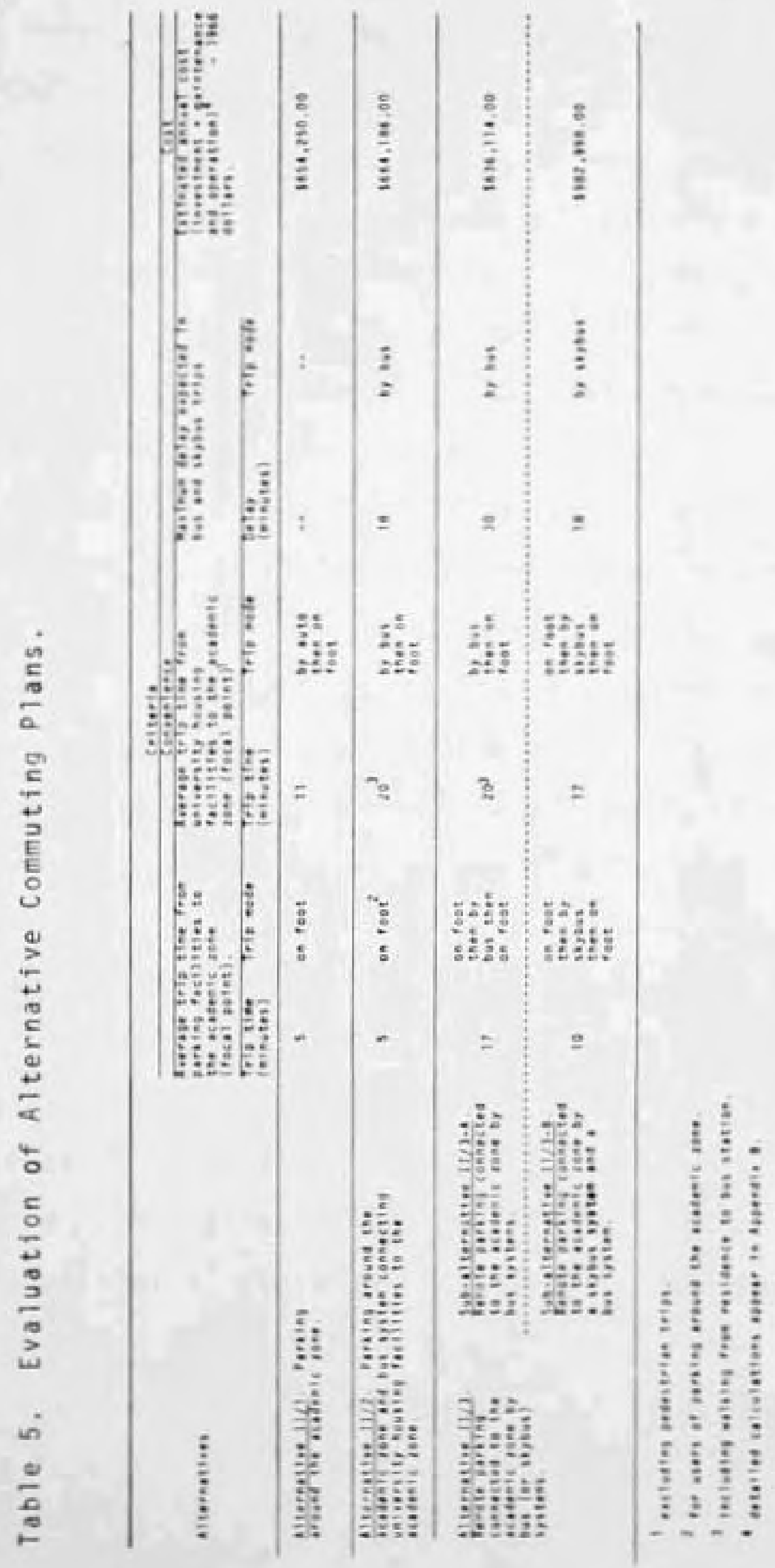


When the alternatives are evaluated on the basis of convenfence and cost together, it is clear that alternative $I I / 2$ and sub-alternative $11 / 3-B$, because of their higher annual costs and/or lower levels of convenience (in terms of the three measures indicated above) would rank lower than alternative $11 / 1$ and sub-alternative $11 / 3-A$. By Iiniting the evaluation to alternative $11 / 1$ and sub-alternative $11 / 3-A$ (on the grounds of their superiority) and by comparing their advantages and disadvantages, it can be seen that one offers a lower annual cost while the other offers a higher level of convenience. The comparison is obviously one between quantity and quality, and as such, it is objectively unfeasible. It can be concluded that in order to decide which of the two alternatives is more appropriate (in terms of the criteria set above), subjective value has to be assigned to the factor of convenience. Such an assignment should be inade in accordance with standards and policies adopted by the university. The cost of alternative II/1, however, is not much greater than that of sub-alternative II/3-A while the convenience provided by alternative $11 / 1$ is much greater than that offered by sub-alternative II/3-A. On this basis, it is expected that alternative $11 / 1$ would be selected as the best plan by most decision-makers. 
CHAPTER IV. CONCLUSIONS AND RECOMMENDATIONS

This study was directed toward the investigation of some aspects of the transportation problems on the Purdue Lafayette campus, the estination of a number of its future transportation requirements, and the formulation of alternative plans to meet these requirenents. On the basis of the findings of this study, the following conclusions and recommendations appear justified.

\section{Conclusions}

1. Based on the opinions of the university faculty and the potential capacity of the existing physical plant, an ultimate future enrollment of about 35,000 students seems reasonable. It is expected that about 35 percent of this ultimate enrollment would be graduate students and about 26 percent would be married students. For this uitimate enrollment, it is estimated that the unfversity will eniploy about 9,450 ful1-tine staff members.

2. On the basis of the envisaged university housing polfcy and the observed trend of student demand on university housing, it is estimated that, in the future (i.e., when the ultimate enrollment is attained), the university will provide housing for 
about 55 percent of the undergraduate single students, 40 percent of the graduate single students, and 40 percent of the married students (graduate and undergraduate).

3. Analysis of the pedestrian circulation in and around the academic zone indicates that:

a. the existing layout and use of the instructional facilities in the academic zone do not provide conditions of minimum pedestrian movenent. A number of instructional facilities with high frequency of use are located on peripheral sites while some conveniently accessible central 10cations are used for facilities that are not used (or infrequently used) for instruction. This tends to decrease the efficiency of pedestrian circulation in the academic zone.

b. pedestrian-vehicle conflifts exist and are expected to increase at a number of locations in the academic zone, and especially on state Street. Around the academic zone, Dedestrianvehicle conflicts are expected to significantly increase on University and Russel Streets between First and Third Streets and on Stadium Avenue south of Cary Hall.

4. Four interrelated student population characteristics were found to influence student demand on parking 
around the academic zone: (1) size and composition of student population, (2) daytime population of students in the academic zone, (3) student behavioral patterns in using their automobiles to commute to the academic zone, and (4) the residential distribution of students on and around the campus. Forecasts were made for these four characteristics for the future. The future student demand for parking around the academic zone was also estimated from these student population characteristics. A student parking demand forecasting model thus developed indicated that the student demand for parking around the acaderific zone is expected to be about 3,685 parking spaces for the ultimate enroliment.

5. On the basis of the observed trend $(1963-1967)$ in the number of parking spaces per full-time staff member working in the academic zone, future staff parking demand was estimated to be about 6,650 parking spaces. It was also estimated that 330 parking spaces will be needed for visitors' use.

6. It is expected that the parking facilities presently operated by the university in and around the academic zone, and an additional 1000 on-street free parking spaces around the academic zone will remain in use by commuters in the future. Thus, a net additional 4,330 parking spaces will be required 
(for the future) to meet the parking demands of students, staff, and visitors at the time of ultimate enrollment. If these are provided in remote parking facilities, a bus system would be required to move the parkers to the academic zone. The peak load on such a system is estimated to be about 2,150 passengers in a 30 -minute period.

7. Of the alternative plans developed to meet the future demands for commuting to and from the academic zone, two appear to offer reasonable solutions. In terms of annual cost, a plan that provides the net future parking demands of students, staff, and visitors in surface lots and multi-story garages on close-by 10cations around the academic zone (alternative II/1), would involve an estimated annual cost of about $\$ 654,250.00$ An alternative plan that provides the same future parking demands in two surface lots located north of Ross Ade Stadium and on the southwest corner of Airport Road and State Street and connected to the acaderic zone by two street bus systems (sub-alternative $11 / 3-A$ ), would require an estimated annual cost of about $\$ 636,114.00$. When convenience was measured by the average trip time from parking facilities to the academic zone, by the average trip time from university housing facilities to the academic zone, and by the maximum delay 
expected for bus trips, it was found that the former offers a much higher level of convenience than the latter. On the basis of cost and convenience, it is expected that the former (alternative II/1) would be selected as the best plan by most decision-nakers.

\section{Recommendations}

1. To maximize the efficiency of pedestrian circulation in the acadenic zone, it is recommended that:

a. non-instructional facilities presently occupying central locations and having mininal functional linkages with other instructional facilities (e.9., Engineering Administration building, the power plant, and Agricultural Experiment Station) be, whenever feasible, relocated to make room for future instructional uses.

b. infrequently used instructional facilities located in the central area be put to more intensive use in the future (e.9.. Pierce Conservatory, Michael Golden Shops, and the Aeronautical and Engineering Sciences building).

c. future instructional facilities planned for intensive use be centrally located (within 1100 feet of the focal point) whenever possibie.

d. the possibility of using centrally located factifties by functions (lecture halls, laboratories, offices, etc.) rather than by najor field 
(Chemistry, Education, Electrical Engineering, etc.) be investigated as a means of reducing the number of problematic pedestrian trips (which cannot be walked within the time-break allowed between classes).

2. To minimize future pedestrian-vehicle conflicts in and around the academic zone, it is recommended that:

a. through vehicular traffic be eliminated on the north campus.

b. vehicular traffic on Stadium Mall be eliminated or 1 imited to one way in the south direction.

c. vehicular traffic and curb parking be eliminated on Oval Drive (between Memorial Mall and State Street), Menorial Mall (between Purdue Mall and Central Drive), Central Drive (between the Chemistry building and Stanley Coulter building) and south of the Hall of Music.

d. an open pedestrian underpass connecting the north and south campuses be provided under state Street along the east side of the Home Economics Administration buflding.

e. a study be made of the pedestrian-vehicular conflicts on state street resulting from the gradwate housing complex south of State Street. 
f. provision for separated pedestrian crossing be studied and appropriate traffic controls be used on Russell and University Streets at Secand Street to secure safe crossings for the heavy concentrations of pedestrians at these locations

3. It is recommended that the future demands for nonpedestrian comnuting to and from the acadenic zone be met by implementation of adequate plans. On the basis of cost and convenience as analyzed in this study, alternative $p 1 a n 11 / 1$ appears to be best. 
LIST OF REFERENCES 


\section{LIST OF REFERENCES}

1. Jakad, Millian, "Committee Controls Traffic Step-byStep," College and University Business, Vol. 32, June 1962 , p p. 47-52.

2. Educational Facilities Laboratories and Duke University, Computer Aided Campus Planning, Educational Facilities Laboratories, New York, New York, 1967.

3. Bartholomew, Harland and Associates, A Traffic and Parking Analysis, The Ann Arbor Thoroughfare Plan in Relation to University of Michigan Central Campus Study, University of Michigan, Ann Arbor, Michigan, 1964 .

4. Bartholomew, Harland and Associates, Long-Range Traffic and Parking Plan, University of Mississippi, University of Mississippi, Mississippi, 1963.

5. Dober, Richard P., Campus Planning, Reinhold Publishing Corporation, Cambridge, Massachusetts, 1963.

6. Bartholomew, Harland and Assoctates, Long-Range Parking plan for the University of Illinots, University of Illinois, Urbana, I17inois, 1962 .

7. Marconi, William, "A Study of Parking Meeds at Two Urban Campuses," Traffic Engineering, Vo1. 38, July 1968, PP. $50-51$.

8. Pendakur, V. Setty, "Access, Parking, and Cost Criteria for Urban Universities," Traffic Quarterly, Vol. 22, July 1968 , PP. 359-387.

9. Purdue Unfversity, "Student Contact Hours by Type of Instruction by Type of Roon," (May 1967 and November 1967), Unpublished Material, Office of Schedule and Space, Purdue University, Lafayette, Indiana.

10. Egner, Anton J., "How Big Can You Get?" College and University Business, Vol. 37, November 1964, PP. 57-61.

11. Purdue University, "Enrollment Reports," (for Fal1 and Spring Senesters during the period 1956-1967), Unpublished Material, Office of the Registrar. Purdue University, Lafayette, Indiana. 
12. Jackson, R. H. B., The Problem of Numbers in University

Enrollment, Canadian Education Association and the Department of Educational Research, Bulletin No. 18, Canada, 1963.

13. Martin, Warren B., "The Problen of Size," The Journal of Higher Education, Vol. 38, March 1967, PP. 144-152.

14. Purdue University, "Faculty Questionnaire on University Policies Affecting Development of Master Plan of University." Unpublished Material, Purdue University, Lafayette, Indiana, 1968.

15. Purdue University, "Inventory of Total and Assigned Areas Per Buflding," Unpublished Material, Office of Schedule and Space, Purdue University, Lafayette, Indiana, Decenber 1967.

16. Purdue Universfty, "Statistical Reports," (Fall semesters during the period 1963-1967), Unpublished Material, Comptroller's office. Purdue University, Lafayette, Indiana.

17. Purdue University, "Student Contact Hours - Each Building by day by Hour." (Fall senesters 1966 and 1967, Spring semesters 1967 and 1968), Unpub1ished Material, Office of Schedules and Space, Purdue University, Lafayette, Indiana.

18. Purdue University, "Statistical Reports," (1962 through 1967), Unpublished Material, Office of Libraries, Purdue University, Lafayette, Indiana.

19. Purdue University, "Statistical Reports," (1965 through 1967), Unpublished Materials, Foods Department, Purdue University, Lafayette, Indiana.

20. Purdue University, "Ten-Year program of Traffic Facil-

ities for Purdue University, " Unpublished Material, Committee on Parking and Movecent, Purdue University, Lafayette. Indiana, 1963 (and supplemented in 1964 through 1968).

21. Purdue University, "Number of Students Living in Different Housing Facilities on and Around the Lafayette Campus," Undublished Material. Dean of Men's Office, Purdue University, Lafayette, Indiana, November 1967.

22. Purdue University, "Statistical Reports," (Fal1 semesters of 1963 through 1967), Unpublished Material, University Residences' Office, Purdue University, Lafayette, Indiana. 
23. Purdue University, "Student Information," Unpublished Material, Data Processing Department, Purdue University, Lafayette, Indiana, Spring Semester 1968.

24. French, David K., "A Simplified Procedure for Major Thoroughfare Planning in Small Urban Areas," an Unpublished Master Thesis, Civil Engineering School, Purdue University, Lafayette, August 1968.

25. Berry, Donald S., G. H. Blomme, P. W. Shuldiner and J. H. Jones, The Technology of Urban Transportation, Northwestern University Press, 1967.

26. MPC Corporation, Report on Testing and Evaluating of the Transit Expressway, Allegheny County, Pittsburgh, Pennsylvania, 1967.

27. Michae1, H. L. "Factors in the Economics of Parking and Bus Systems," An Unpublished Inter Office Memorandum, School of Civil Engineering, Purdue University, Lafayette, Indiana, 1968.

28. Smith, Wilbur and Associates, Parking in the City Center, New Haven, Connecticut, 1965.

29. Hewes, L. I. and C. H. Oglesby, Highway Engineering, John Wiley and Sons, 1954, p. 60 , Table 5. 
APPENDIX A. SUMMARY OF RESULTS - FACULTY QUESTIONNAIRE ON UNIVERSITY POLICIES AFFECTING DEVELOPMENT OF MASTER PLAN OF THE LAFAYETTE CAMPUS OF PURDUE UNIVERSITY 
岕

w

는

는

뭉

긱

意

근

닌

므

$>$ 悉

롱

今

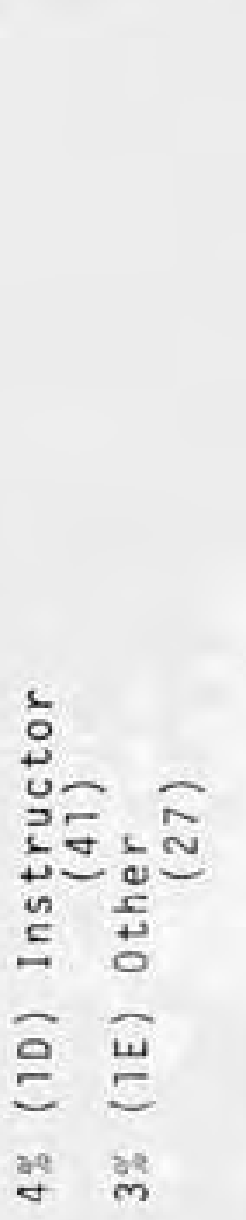

zo

山气

$\simeq \frac{1}{2}$

땅

$z$

Ow

반

ज出

世1>

단

$>s$

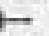

로폴

迎

4㟔

,

is

与모

जั०

พัฒ

它

范

$>4 \quad 4$

잉

ㄴ.

츤

ज电

응

$\dot{\alpha} \vec{w}$

$x \vec{u}$

$\Rightarrow$

을

แิ

음

$\frac{\ddot{0}}{\frac{2}{3}}$

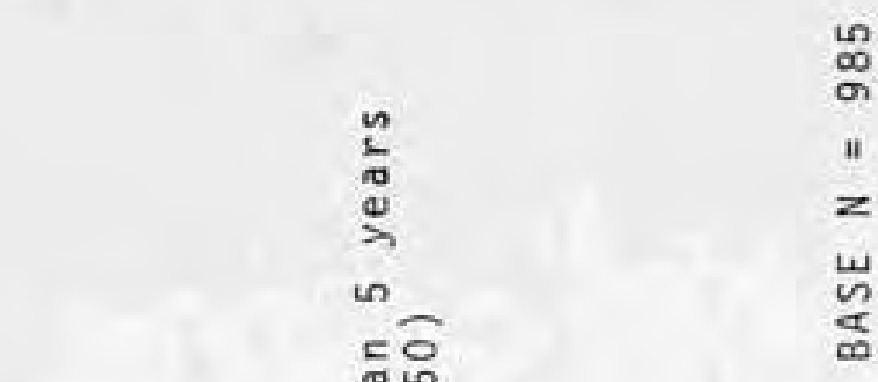

$\stackrel{12}{\infty}$

II

w

낭

ᄃm

..

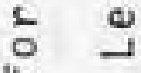

I

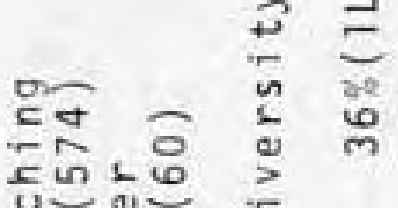

U-

¿ 5

I I

$\frac{\sum}{a}$ 음

a

4 언

$>$ เ

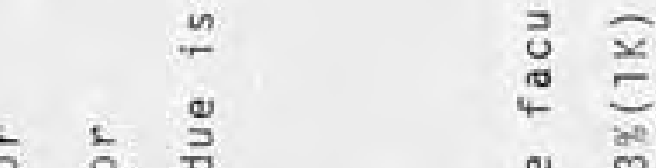

is is :

ક

$\frac{1}{5}$

\& \&

$\stackrel{4}{\circ}+$

- $\rightarrow$ के

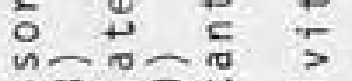

nm:-

ข $\mathrm{N}$ บ $\mathrm{G}$

๖

药它

$=0$

ᄃ

E己 的

$\therefore \leqslant n$

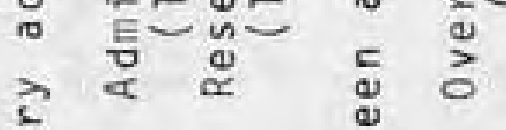

\%

का

ก

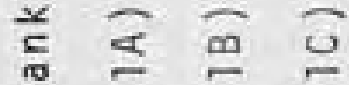

$==5$ 虫

$-\frac{1}{2}$

a $=$

2

$>$

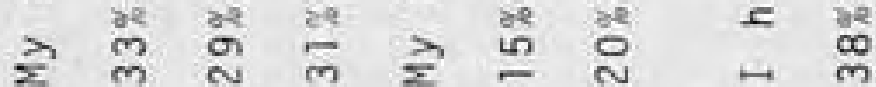

$\dot{\sim}$

$\dot{m}$ 


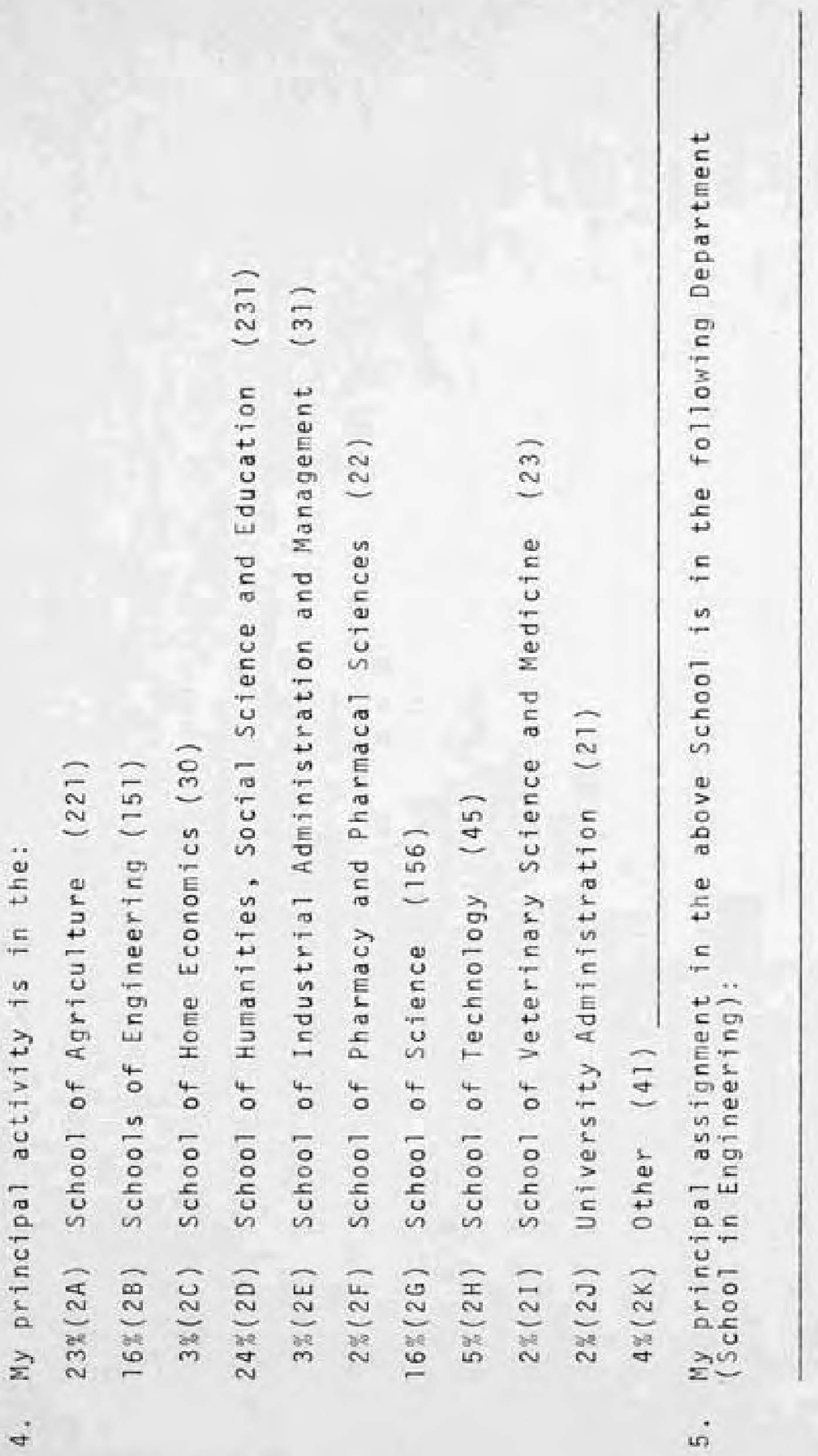


䒺

눙

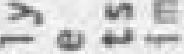

a $4=x$

40 웅

욜

$-6+4$

$\times 2 n=$

o ch

a 00

at in.

a

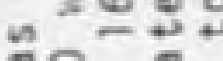

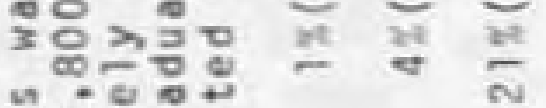

$\rightarrow:+0+2$

a. 0 O E

ETE E

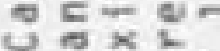

$$
\text { o } 40
$$

ข

it a

$4 \pi \pi 0=$

$\rightarrow 3-3$

$00 \%=0$

$4=\frac{1}{4} \mathrm{~m}$

10 $5 \frac{1}{3} 0$

L

(4) 4 क 03

워 돈엉

c

5.34

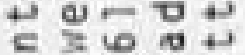

(4) 0 s 10

EO- on

$=-0 \div 4$

$0 \% \frac{1}{0}$

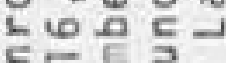

(1) 4 ब

$4+4=$

룽 $\frac{\Omega}{4}$

in

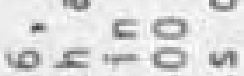

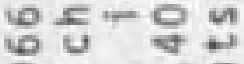

or $* \dot{c}$

$3 \mathrm{cor}-\mathrm{D}$ $\frac{1}{4}+10$ a 0 n 3 n

E 50

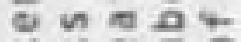

$4+400$

ac

c $3>\div$

인 $\quad \Rightarrow$ in

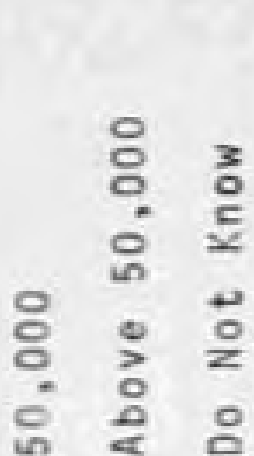

$\therefore$

to

$\therefore=\frac{1}{c}$

UE

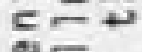

눙

난

in

gy $=0$

$0+1$

궁요

0

L E O

क्य

c)

(4) 0

$z=$

is 하의

遖

-

$=4 \frac{7}{0}$

in in

$+n$

E

ㅇㅇㅇ원

000

30

in 4 in

का क

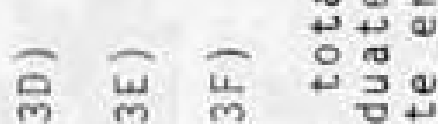

$m$ m

à as a2

N

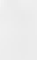<smiles>C1CCCCC1</smiles>

d) 0

다닐

405

$\Phi$

aq $\frac{\Phi}{3}=$

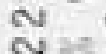

or 5

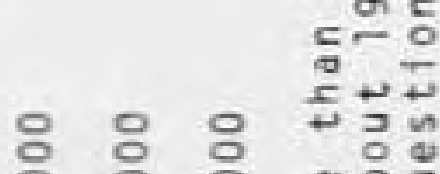

$\begin{array}{lllll}0 & 0 & 0 & +3 & 0 \\ \circ & 0 & 0 & 0\end{array}$

- i.

i m

잉

E $>$ 드

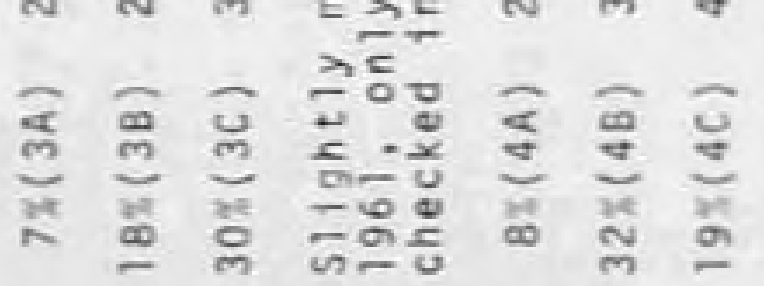

n

in 6 N $\infty$

in $>$

$\frac{\pi}{2} \frac{3}{6}$

$\geqslant \underset{c}{2}+2$

in is

$\frac{2}{3} 0$

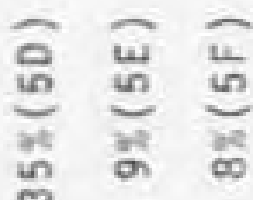

$\begin{array}{lll}2 & \text { ant } \\ 0 & 0 & 0\end{array}$

วิ $2 \frac{5}{3}$

$\forall$ \& 4 4

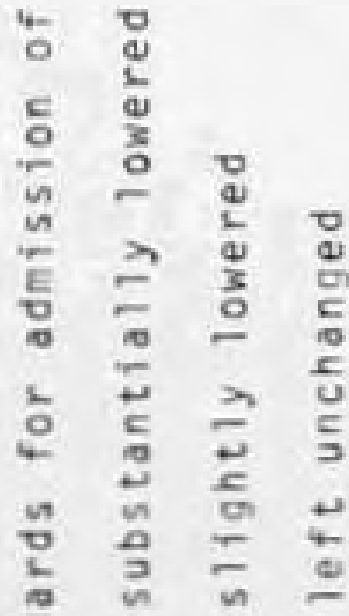

5

a) 20

in in an u

a is as

$\stackrel{0}{=} \mathrm{d}$ 


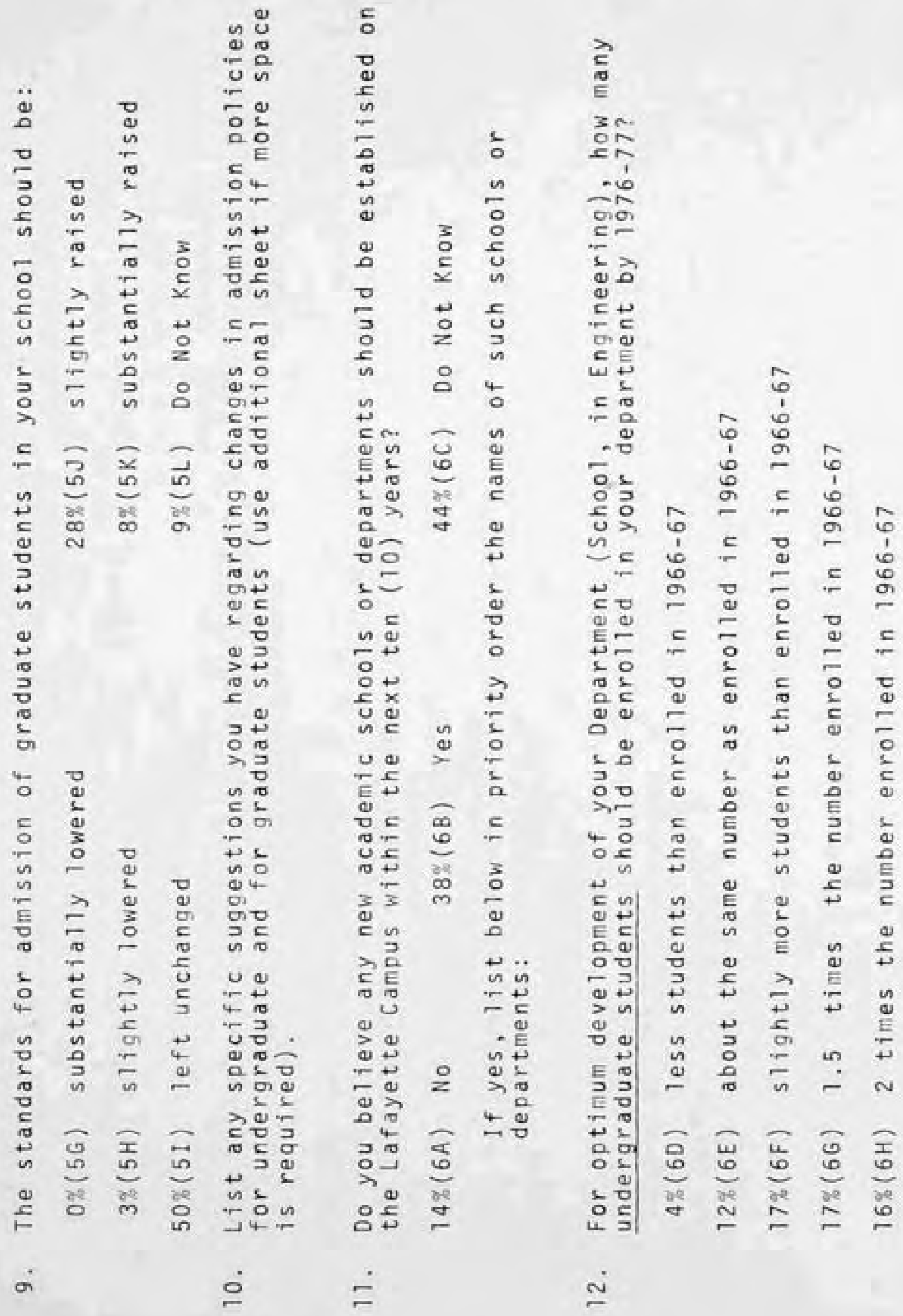




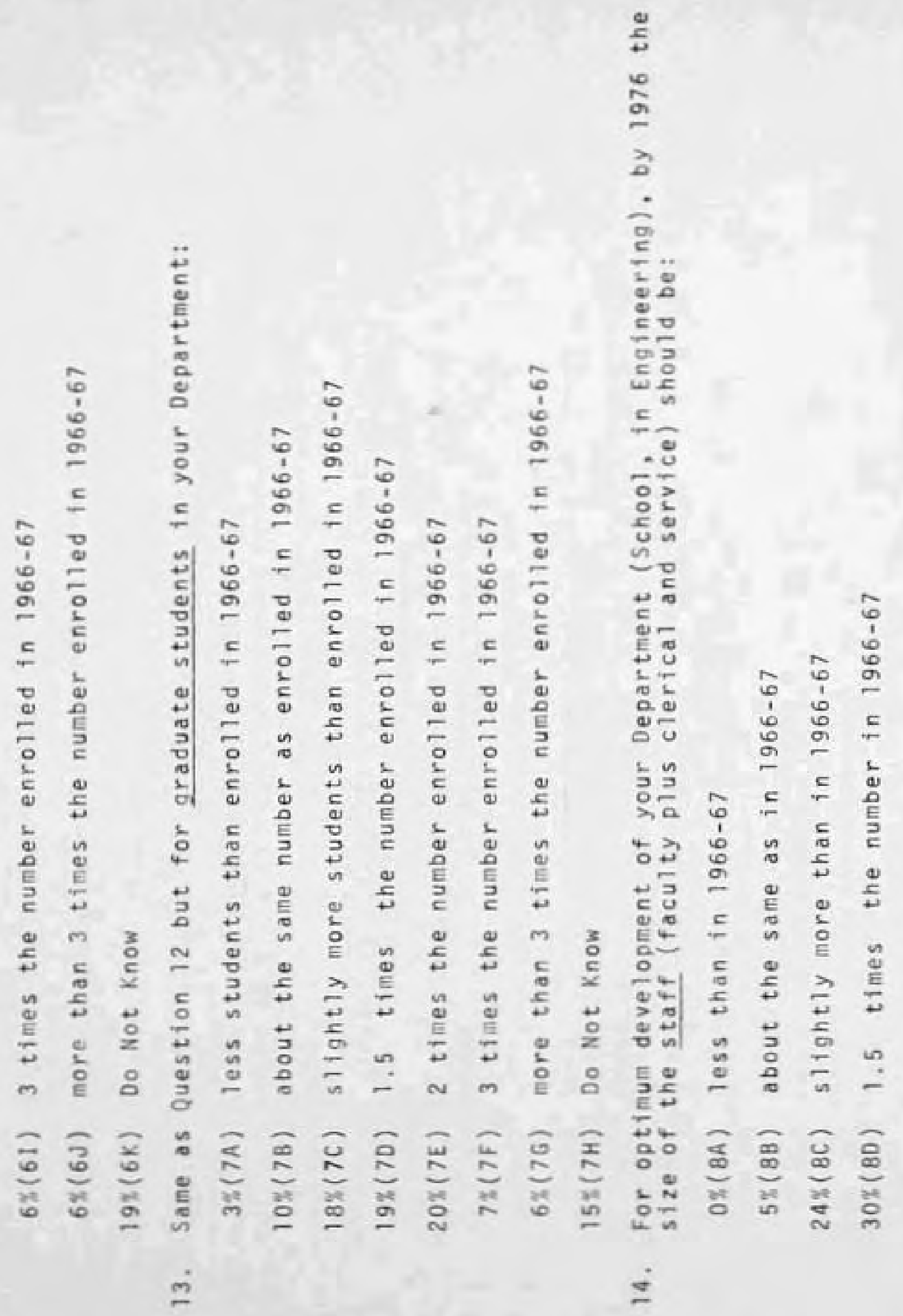




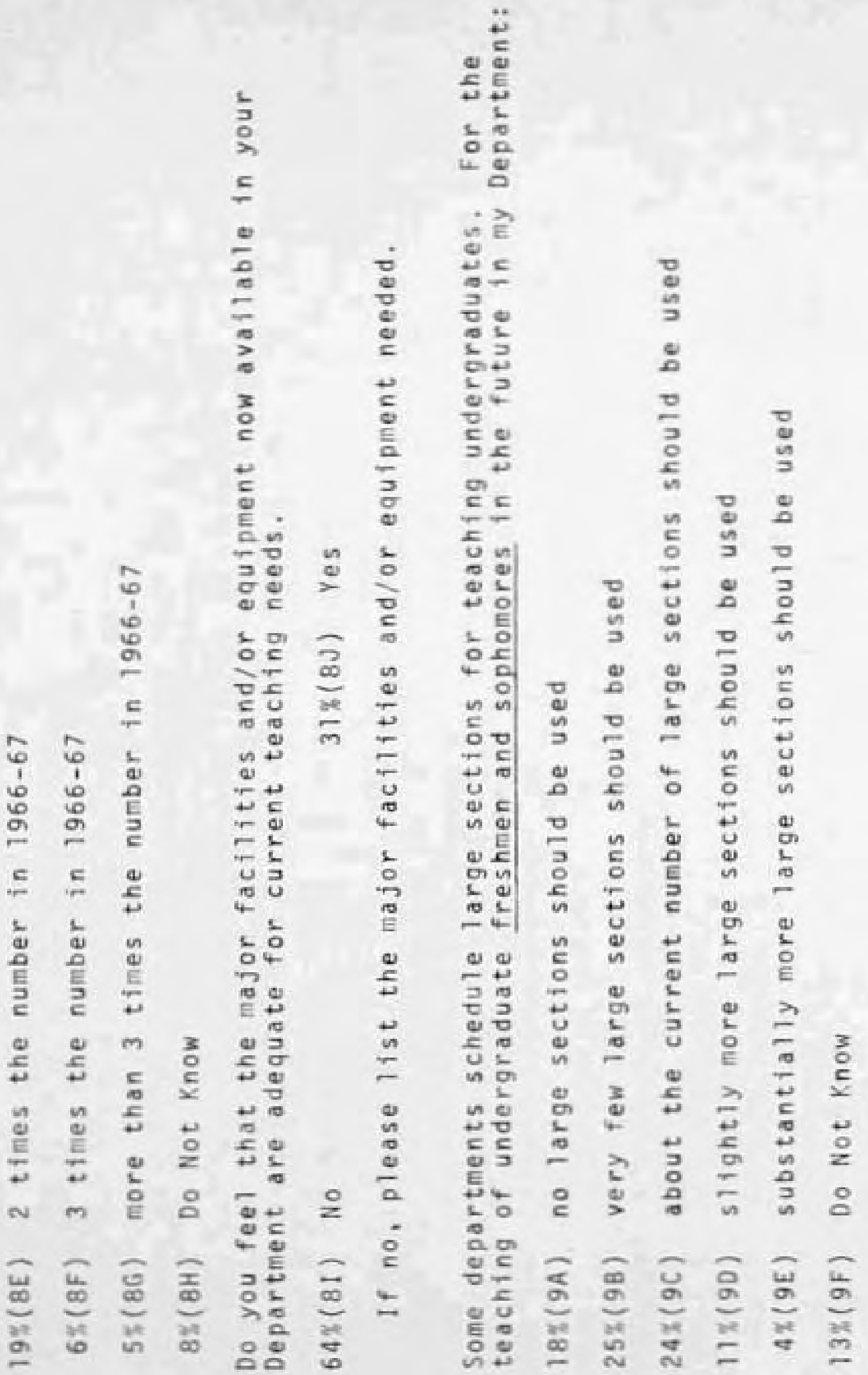

$$
\begin{aligned}
& \doteq \stackrel{\circ}{\circ}
\end{aligned}
$$




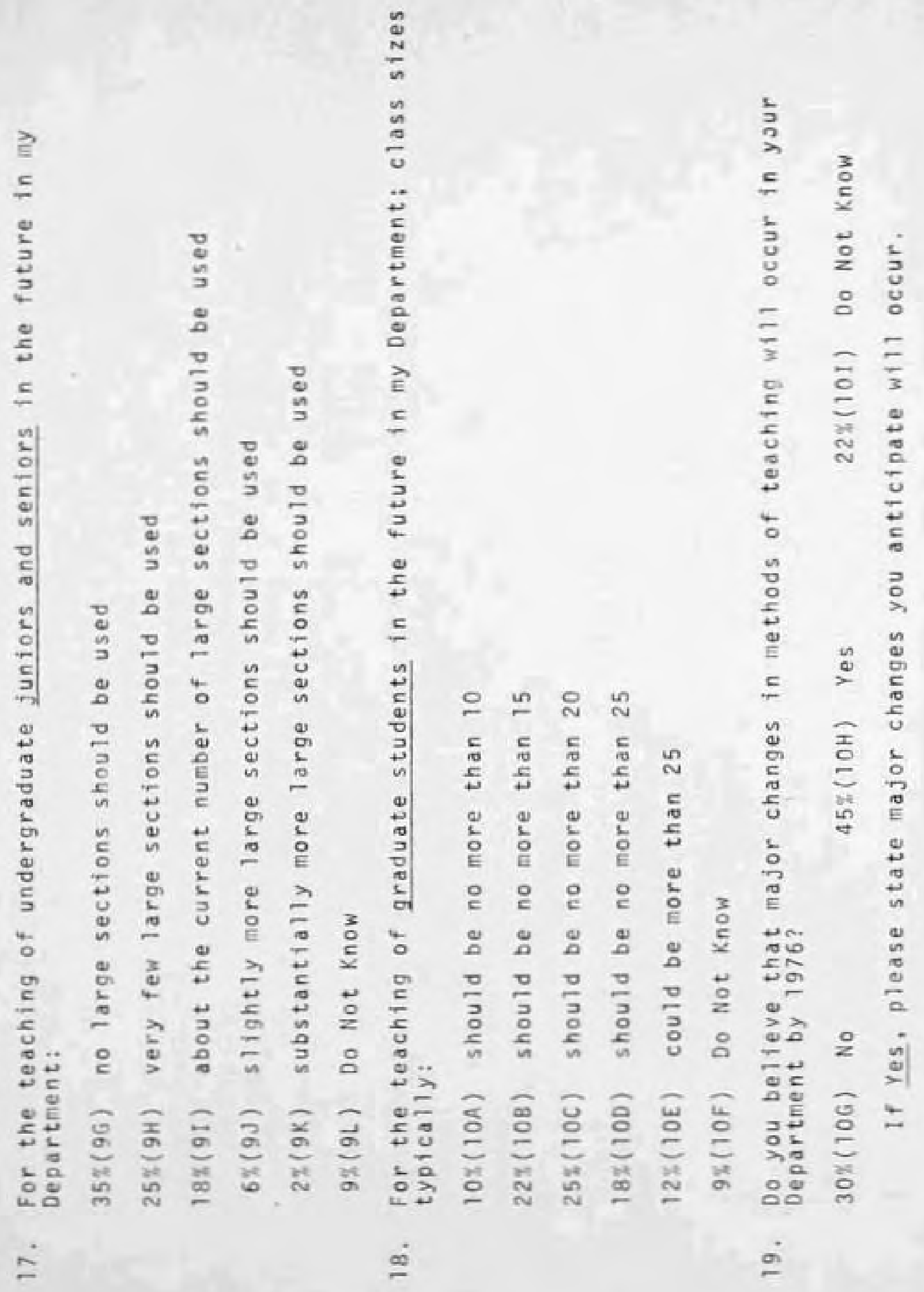




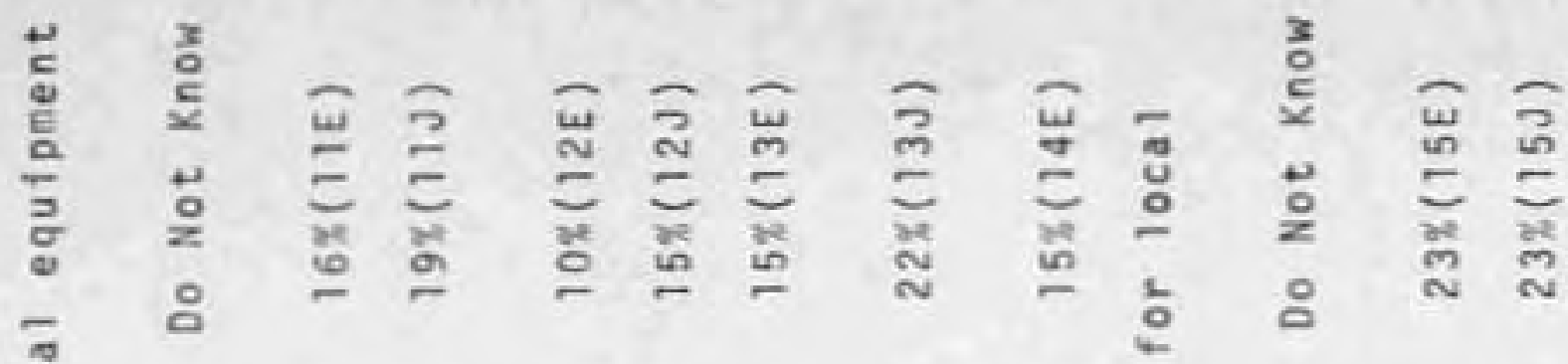

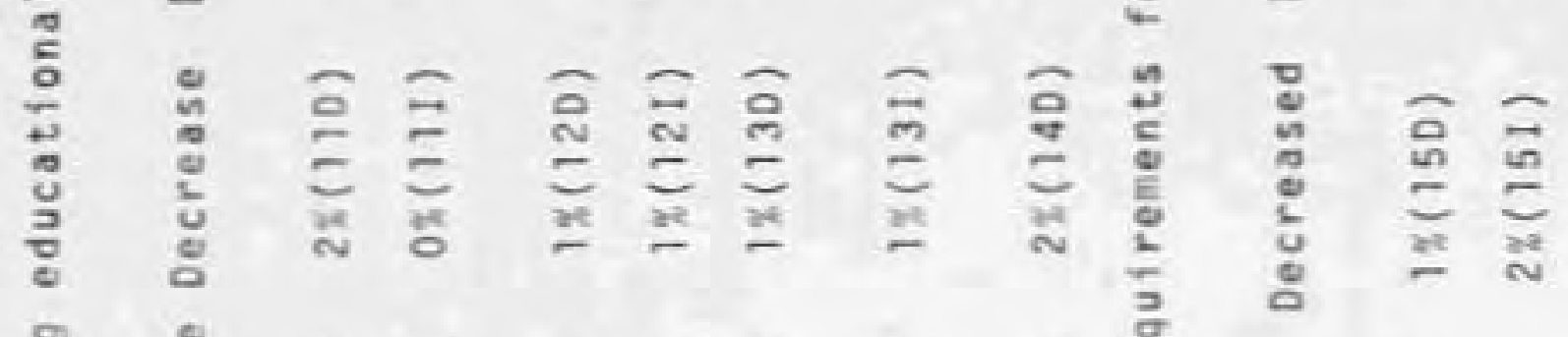

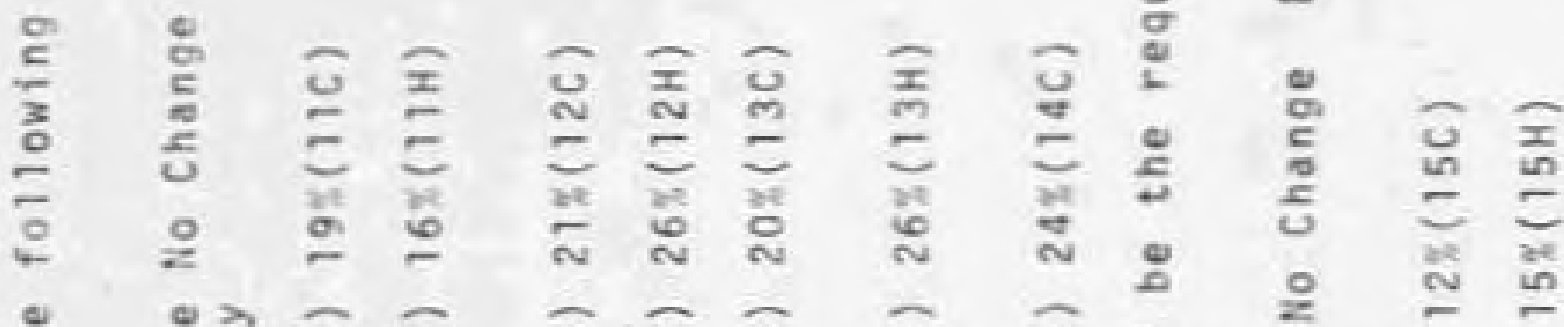

E

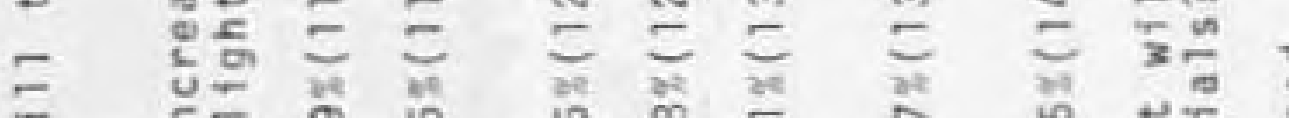

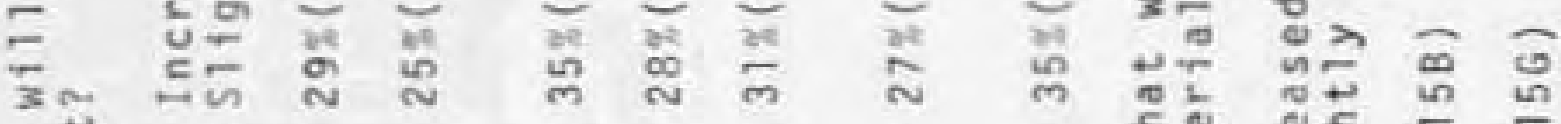
茂

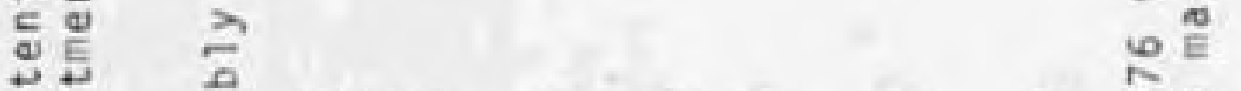

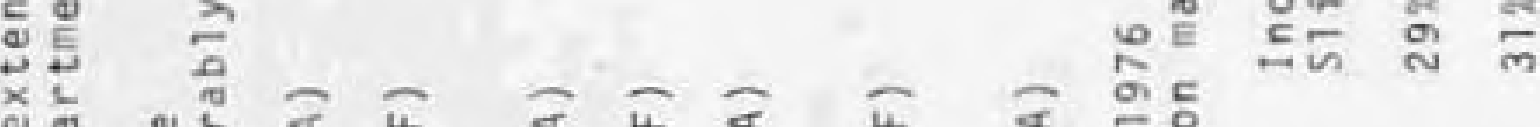

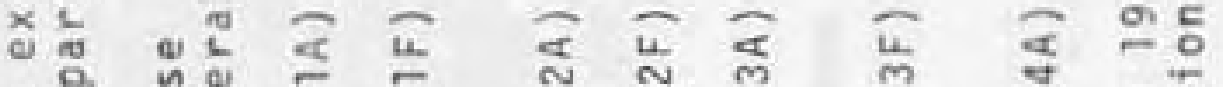

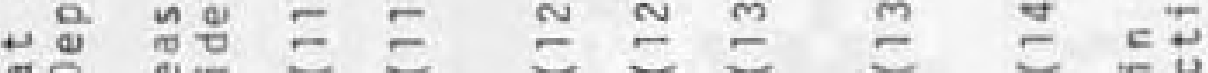

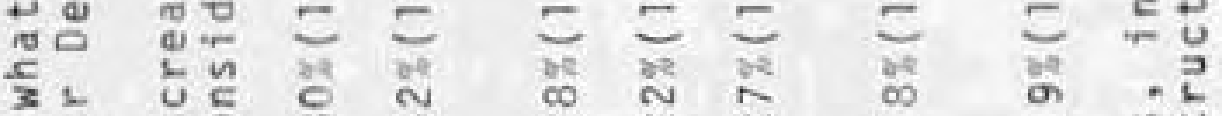

品 突

$-5$

。.

io

ज赵

บक

$\stackrel{\circ}{c}$

$\Phi \div$

⿶

๑

t.

웅

(n)

⿷

$\frac{i}{\frac{1}{2}}$

드

T.

$i_{0=0}=$

0 E U क का

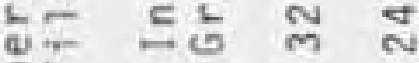
Q.

8

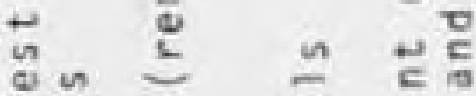

ज进

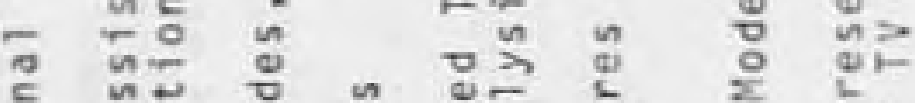

min

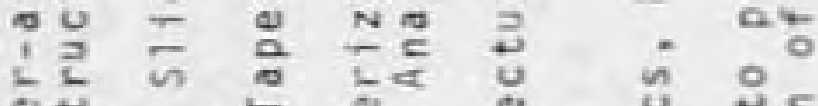

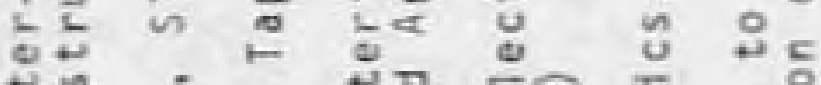

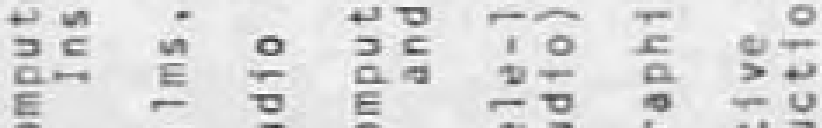

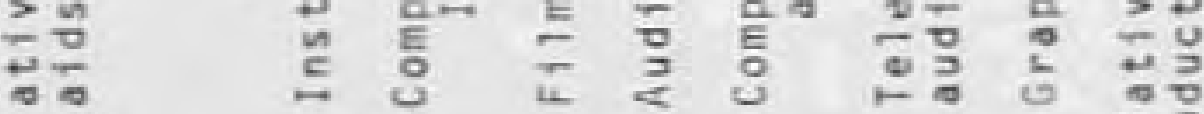

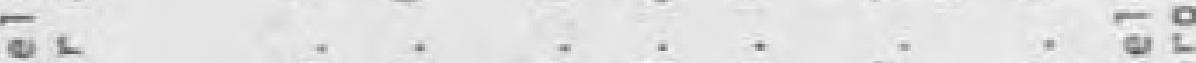

$\propto 0$

i

i :

요 


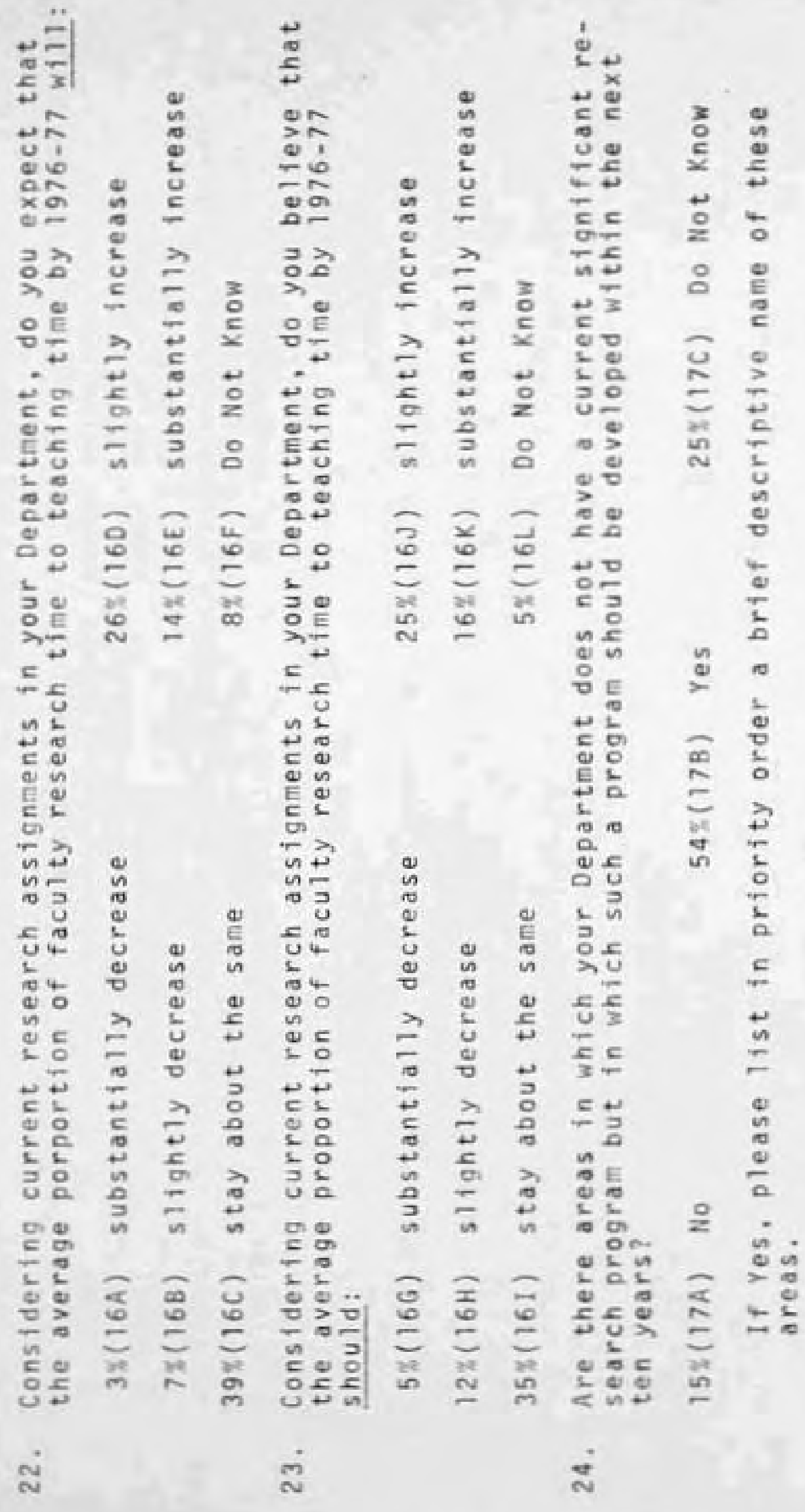




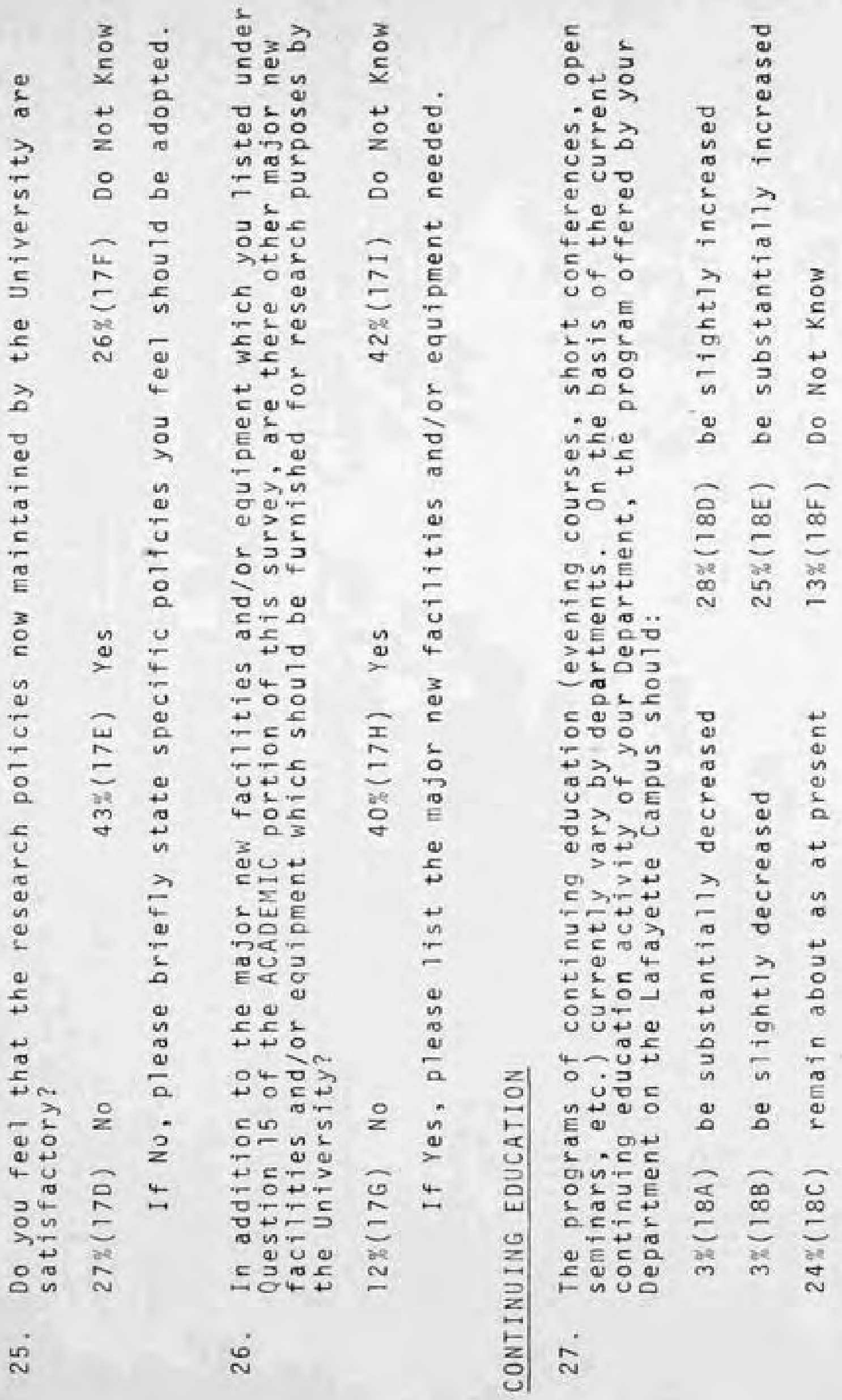




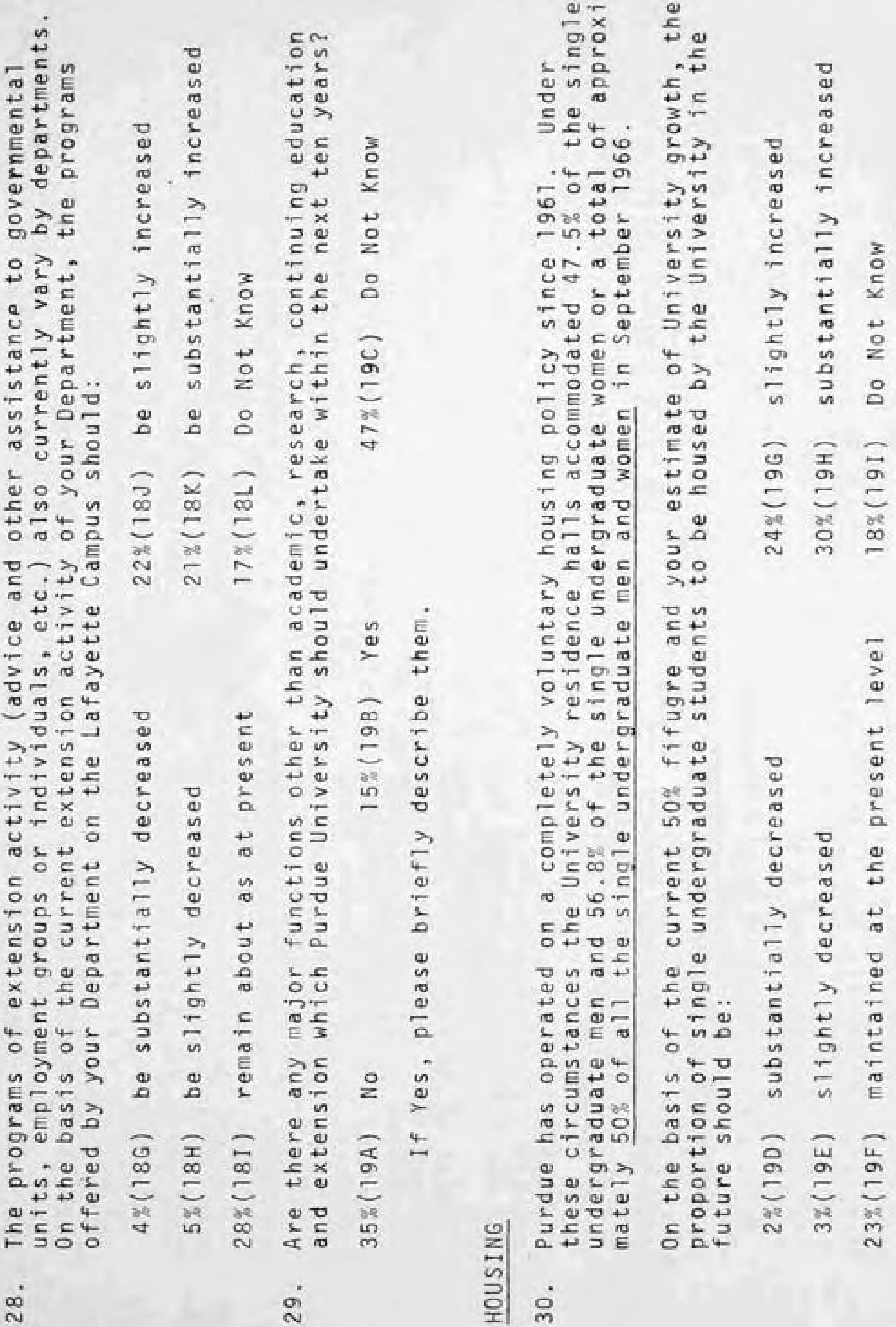




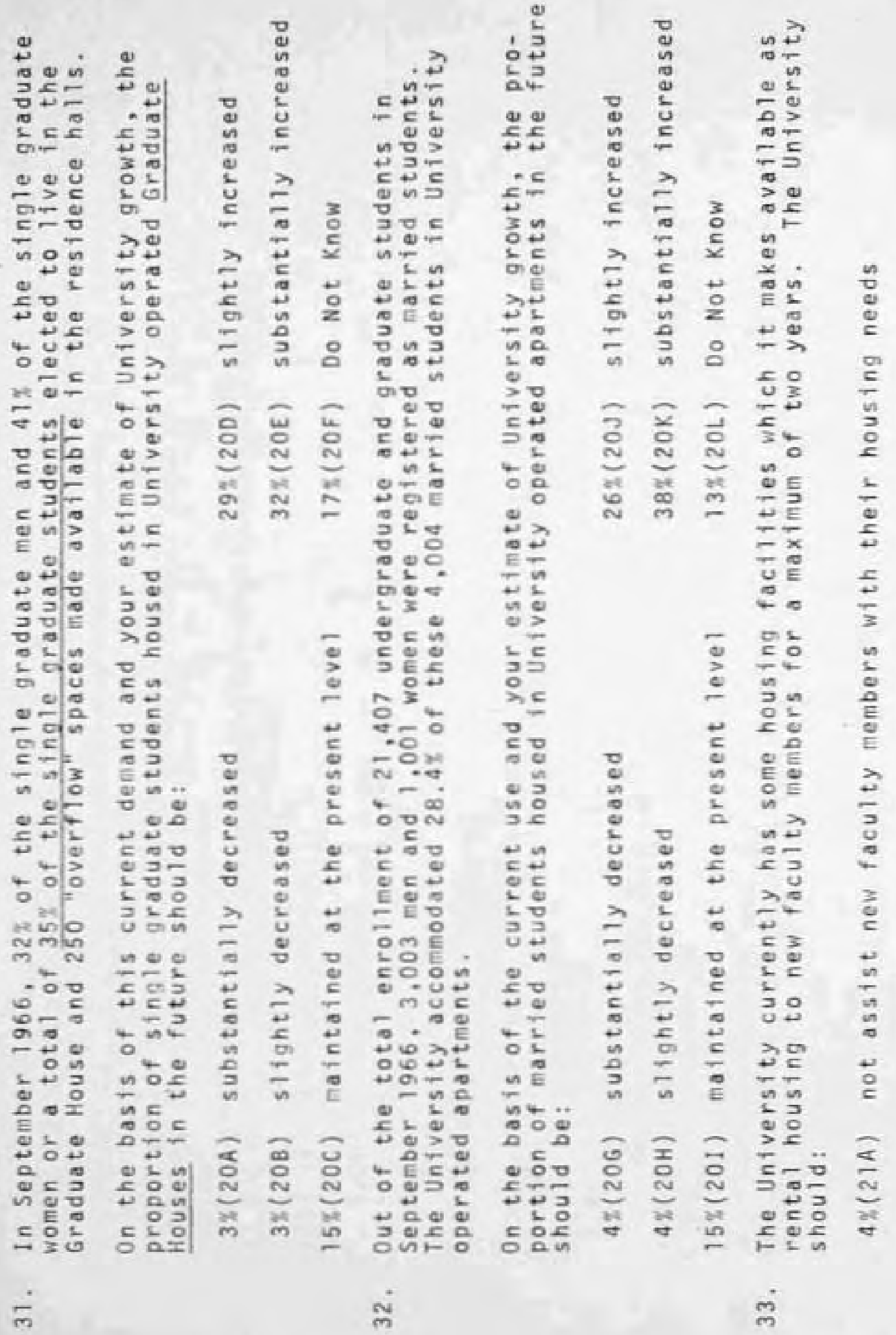




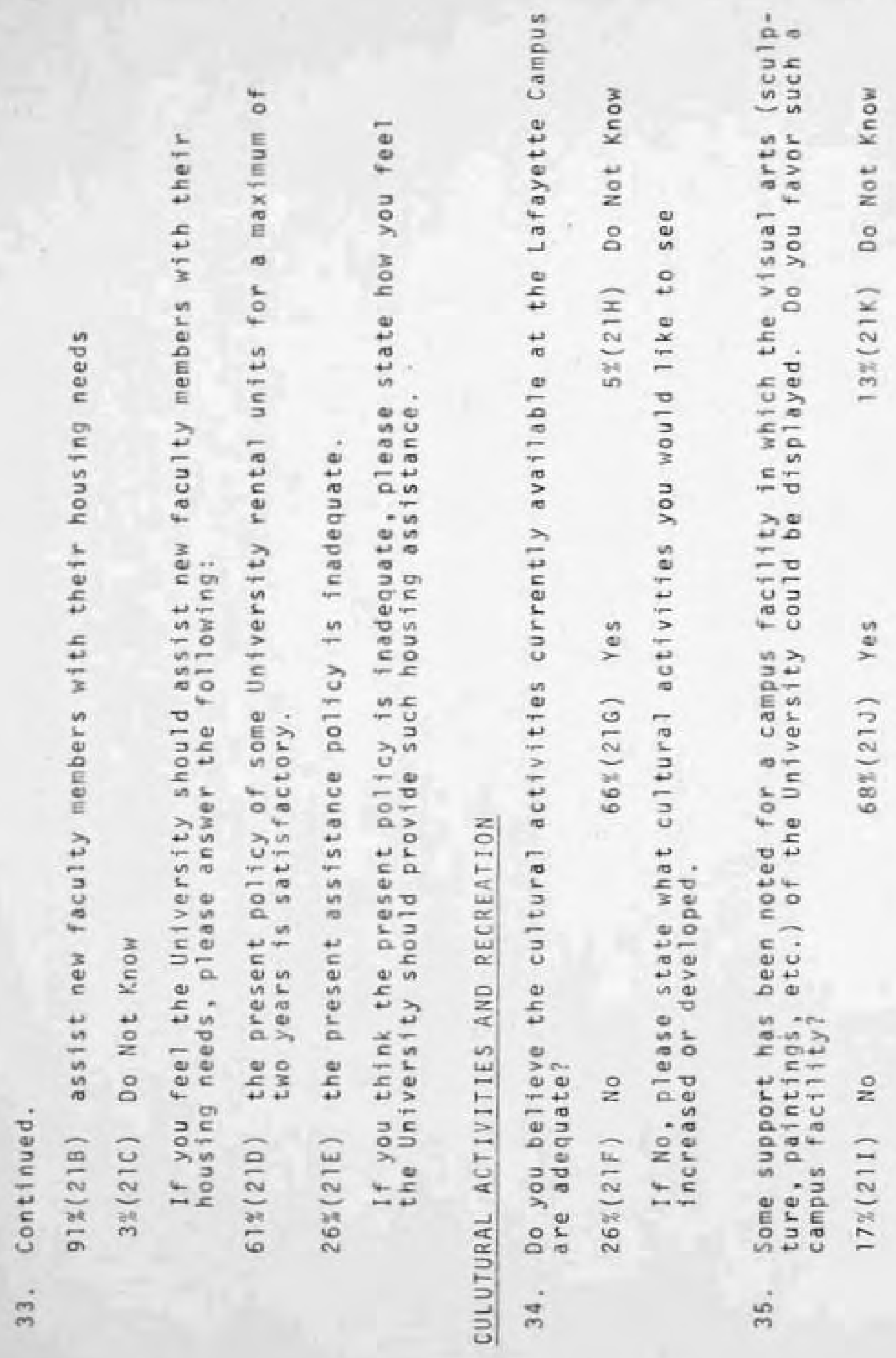




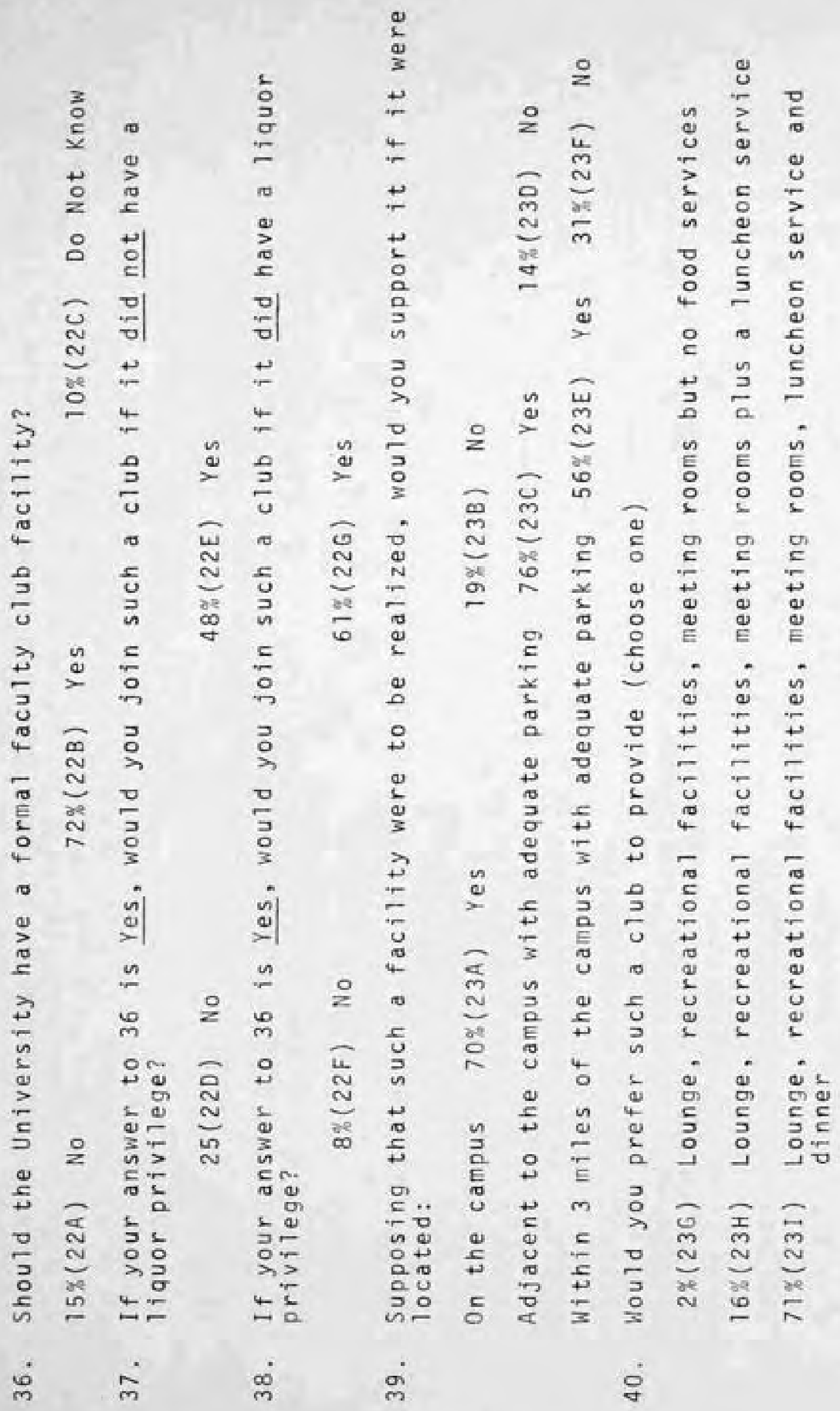




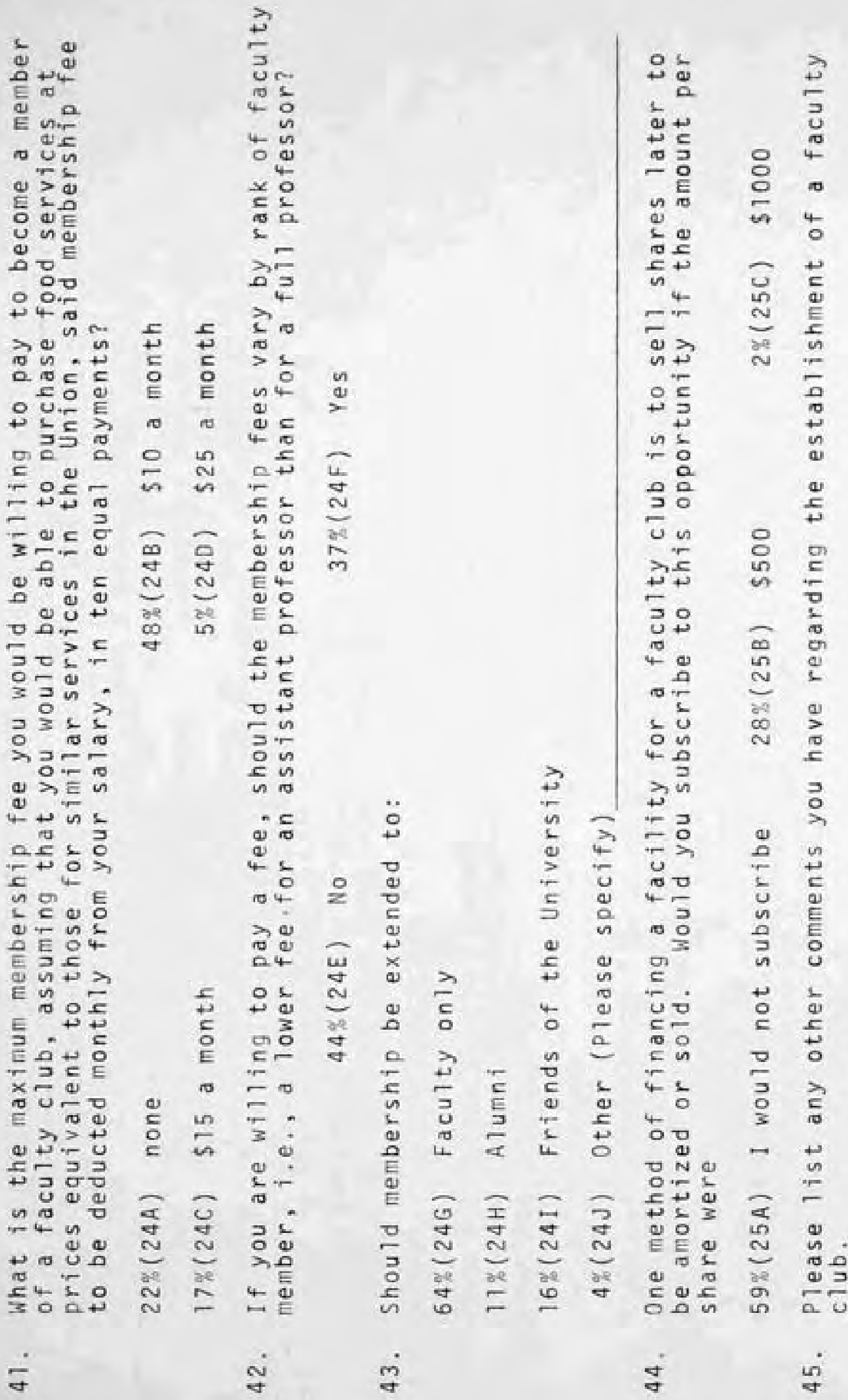




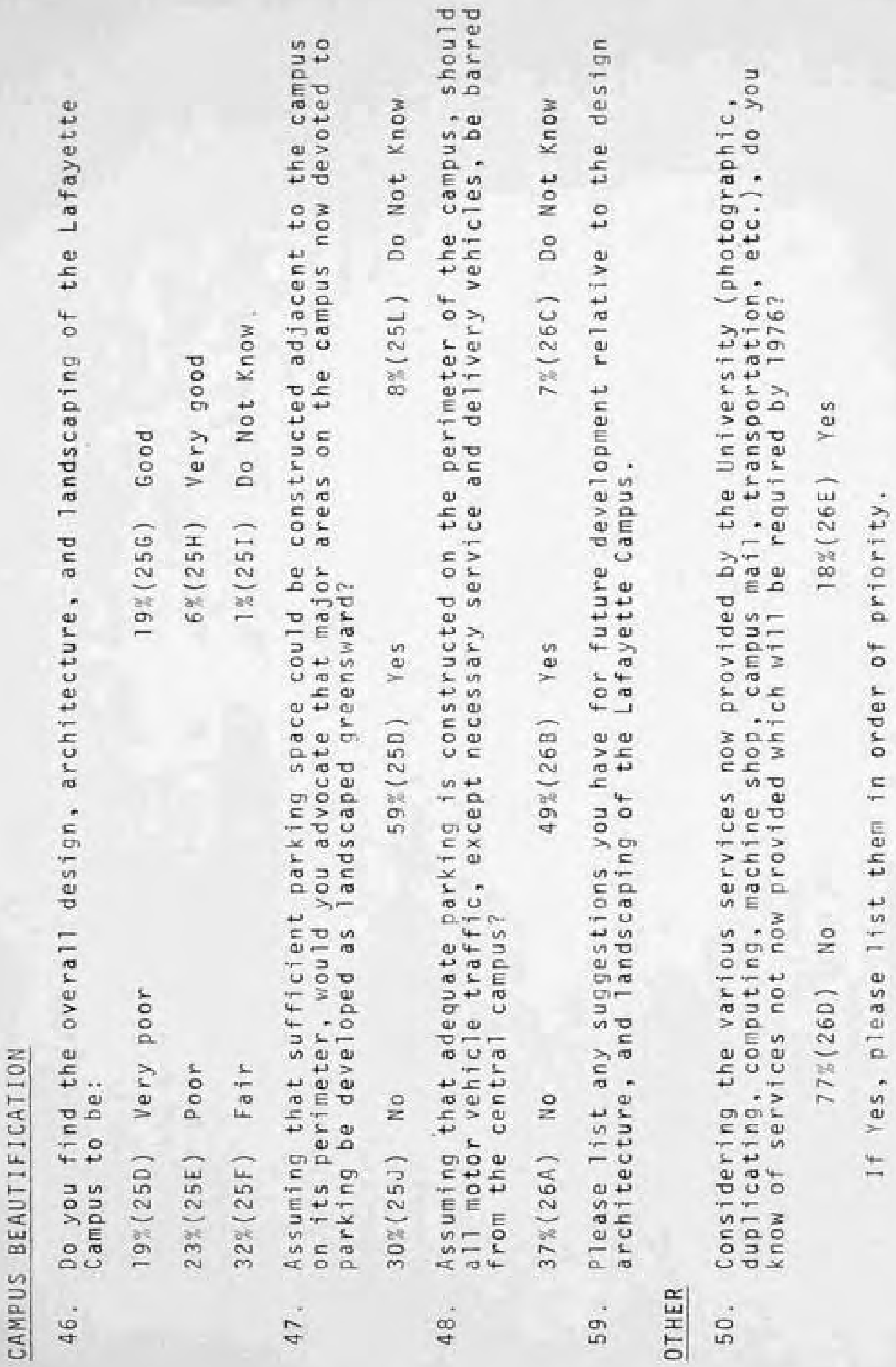




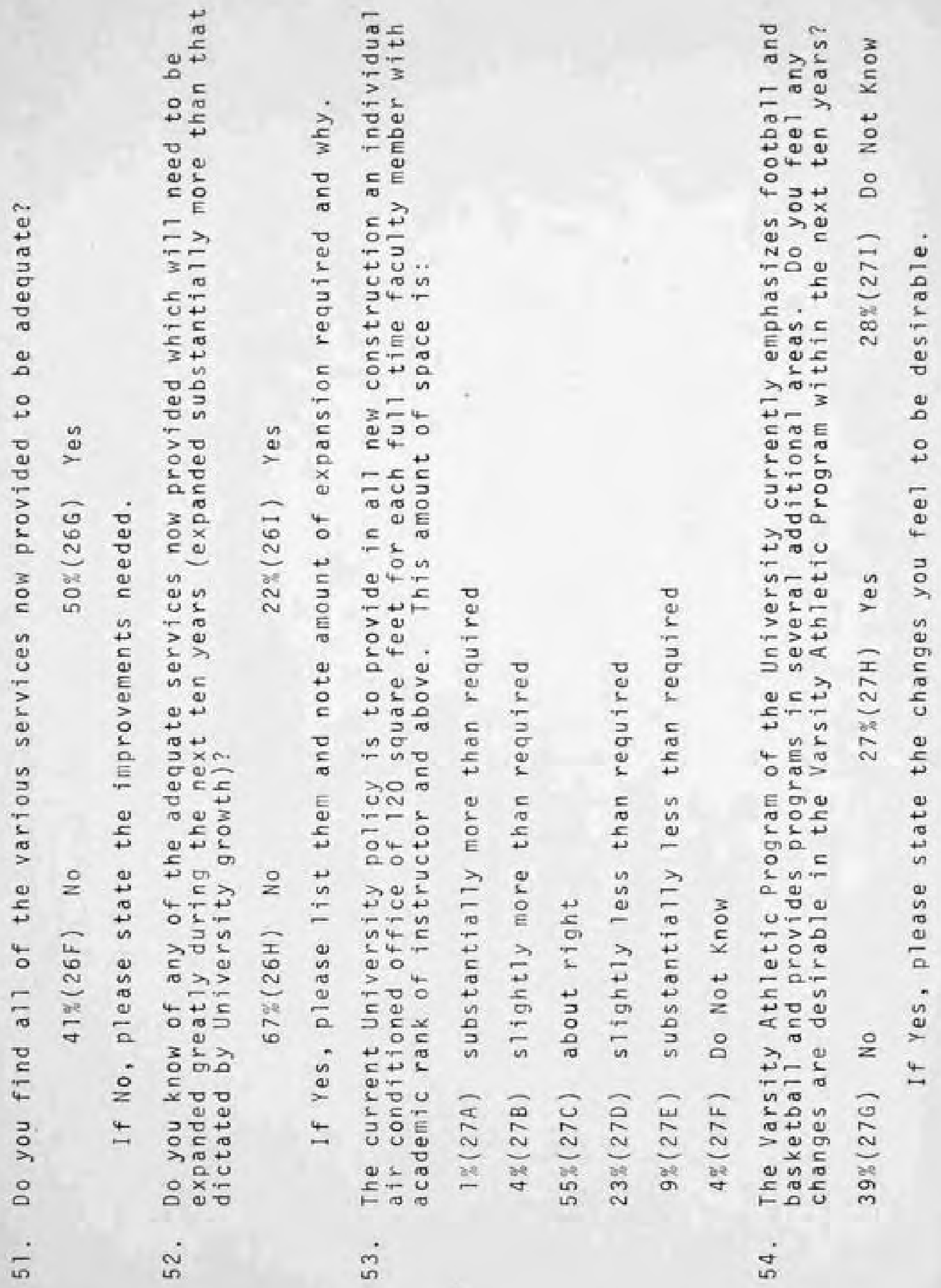




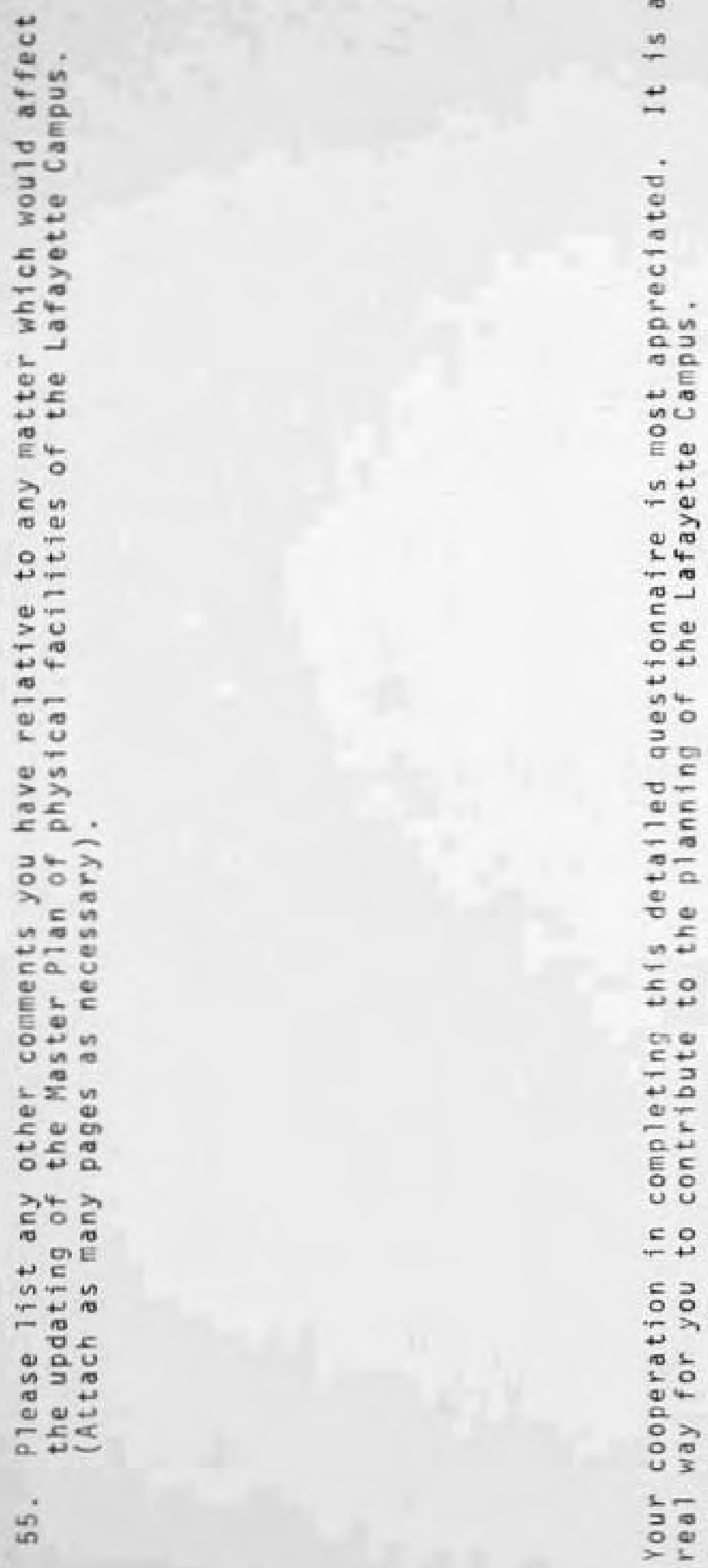


APPENDIX B. ALTERNATIVE COMMUTING PLANS ESTIMATED ANNUAL COSTS 


\section{APPENDIX B. ALTERNATIVE COMMUTING PLANS - ESTIMATED ANNUAL COSTS}

This appendix comprises four sections:

1. Estimated annual costs of different types of parking facilities (per parking space).

2. Alternative $I 1 / 1$ - estinated annual cost.

3. Alternative $11 / 2$ - estimated annual cost.

4. A1ternative $11 / 3$ - estinated annual cost.

Investment costs (constructions and equipment) are based on information as of 1966. Annual costs of investment are estimated on the basis of an interest rate of 5.25 percent and according to the expected economic life time of the iter under consideration. Average total annual cost includes both investment cost and maintenance and operation costs.

Section 1 - Estimated Annual Costs of Different Types of Parking Facilities (Per Parking Space)

The following is a comparison between the estimated annual costs of providing parking spaces in different types of facilities. The estimates are made according to the following assunptions:

1. Parking facilities provided on land owned by Purdue University require no expenditures for 1 and acquisition. 
2. Cost of 1 and in the first row of blocks around the acadenic zone is about $\$ 4.00$ per square foot (as of 1966) (27).

3. Above ground garages are four-stories high.

4. One parking space in a four-story garage needs about 100 square feet of 1 and area (28).

5. One parking space in a surface parking lot needs about 300 square feet of 1 and area (27).

\section{Parking in Underground Garages on University Owned Land -}

\section{Annual Cost Per Parking Space.}

- economic 1 ife

- cost of construction

- cost of land

- total cost of investment

- capital recovery factor

- annual cost of investment

- annual cost of maintenance and operation $=\$ 100.00$

- annual cost (total)
$=40$ years

$=\$ 4,000.00$

$=\$+. . .+.$.

$=\$ 4,000.00$

$=.060325$

$=\$ 241.00$

$=\$ 341.00$

Parking in Four-Story Garages on Non-University Owned Land Annual cost Per Parking Space.

- economic life

- cost of construction

- cost of land

- total cost of investment

- capital recovery factor
$=40$ years

$=\$ 1,500.00$

$=\$ 400.00$

$=\$ 1.900 .00$

$=.060325$ 
- annual cost of investment $=\$ 115.00$

- annual cost of maintenance and operation= $\$ 50.00$

- annual cost (total)

$=\$ 165.00$

Parking in Surface Lots on Non-University Owned Land - Annual Cost Per Parking Space.

- economic 1ife

$=20$ years

- cost of construction

$=5300.00$

- cost of land

$=\$ 1,200.00$

- total cost of investrent

$=\$ 1,500.00$

- capital recovery factor

$=.08197$

- annual cost of investment

$=\$ 123.00$

- annual cost of maintenance and operation $=\$ \$ 50.00$

- annual cost (total)

$=\$ \quad 173.00$

Parking in Surface Lots on University Owned Land - Annual Cost Per Parking Space.

- economic 1 ife

- cost of construction

- cost of land

- total cost of investment

- capital recovery factor

- annual cost of investment

- annual cost of maintenance and operation $=\$ 50.00$

- annual cost (total)
$=20$ years

$=\$ 300.00$

$=\$ \ldots . . . . .$.

$=\$ 300.00$

$=.08197$

$=5 \quad 24.60$

$=\underline{\$ \quad 74.60}$ 
Section 2 - Alternative $11 / 1$ - Estimated Annual Cost

Future parking demand was estimated to be 3,685 parking spaces for students, 6,650 for staff, and 330 for visitors. of these, the university presently (1968) provides 5,633 parking spaces and about 1,000 on-street parking spaces are assumed to renain available in the future. The present parking supply will be reduced by 302 parking spaces due to the proposed changes in the acadenic zone. Therefore, the net number of parking spaces which should be added in the future is about 4,330 parking spaces. In this alternative, an additional 315 parking spaces presently provided in parking lots will be removed upon construction of the proposed multi-story garages. Therefore, the net additional parking demand in this alternative is about 4,650 parking spaces. Annual cost. In alternative $11 / 1,1,250$ parking spaces are provided as surface parking on university owned 1 and and 3,400 parking spaces are provided in four-story above ground garages on non-university owned 1and.

According to Appendix B - Section 1, the annual cost of providing these numbers and types of parking spaces is estimated to be $1,250 \times 74.60+3,400 \times 165.00=\$ 654,250.00$.

Section 3 - Alternative $11 / 2$ - Estinated Annual Cost In this alternative, the street bus system provided between university housing facilities and the acadenic zone (Figure 23) will have to carry an estinated peak load of about 430 students around $8: 30 \mathrm{a} \cdot \mathrm{m}$. On the basis of the 
operational criteria outlined in the description of this alternative in the text, the annual cost of providing this bus systen is estimated as follows:

- economic life of bus units

$=12$ years

- capital cost per bus unit

$=\$ 30,000.00$

- capital recovery factor

$=0.11785$

- annual cost of investment per bus unit $=\$ 3,536.00$

- mileage per bus unit per year =

13.75 daily trips $x 196.2$ full days

$\times 5.00$ eiles per trip

to this mileage, 10 percent is added to

$=13,481$ mfles

provide for necessary non-assigned trips

- total mileage per bus unit per year

$=14,829$ miles

- cost of maintenance and operation per vehicle mile

$=5 \quad 0.65$

- annual cost of maintenance and operation per bus unit $=14,829 \times 0.65=\$ 9,639.00$

- annual cost per bus unit (investment + maintenance and operation) $=3,536.00+$ $9,639.00$ $=\$ 13,175.00$

- number of bus units needed $=8+$ one additional unit in maintenance or repair

$=9$ bus units

- annual cost of the bus system (total) $=8 \times 13,175.00+3,536.00$

$=\$ 108,936.00$

On the other hand, if the bus systen were not used, it would have required 600 additional parking spaces around the acadenic zone (the number of spaces expected to be used by students living in university housing facilities). If these spaces were provfded in four-story garages on non-university owned 1and, they would have cost about $600 \times 165.00=$ $\$ 99,000.00$. 
The estimated annual cost of providing all the future parking demand around the academic zone (alternative $I I / 1$ ) is $\$ 654,250.00$. If the bus system is used, the tota1 parking demand around the academic zone will be reduced by 600 spaces. This means that the annual cost of providing the rest of the parking demand around the academic zone would be about $\$ 654,250.00-99,000.00=\$ 555,250,00$. This total cost would have been higher if the substituted parking spaces were provided in surface parking on university owned 1 and. Accordingly, the annual cost of alternative $I I / 2$ is estimated to be about $555,250.00+108,936.00=\$ 664,186.00$.

Section 4 - Alternative $11 / 3$ - Estimated Annual Cost In this alternative, the two remote parking facilities are connected to the academic zone by two street bus systens in sub-alternative II/3-A and by a combination of a skybus system (from the Ross Ade Stadium parking $10 \mathrm{t}$ ) and a street bus system (from the Airport Road parking $10 t$ ) in suba)ternative $11 / 3-B$. The annual costs of the parking facilities, the street bus systems, and the skybus system are here estimated separately. The annual costs of subalternatives II/3-A and II/3-B are then obtained.

Annual cost of Parking Facilities. According to Appendix B - section 1, the annual cost of providing 3,730 parking spaces in remote parking lots on university owned land $=3,730 \times 74.60=\$ 278,258.00$. 
Annual cost of the Street Bus Systems. The two bus systems connecting the Ross Ade Stadium parking lot and the Airport Road parking lot to the academic zone are almost identical fn load and round trip length. The estimates of the annual costs are thus made per system and on the basis of the operational criteria outlined in the description of sub-alternative $11 / 3-A$ in the text.

- economic life of bus units

$=12$ years

- capital cost per bus unit

$=\$ 30,000.00$

- capital recovery factor

$=0.11785$

- annual cost of investment per bus unit $=\underline{\$ 3,536.00}$

- mileage per bus unit per year $=19.30$ daily trips $\times 196.20$ ful1 days $\times 3.20$ miles per trip (classes in session) + 13.20 dally trips $\times 80.00$ full days $\times 3.20$ miles per trip (classes not in session)

to this mileage, 10 percent is added $=15,496$ miles

to provide for necessary non-assigned trips.

- total mileage per bus unit per year $=17,046$ miles

- cost of maintenance and operation per vehicle mile

$=\$ 0.65$

- annual cost of maintenance and operation per bus unit $=17,046 \times 0.65=\$ 11,080.00$

- annual cost per bus unit (investment + maintenance and operation) = $3,536.00+11,080.00$

$=\$ 14,616.00$

- number of bus units needed per systen $=12$ + one additional unit in maintenance or repair

$=13$ bus units

- annual cost per bus system

$($ total $)=12 \times 14,616.00+3,536.00$

$=\underline{\$ 178,928.00}$ 
Annual cost of the Skybus System. In sub-alternative $11 / 3-B$, the skybus system is used to connect the Ross Ade Stadium parking lot to the academic zone. On the basis of the operational criteria outlined in the description of this sub-alternative in the text, its average total annual cost is here estimated according to infornation provided by the nanufacturer (26).

- econonic life of roadiay and control equipment

$=40$ years

- cost of roadway construction and control equipment:

- at grade station

- three aerial stations

- roadway construction:

- curved single track - at grade (1300 feet)

- curved single track - aerial (1700 feet)

- straight double track - aerial ( 5400 feet)

- total cost of roadway (including engineering and administration)

$=\$ 727.280 .00$

$=\$ 2,031,840.00$

$=\$ 100,724.00$

$=\$ 321,300.00$

$=\$ 1,382,400.00$

$=\$ 2,020,954.00$

- one transfer table

- heating installation

- automatic train operation system

- power system

- facilities for maintenance and repair (to handle 10 vehicles)

- audio and visual system

- spare parts

- total cost of investment for roadway construction and control equipment

= $543,503.00$

= S $76,740.00$

$=\$ \quad 165,876.00$

= $5 \quad 512,118.00$

$=5 \quad 23,448.00$

$=5 \quad 47,334.00$

$=5100,000.00$

$=\$ 5,749,093.00$

- capital recovery factor (for roadway and equipment)

$=0.060325$

- annual cost of investment for roadway construction and control equipment

$=\$ 346,814.00$ 
- economic life of vehicles

- capital cost per vehicle

- capital recovery factor (for vehicles) $=0.08197$

- annual cost of investment per vehicle =

- mileage per vehicle per year = 44.00 daily trips $\times 196.20$ full days $\times 2.60$ miles per trip (classes in session) +35.30 daily trips $x$ 80.00 full days $\times 2.60$ miles per trip (classes not in session)

- cost of maintenance and operation per vehicle mile

- annuar cost of maintenance and operation per vehicle $=$ $29,788 \times 0.70$ $=29,788 \mathrm{miles}$

$=\$$

0.70

$=\$ 20,852.00$

- annual cost per vehicle (investment + maintenance and operation) = $7,698.00+20,852.00$ $=\$ 28,550.00$

- number of vehicles needed $=6+$ one additional vehicle in maintenance or repair

- annual cost of vehicles $=6 x$ $28,550.00+7,698.00$

$$
=\$ 178,998.00
$$

- annual cost of the skybus system (roadway, control equipment, and vehicles) $=346,814.00+$ $178,998.00$
$=20$ years
$=\$ 93,910.00$

$7,698.00$ 